\title{
Safe Motherhood Demonstration Project, Western Province: Final Report
}

Charlotte E. Warren

Population Council

Wilson Liambila

Population Council

Follow this and additional works at: https://knowledgecommons.popcouncil.org/departments_sbsr-rh

Part of the Demography, Population, and Ecology Commons, Family, Life Course, and Society Commons, International Public Health Commons, and the Maternal and Child Health Commons How does access to this work benefit you? Let us know!

\section{Recommended Citation}

Warren, Charlotte E. and Wilson Liambila. 2004. "Safe Motherhood Demonstration Project, Western Province: Final Report," Final report. Nairobi: Republic of Kenya Ministry of Health, University of Nairobi, and Population Council. 


\section{Safe Motherhood Demonstration Project Western Province}

\section{Approaches to providing quality maternal care in Kenya}

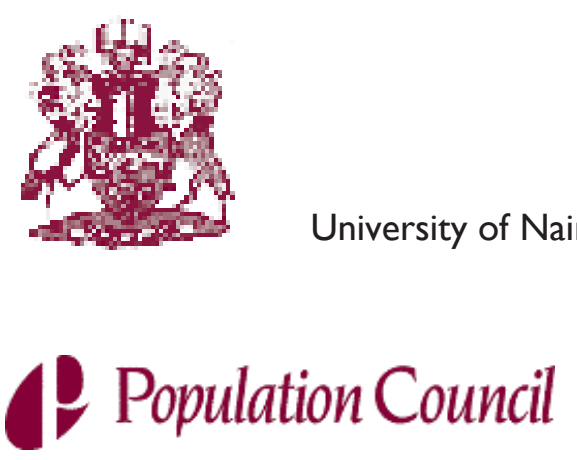




\title{
Safe Motherhood Demonstration Project Western Province
}

\author{
Final Report
}




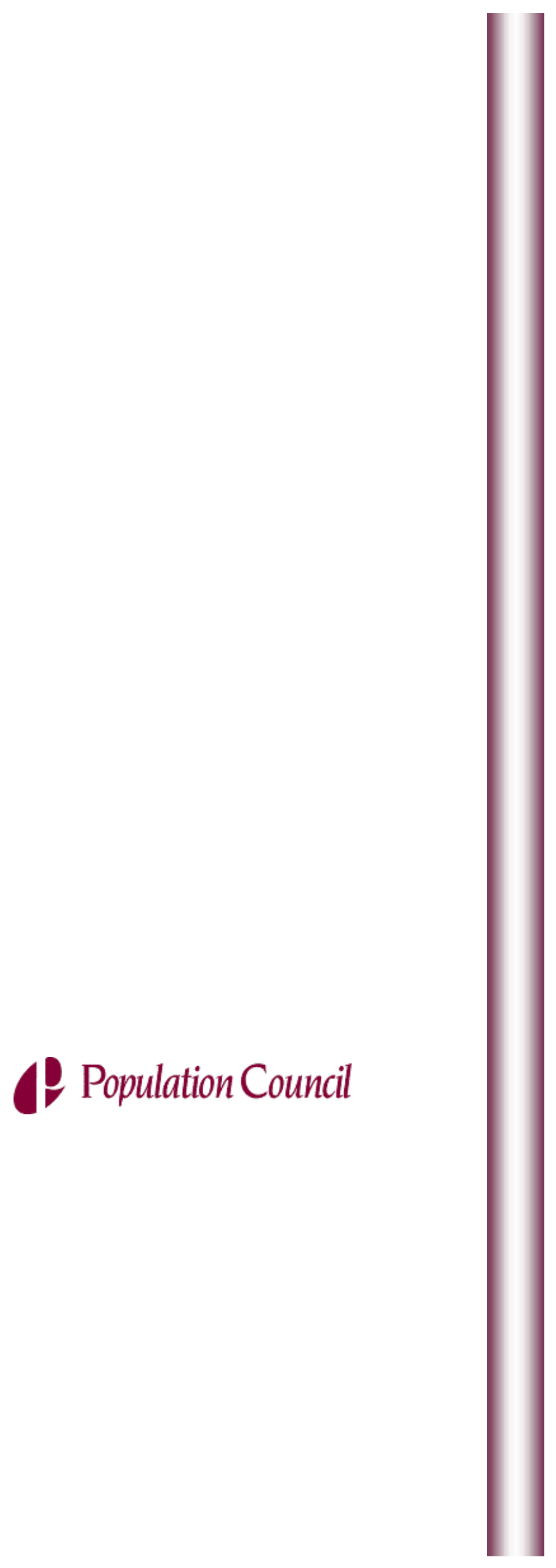

The Population Council is an international, nonprofit, nongovernmental institution that seeks to improve the well-being and reproductive health of current and future generations around the world and to help achieve a humane, equitable, and sustainable balance between people and resources. The Council conducts biomedical, social science, and public health research and helps build research capacities in developing countries. Established in 1952, The Council is governed by an international board of trustees. Its New York headquarters supports global network of regional and country offices.

Sub-Saharan Africa Region, Nairobi Office Genereal Accident Insurance House Ralph Bunche Road

P.O. Box 17643-00500 Nairobi, Kenya

Tel: +254-20-2713480-3 Fax: +254-20-2713479

Email: info@pcnairobi.org 


\title{
FOREWORD
}

The Ministry of Health has been piloting Safe Motherhood (SM) activities in Western Province since 2000 by developing approaches to reducing maternal and neonatal morbidity and mortality. The overall goal of the project was to improve maternal health in Kenya especially for poor women. It is evident from the results that the project has achieved substantial progress in the area of maternal and perinatal health through building partnerships, supporting and strengthening community action, use of skilled attendance and birth and ensuring institutional preparedness at all levels.

A review of findings in the report shows that despite the short implementation phase of program activities, achievements were recorded in antenatal, intra partum and post partum cares services. The proportion of women with knowledge of risk and danger signs during pregnancy, labour and puerperium period was significantly higher at endline compared to the baseline data. More women received malaria prophylaxis and had appropriate laboratory tests during pregnancy. There was also significant improvement in the knowledge and skills of health care providers, which included the significant increase in the number of providers who use the partograph in the management of labour to prevent prolonged labour, as well as institutional preparedness in the management of obstetric complications and improved referral system.

Despite the achievements, the report has also outlined a few challenges. These include the need to focus on neonatal health, the early post-partum period and to encourage grater participation of men and the rest of the community in reproductive health including safe motherhood activities.

However, the report contains useful results and lessons that could be replicated in other districts in Kenya. Some of the lessons learnt could serve as a source of vital information on key strategies that could be applied to tackle some of the barriers in order for Kenya to achieve the appropriate Millennium Development Goals (MDGs) by 2015.

On behalf of the Ministry, I wish to take this opportunity to thank the Department for International Development (DFID) for having provided financial support to this project and Population Council and the University of Nairobi for providing technical assistance to the project at all levels during the planning, implementation and evaluation stages.

\author{
Hon. Charity Kaluki N gilu; MP \\ MINISTER FOR HEALTH
}




\section{TABLE OF CONTENTS}

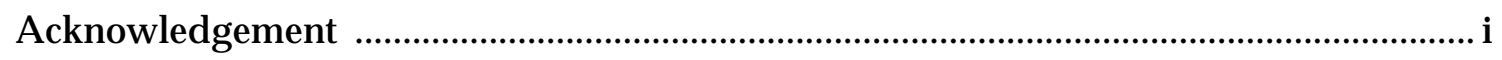

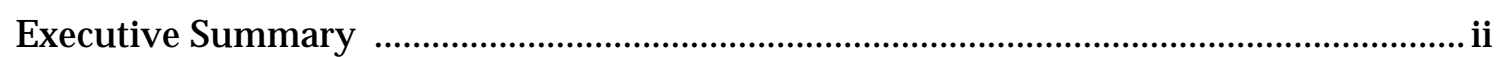

Introduction ................................................................................................... ii

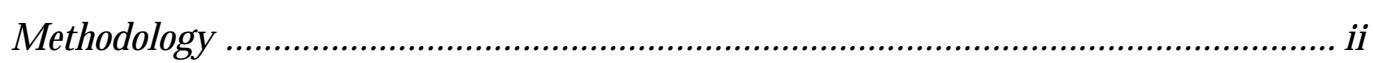

Programme interventions to en hance access to maternal care ..................................... ii

Project Coordination and $M$ anagement ................................................................ iii

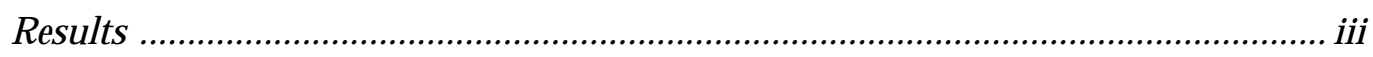

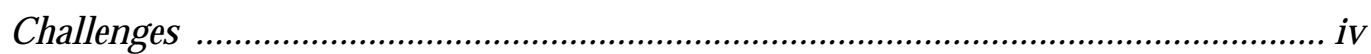

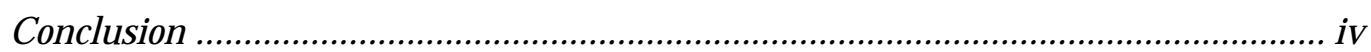

Recommendations .......................................................................................... iv

A bbreviations and A cronyms ………………………......................................vi

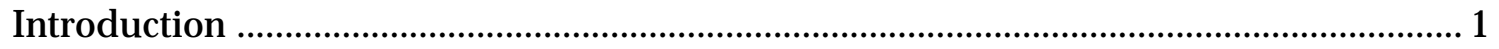

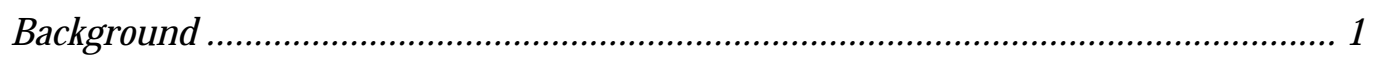

The Safe M otherhood Partnership Fund …………………………………………... 1

The Safe M otherhood D emonstration Project …………….................................... 2

Conceptual framework and approach ................................................................. 3

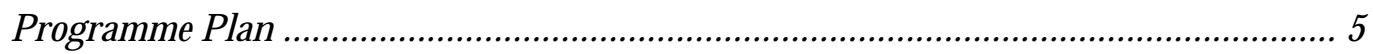

Programme interventions to enhance access to maternal care .................................... 6

Project coordination and management ............................................................. 15

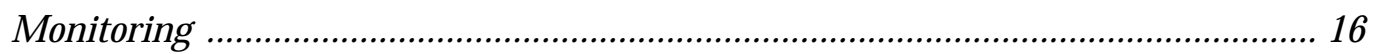

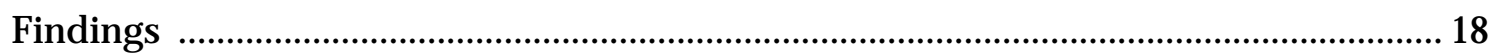

Improving comprehen sive and basic essential obstetric care and essential newborn care .... 18

O bstetric met need ......................................................................................... 19

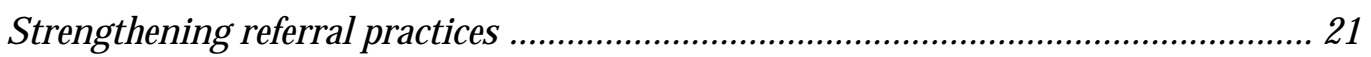

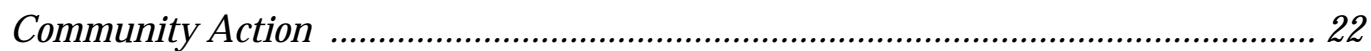

M aternal Health Services ................................................................................... 26

Health organisational and management issues ...................................................... 39

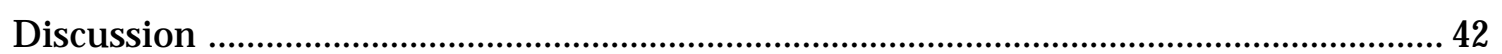

Skilled A ttendance .............................................................................................. 43

Institutional Capacity Building ......................................................................... 43

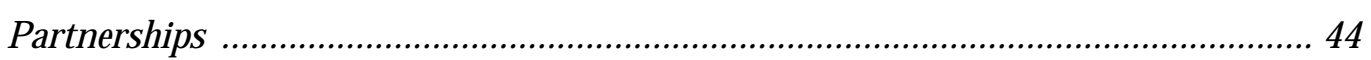

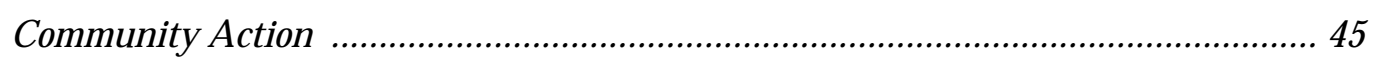

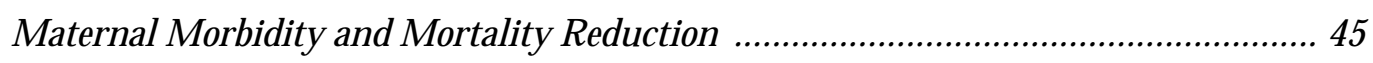

Lessons Learned from theSM DP ............................................................................ 45 
Challenges for Scaling up Safe M otherhood and N eonatal Health Programming ........ 47

W ay Forward and Programme Sustainability .............................................................. 48

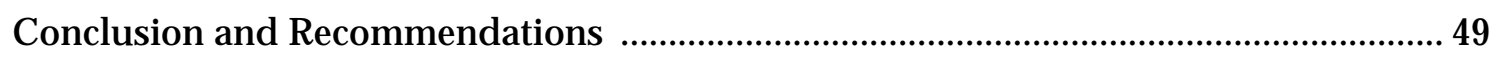

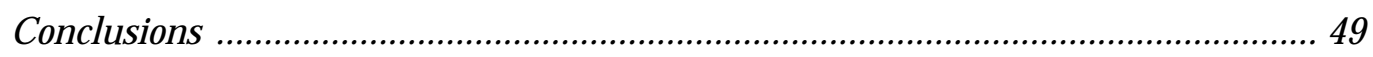

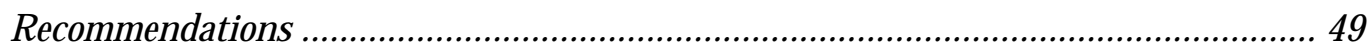

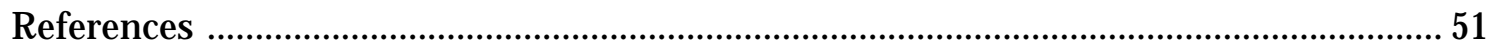

A ppendix 1: Safe Motherhood Conceptual Framework ............................5

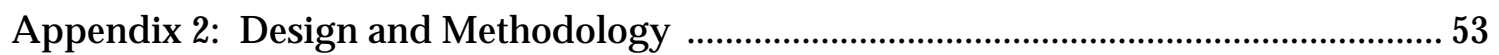

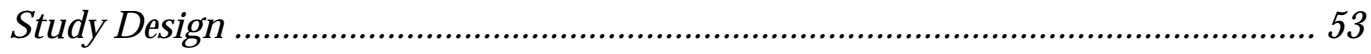

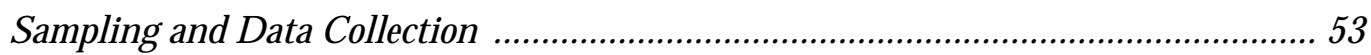

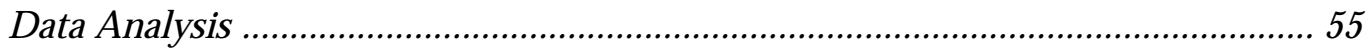

A ppendix 3: Summary of providers recall on signs and action required for obstetric

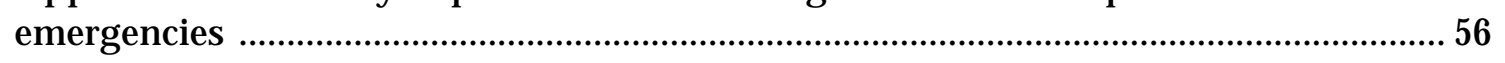

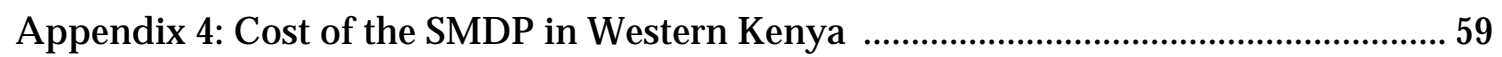

Appendix 6: List Of Operational Health Facilities By District ........................................ 62

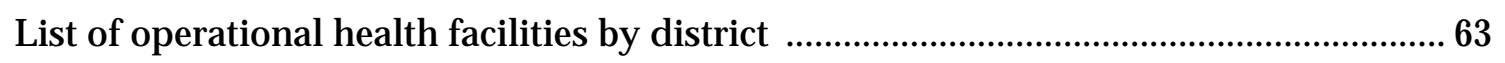

A ppendix 7: Kenya Safe Motherhood and Neonatal Health Model .................................64 64

A ppendix 8: Lists of Co-ordinators, Supervisors and Research A ssistants ................... 65

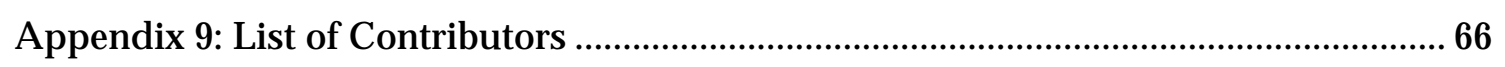

A ppendix 10: District maps showing distribution of heal th facilities ..............................67 


\section{LIST OF FI gURES AND CHARTS}

Chart 1: $\quad$ Percent of women who received a first dose of SP at AN C ..................... 27

Chart 2: $\quad$ Percent of facilities using $\mathrm{MOH}$ standard ANC cards............................. 30

Chart 3: $\quad$ Percent of nurses by signs used to establish labour during the last delivery they attended ............................................................................. 311

Chart 4: $\quad$ Percent of providers by warning signs that would prompt a referral .. 344

Chart 5: $\quad$ Percent of facilities requesting women in labour to bring drugs and

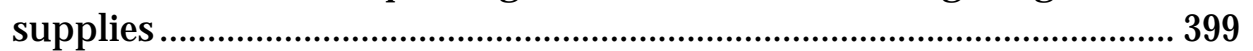

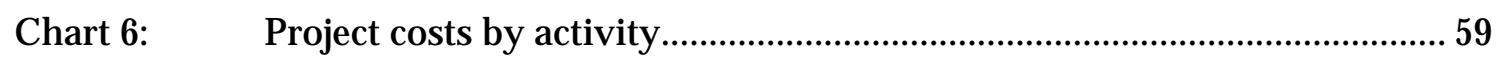

Figure 1: $\quad$ Approaches to addressing safe motherhood ............................................. 4

Figure 2: Birth Preparedness Model ..................................................................... 8

Figure 3: $\quad$ Health care procedure manual for health providers at facility level ...... 40 


\section{LIST OF TABLES}

Table 1. Data for districts selected for SMDP …....................................................... 3

Table 2. Instruments used and sample sizes at baseline and endline surveys ........... 6

Table 4. Coverage of Essential Obstetric Care Services March 2003......................... 19

Table 5. Process indicators and met need for obstetric care ...................................... 20

Table 6. Proportion of health facilities with capacity to providekey services or

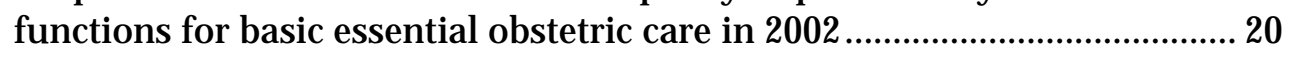

Table 7. Time taken to get to the nearest health facility .......................................... 22

Table 8. Percent of facilities with stocks of SP, iron and folic acid, 2002 .................. 27

Table 9. Improvements in A ntenatal care in Western Province .................................. 28

Table 10. Attendants assisting women to give birth in their homes (\%) ..................... 30

Table 11. Quality of intrapartum care - health provider recall .................................. 32

Table 12. Quality of intrapartum care - normal birth records ................................... 32

Table 13. Heal th providers experience and management of obstetric problems ....... 33

Table 14. Major causes of death according to heal th providers' experience ............33

Table 15. Assessing health providers knowledge and practice in their management of obstetric complications....................................................... 34

Table 16. Improvements in management of obstetric complications........................... 35

Table 17. A ge range of women from case patient records reviewed (by numbers)... 37

Table 18. Type of postpartum service received by mother since giving birth ............ 38

Table 19. Major problems facing health facilities as perceived by providers ............ 41 


\section{ACKNOWLEDGEMENT}

The process of planning and implementing interventions was undertaken through substantial input from many people and organisations. We would like to take this opportunity to thank the Department for International Development (DFID) for having availed funds to support the entire project activities. The following organisations/ institutions and communities are thanked for having played a key role during the various stages of the project:

The Ministry of Health Headquarters, Department of Preventive and Promotive Care; the Division of Reproductive Health, The Division of Nursing, the Provincial Health Management Team, the District Health Management Teams and Boards for Kakamega, Vihiga, Bungoma and Lugari Districts. The Hospital Management Teams as well as the Hospital Management Boards for the PGH Kakamega, Bungoma District Hospital, Webuye and Kimilili Sub-District Hospitals and the management and staff of all Hospitals and Nursing Homes who participated in the project, namely, Mukumu Mission Hospital, Kaimosi Mission Hospital, Lugulu Mission Hospital, Misikhu Mission Hospital, Kima Mission Hospital and Lumboka Memorial Hospital. In addition, all Rural Health Facility Management Committees, staffs from all health centres and dispensaries in the four districts are also acknowledged.

The women of Kakamega, Vihiga, Bungoma and Lugari Districts who put aside their valuable time in order to participate in various stages of the project including household surveys and exit interviews at facilities are also acknowledged. We also wish to thank Maendeleo Ya Wanawake Organisation (MYWO) officials at all levels and the Department of Social Services for their active involvement in project activities.

The following individuals are acknowledged for having provided technical input at various stages of the project: Dr. Richard Muga Director of National Council of Population and Development (former Director of Medical Services, MOH); Drs. Amira, Adungosi, Songa, Ayisi (former Provincial Medical Officers -Western Province) and Olang'o Onudi (current Provincial Medical Officer-Western Province); Dr. Oyieke (Chairman, Dept. of Obstetrics and Gynaecology - University of Nairobi), Dr. J. G. Karanja, Dr. Patrick N davi and Dr. G. Jaldesa (Dept. of Obstetrics and Gynaecology University of Nairobi); Prof. J. Wang'ombe, Dr. Joel Rakwar, Dr. P. Muriithi, Prof. J. Olenja and Dr. P. Njoroge (Department of Community Health - University of Nairobi); Dr. Josephine Kibaru, Dr. Margaret Meme, Mrs. Nancy Waweru, Mrs. Charity N dwiga, Dr. Marsden Solomon, Dr. Pamela Godia (Division of Reproductive Health - Ministry of Health); Mrs. Grace Kandie and Mrs. Agnes Waudo (Division of Nursing); Mr. Joseph Ole Kiu (Division of Clinical Medicine); Dr. Tom M boya and Chris Rakuom (Department of Standards and Regulatory Services); Dr. A yo Ajayi, Dr. Ian Askew, Dr. Esther Muia, Wilson Liambila and Charlotte Warren (Population Council); and Marilyn McDonagh (Health Advisor - DFID).

Field supervisors and research assistants who worked tirelessly to ensure thorough collection and processing of data as well as having played other roles in the project are sincerely thanked (see full list in appendix 8). Thanks are also due to all other people who contributed in one way or another in various phases of the project. 


\section{EXECUTIVE SUMMARY}

\section{I ntroduction}

Maternal mortality is a major public health problem in Kenya. Most recent estimates from the Kenya Demographic Health Survey 2003 are 414 deaths per 100,000 live births. Deteriorating public health services and the HIV/ AIDS epidemic are contributing factors. Kenyan women face a 1 in 20 lifetime risk of maternal death, which is the leading cause (27\%) among women of childbearing age in Kenya. Since March 2000, Population Council and the University of Nairobi have been assisting the Ministry of Health to implement Safe Motherhood activities in Kakamega, Vihiga, Bungoma and Lugari districts of Western Kenya. The purpose of the project was to increase utilization of quality maternal services in the selected districts.

\section{Methodology}

The Safe Motherhood Conceptual Framework provided the basis for designing the project interventions and overall approach. In addition, use of the three delay model focused the activities in reducing maternal, perinatal and neonatal deaths: (i) delay in deciding to seek appropriate care; (ii) delay in reaching an appropriate health care level; and (iii) delay in receiving adequate emergency care once at a facility. Key issues identified that contributed to high maternal and perinatal morbidity and mortality were: poor referral systems, limited competence and skills among health providers, poor health information system, frequent shortages of essential equipment and supplies, weak management systems at all levels and limited access to basic obstetric care at community level.

A participatory approach involving relevant institutions and sectors was used in problem identification, analysis and implementation of interventions. A quasi-experimental design using a before and after approach was followed to compare and assess the impact of interventions at the community level and within health institutions in the four districts. A baseline survey was conducted in the year 2000 and an endline in 2003. Both probability and non-probability sampling procedures were used to address different study units and subjects within the project.

\section{Programme interventions to enhance access to maternal care}

In an effort to improve pregnancy outcome, the project focused on improving quality of antenatal care, essential obstetric care, clean and safe delivery, post-partum care, post-abortion care and management issues at all levels. In addition, the project also focused on strengthening referral practices and on addressing factors responsible for delays by pregnant women in making decisions on when, where and how to seek care .

\section{Community Action}

A number of interventions were piloted within the community to make essential obstetric care services more available at the community level. For example: improving the opening hours of rural health facilities; encouraging dispensaries to conduct deliveries; introduction of a birth preparedness scheme; educating women on danger signs in pregnancy and child birth; piloting a domiciliary birth model and involving TBAs in referral practices. Other interventions that were piloted at the community level include mobile laboratory services and increasing the number of outreach $\mathrm{MCH}$ clinics.

\section{Referral}

Improving access for women with obstetric complications can only be effective where there is a functional referral system and equipment and supplies including availability of emergency drugs within facilities. The following interventions were put in place: improving telephone communications, maintenance and repair of vehicles/ambulances; management of referred cases with obstetric complications; training/ updates on obstetric complications; and community involvement in developing revolving funds for emergency transport. 


\section{$M$ anagement and institutional capacity}

Strengthening of specific systems in health management took place at all levels within the four districts. At baseline, weak management of health services was a major factor in the lack of quality maternity care. The interventions involved a series of teambuilding workshops, management skills workshops as well as improving their organisation structure and interinstitutional and inter-personal communication. In addition a review of flow of patients at the facilities, collection and utilisation of funds, planning and management of human resources; health information systems, and developing a sustainable procurement system of essential supplies, equipment and drugs were also undertaken.

\section{Competency and skills of health care providers}

The competency and skills of health care providers at the various levels of institutions was improved through structured competency based training, regular facilitative supervision and technical updates for health care providers. This included on-the-job training (OJT) for health care providers in all aspects of essential obstetric care and incorporates the continuum of care from antenatal through to the post partum period and obstetric and neonatal complications.

\section{Project Coordination and $M$ anagement}

Division of Reproductive Health (DRH) was responsible for the policy aspects of the project. Population Council in collaboration with the University of Nairobi (UoN) provided Technical Assistance for the SMDP. The Provincial Medical Officer (PMO) chaired the Project Steering Committee, which provided guidance and coordination of all activities within the project area and served as a link between the districts and DRH at national level.

\section{Results}

Given the relatively short intervention, this report demonstrates process and outcome indicators. Although the obstetric met need is still low there has been a marked increase over the project period including a reduction in the Case Fatality Rate.

A ntenatal Care: significant increases were noted in use of standard ANC cards, the number of women receiving Intermittent Preventive Treatment for malaria, blood tests for $\mathrm{Hb}$ and syphilis and blood pressure recorded when they attended antenatal clinic. More women said they were seen in privacy and given the opportunity to ask questions and remembered danger signs during pregnancy.

Intrapartum Care: Provider knowledge and experience was to seen to improve over the project period. Significantly more providers are using partograph to manager labour and improved management of complications. More providers are monitoring labour more effectively and referring earlier. Fewer women gave birth after more than 12 hours of labour. Significantly more women are delivering with Skilled Attendance at home. Health care providers are now more knowledgeable about obstetric problems and have more experience to manage them.

Post partum Care: More women attend postpartum care especially if a skilled health care provider assisted them at birth. Women are now morelikely to have their blood pressure measured and physical examination in postpartum clinic. However this is an area where an increased effort is required.

$M$ anagement and organisational issues have improved including an improvement in systems for procurement of equipment, drugs and supplies. Fewer women had to bring in drugs and supplies during labour. More facilities are now able to provide Manual Vacuum Aspiration (MVA) services for post abortion care and provide 24-hour cover for maternity services. More heal th facilities are now using guidelines and protocols and there have been improvements in heal th facility management. 
At the community level there was a significant increase in the number of women who gave birth at home with a skilled attendant and more dispensaries are providing care for women in labour and childbirth. Prepayment schemes for maternity care and birth preparedness models showed increased skilled attendance in areas where they were piloted.

A strong referral system is crucial in providing the linkages between community and facilities that offer essential obstetric and neonatal services. There were notable improvements the number of facilities that had access to working telephones and vehicles for transportation of emergency cases.

Overall, the proportion of women who had heard of a woman dying due to obstetric related complications reduced over the project period. However, despite a reduction in the proportion, a review of maternal deaths records showed that the number of maternal deaths during pregnancy increased at endline. This increase of deaths during pregnancy may indicate more deaths due to abortion complications an probably due to indirect causes such as severe mal aria in pregnancy, HIV/ AIDS, turberculosis, cardiac diseases, sever anaemia, etc.

The situation regarding neonatal and perinatal health only improved marginally. For instance, thirty percent of women said they had lost at least one child at baseline compared to $28 \%$ at endline. The age of children who had died was not asked at baseline but among women who had lost a child aged one year or less at endline, 36\% died within the first month of birth.

\section{Challenges}

Despite the achievements mentioned within this report, there remain some challenges. These include weaknesses in providing essential newborn care and early postpartum care and to ensure adolescent mothers are supported to give birth safely. Men need to be more involved in the care of women and children. Wider community participation is crucial to encompass the cultural and social aspects of making motherhood safe. The Ministry of Health must take a more pro-active role in coordinating all aspects of $\mathrm{MNH}$ services in order to reduce maternal and neonatal morbidity and mortality.

\section{Conclusion}

It is evident from the results that the project has largely achieved its purpose, which was to increase utilization of quality maternal services in the selected districts. Specifically, the project has made substantial progress in the area of maternal health as well as in the broader health system issues through building partnerships, supporting and strengthening community action, use of skilled attendance at birth and having in place a strengthened and supportive health management system at all levels. Emerging lessons from the project point to the fact that realising improvements requires a systems approach and that the four strategic interventions identified above need to work in a synergistic manner to increase utilisation of maternal services and increase the obstetric need in order to improve maternal health in Kenya especially for poor women.

\section{Recommendations}

- Ensure effective replication and scale up of safe motherhood initiatives in other provinces in Kenya in line with the Division of Reproductive Health Safe Motherhood and Neonatal Model.

- Strengthen the technical capacity of the Division of Reproductive Health as well as the Provincial Reproductive Health Supervision and Training Teams. 
- Incorporate the integrated reproductive health curricula into the basic training courses in all health-training institutions and disseminate evidence based best practice widely, including updates for all trainers/ lecturers.

- Safe Motherhood and Neonatal Health is considered one of the essential packages within health sector reform and linkages with the other packages must be strengthened at national level in order to guide linkages at provincial and district levels.

- Develop a National RH policy and National Advocacy Strategy for Maternal and Neonatal Health: improve policy clarity and wide communication on making pregnancy safer issues (e.g. a national transitional strategy for TBAs is developed and domiciliary care strengthened).

- Ensure pro poor systems are in place to provide equitable maternity services countrywide.

- Strengthen post-partum care at all levels.

- Inter-sectoral action is needed to support adolescent mothers to give birth safely.

- Strategies aimed at encouraging communities to participate in safe motherhood activities should take into account the need to involve men as well as appreciate the importance of the cultural and social aspects of making motherhood safe. 


\section{ABBREVI ATI ONS AND ACRONYMS}

ANC

Antenatal Clinic

APH Antepartum Haemorrhage

AMDD A verting Maternal Death and Disability (Program)

BEOC Basic Essential Obstetric Care

BP Blood Pressure

$\mathrm{BOH} \quad$ Bad Obstetric History

C/ S Caesarean Section

CEOC Comprehensive Essential Obstetric Care

CFR Case Fatality Rate

CIF Community Improvement Fund

CO Clinical Officer

CORP Community Owned Resource Person

Cx Cervix

DFID Department for International Development

DHMB District Health Management Board

DHMT District Health Management Team

DMC Division of Malarial Control

DPHN District Public Health Nurse

DO District Officer

DRH Division of Reproductive Health

EAs Enumeration A reas

ECSA OGS East, Central and Southern A frica Obstetrical and Gynaecological Societies

ENC Essential Newborn Care

EOC Essential Obstetric Care

FHR Foetal Heart Rate

FGD Focus Group Discussion

FIF Facility Improvement Fund 


\begin{tabular}{|c|c|}
\hline FP & Family Planning \\
\hline $\mathrm{Hb}$ & Haemoglobin \\
\hline HFMC & Health Facility Management Committee \\
\hline HIS & Health Information System \\
\hline HIV & Human Immuno Deficiency Virus \\
\hline HMT & Hospital Management Team \\
\hline Hosp & Hospital \\
\hline ICPD & International Conference on Population and Development \\
\hline IEC & Information, Education and Communication \\
\hline IPPF & International Planned Parenthood Federation \\
\hline IV & Intravenous \\
\hline IM & Intramuscular \\
\hline IMR & Infant Mortality Rate \\
\hline KDHS & Kenya Demographic and Health Survey \\
\hline KOGS & Kenya Obstetrical and Gynaecological Society \\
\hline KQM & Kenya Quality Model \\
\hline KSPA & Kenya Service Provision Assessment \\
\hline $\mathrm{MCH}$ & Maternal Child Health \\
\hline MCSS & Ministry of Culture and Social Services \\
\hline $\mathrm{MoH}$ & Ministry of Health \\
\hline $\mathrm{MOH}$ & Medical Officer of Health \\
\hline MMR & Maternal Mortality Ratio \\
\hline MVA & Manual Vacuum Aspiration \\
\hline MYWO & Maendeleo Ya Wanawake Organisation \\
\hline NGO & Non-Governmental Organisation \\
\hline NHSSP & N ational Heal th Sector Strategic Plan \\
\hline NNAK & National Nurses Association of Kenya \\
\hline
\end{tabular}




\begin{tabular}{ll} 
OBS/ GYN & Obstetric/ Gynaecology \\
OJT & On-theJob Training \\
OPR & Output to Purpose Review \\
PAC & Post A bortion Care \\
PC & Population Council \\
PGH & Provincial General Hospital \\
PHC & Primary Health Care \\
PHMT & Provincial Health Management Team \\
PHO & Public Health Officer \\
PMO & Provincial Medical Officer \\
PPC & Postpartum Clinic \\
PPH & Postpartum Haemorrhage \\
RHF & Rural Health Facility \\
RH & Reproductive Health \\
SP & Sulphadoxine and Pyrimethamine \\
SMDP & Safe Motherhood Demonstration Project \\
SPSS & Statistical Package for Social Sciences \\
TBAs & Traditional Birth Attendants \\
TT & Tetanus Toxoid \\
UN & United Nations \\
UNDP & United Nations Development Program \\
UNFPA & United Nations Population Fund \\
UNICEF & United Nations Children's Fund \\
VDRL & Venereal Diseases Research Laboratory \\
WHO & World Health Organisation \\
\hline
\end{tabular}




\section{NTRODUCTI ON}

\section{Background}

Maternal mortality is a major public heal th problem in Kenya. M ost recent estimates by Kenya Demographic Health Survey 2003 are 414 maternal deaths per 100,000 live births. Deteriorating public health services and the HIV/AIDS epidemic are contributing factors. Kenyan women face a 1 in 20 lifetime risk of maternal death, which is the leading cause (27\%) among women of childbearing age in Kenya. There are five major causes of maternal death: haemorrhage, infection, hypertensive disease in pregnancy, unsafe abortion and obstructed labour. Many of these deaths could be averted if women had access to essential obstetric care when they need it.

The conceptualisation and development of the Safe Motherhood Demonstration Project (SMDP) in Western Kenya was influenced by the growing international evidence on the need to operationalise crucial aspects of Reproductive Health including Safe Motherhood that stemmed from the International Conference for Population and Development (ICPD) in Cairo in 1994; the National RH Strategy (1997 to 2010) and the Reproductive Health Implementation Plan (1998 to 2003); and the DFID funded review of Safe Motherhood in Kenya (A Question of Survival 1997). Subsequently the Safe Motherhood Partnership Fund was set up in conjunction with DFID and the Ministry of Health. One of the aims was to pilot safe motherhood interventions, to generate lessons and best practices for scaling up maternal health activities throughout the rest of the country.

\section{The Safe Motherhood Partnership Fund}

Under the Safe Motherhood Partnership Fund (SMPF) approved by DFID in 1999, the Safe Motherhood Demonstration Project was awarded to Population Council in partnership with the University of Nairobi's Departments of Obstetrics \& Gynaecology and Community Health. The other two projects under the Partnership Fund were awarded to Family Care International (training of health staff in life saving skills in Garissa District) ${ }^{1}$ and to JHPIEGO (developing guidelines in managing malaria in pregnancy including focused antenatal care in 19 districts) ${ }^{2}$.

The goal of the Safe Motherhood Partnership Fund was to improve maternal health in Kenya especially for poor women while the purpose was to increase utilisation of quality maternal services in selected districts. In order to achieve the purpose, three outputs were identified. These were:

I. Improved service quality in antenatal, intrapartum, postpartum and postabortion care in selected districts;

II. Demonstrated effectiveness of systems of referral, access, health management and IEC in selected districts; and

III. Government, non-Government and donor health strategies include enhanced and appropriate safe motherhood components.

\footnotetext{
1 The $\mathrm{FCl}$ project on life saving skills was completed in N ovember 2001.

2 The JHPIEGO project was initially started in two districts but has since been extended to cover 19 districts.
} 


\section{The Safe Motherhood Demonstration Project}

Population Council and the University of Nairobi assisted the Ministry of Health to implement the Safe Motherhood Demonstration Project in Kakamega, Vihiga, Lugari and Bungoma Districts in Western Province, Kenya. The criteria for selecting the four districts included:

- High fertility rate

- High maternal and neonatal mortality

- High proportion of people living in total poverty

- Population Density

- Maternal health and child survival identified as areas of concern by the districts.

Geographically, Western Province lies on the equator at an altitude ranging from 1000 to 4300 metres (the peak of Mount Elgon). The Province borders Uganda to the West, Lake Victoria/ Nyanza Province to the South and Rift Valley Province to the North and East. The total province population is around 3.5 million whereas the population in the four demonstration districts is 2.4 million (See Table 1 for more information).

Kakamega District has two comprehensive essential obstetric care (CEOC) centres namely Kakamega Western Province, Kenya

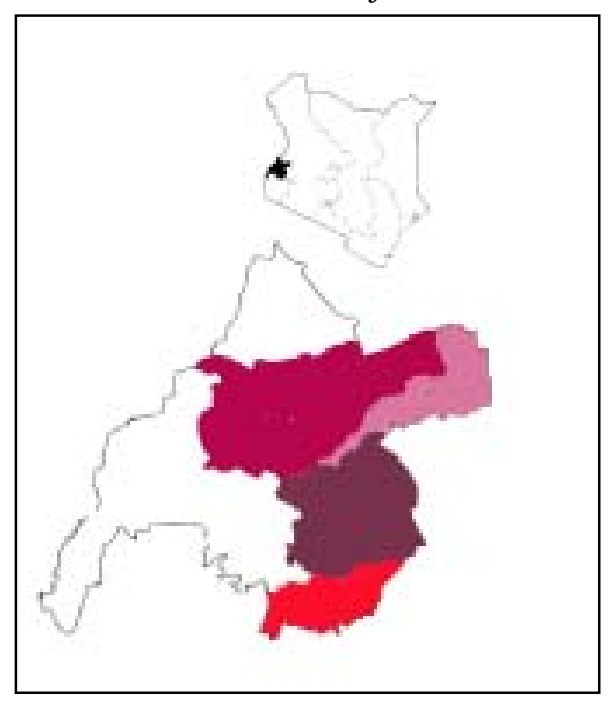

Provincial General Hospital and St Elisabeth's Mukumu Mission Hospital. Although Malava health center was upgraded to a district, there are plans to scale up two health centres (Iguhu and Bukura) to sub district hospitals to reduce over crowding at the provincial hospital. The district has $14 \mathrm{H}$ ealth Centres, 13 Dispensaries and 11 Nursing Homes.

V ihiga District was carved out of the larger Kakamega District in 1991. In 2000 there was no district hospital. Two mission hospitals existed but due to management problems and staffing, neither of these provided CEOC. Women requiring emergency obstetric care services had to travel to Kakamega PGH, St Elisabeth's M ission Hospital in Kakamega District or PGH Kisumu in Nyanza Province. Since February 2002, Vihiga District Hospital has been providing CEOC. There are 17 Health Centres, 12 Dispensaries and $2 \mathrm{Nursing}$ Homes in the district.

Bungoma District has six hospitals providing CEOC. One district hospital in Bungoma, two sub district hospitals (at Webuye and Kimilili), two mission hospitals (Misikhu Mission Hospital and Lugulu Friends Hospital) and one private hospital (Lumboka Hospital). There are 13 Health Centres, 33 Dispensaries, and 5 Nursing Homes. However, some divisions such as Ndivisi have no health facilities at all. Few of the rural heal th facilities are able to provide basic essential obstetric care (BEOC).

Lugari D istrict was carved out of the larger Kakamega District in 1997. It has no CEOC and women requiring these services have to travel to Webuye (Bungoma District) or to hospitals in Eldoret or Kitale (Rift Valley Province). There are 5 Health Centres, 10 Dispensaries and 3 Nursing Homes. None of these are able to perform all the basic essential obstetric care functions. 


\section{Project Beneficiaries}

The primary beneficiaries were childbearing women and their newborn infants in the four districts. Secondary beneficiaries included immediate relatives and community members who often bear both the direct and indirect costs associated with maternal and perinatal morbidity and mortality. Health care providers and their managers were also considered as secondary beneficiaries.

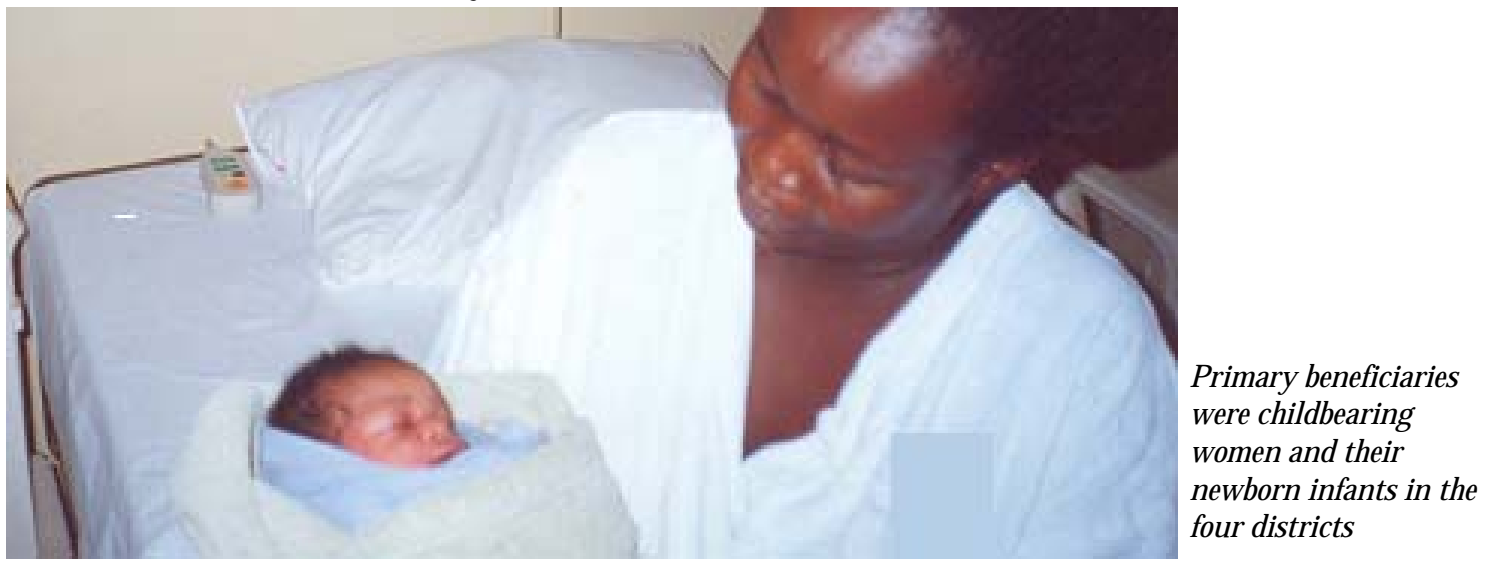

Table 1. D ata for districts selected for SM D P

\begin{tabular}{|l|r|r|r|r|r|r|r|r|}
\hline & \multicolumn{1}{|l|}{$\begin{array}{l}\text { Population } \\
1999\end{array}$} & $\begin{array}{l}\text { Population } \\
2002\end{array}$ & $\begin{array}{l}\text { Density } \\
\text { Persons/ km² }\end{array}$ & $\begin{array}{l}\text { Crude } \\
\text { birth } \\
\text { rate }\end{array}$ & $\begin{array}{l}\text { Total } \\
\text { Fertility } \\
\text { Rate }\end{array}$ & $\begin{array}{l}\text { Births } \\
\text { 15-19 } \\
\text { yr } \\
\text { females }\end{array}$ & $\begin{array}{l}\text { IMR/ } \\
1000 \\
\text { live } \\
\text { births }\end{array}$ & $\begin{array}{l}\text { MMR/ } \\
\text { 100,000 } \\
\text { live } \\
\text { births }\end{array}$ \\
\hline Kenya & $28,62,000$ & $31,517,00$ & 49 & 41.3 & 5.0 & 11.8 & 77.3 & 590 \\
\hline $\begin{array}{l}\text { Western } \\
\text { Province }\end{array}$ & $3,357,000$ & $3,676,000$ & 406 & 45.0 & 6.0 & 10.6 & 100.6 & $*$ \\
\hline $\begin{array}{l}\text { Kakamega } \\
\text { District }\end{array}$ & 603,000 & 670,000 & 432 & 44.0 & 5.7 & 11.0 & 110.9 & $*$ \\
\hline $\begin{array}{l}\text { Vihiga } \\
\text { District }\end{array}$ & 499,000 & 543,000 & 886 & 37.6 & 5.1 & 8.6 & 81.9 & $*$ \\
\hline $\begin{array}{l}\text { Bungoma } \\
\text { District }\end{array}$ & 876,000 & 977,000 & 423 & 46.6 & 6.4 & 9.6 & 97.0 & $*$ \\
\hline $\begin{array}{l}\text { Lugari } \\
\text { District }\end{array}$ & 216,000 & 240,000 & 322 & 44.8 & 6.1 & 9.5 & 64.1 & $*$ \\
\hline
\end{tabular}

*Inaccurate data available to compute

Data source: Kenya Population and Central Bureau of Statistics Ministry of Planning and National Development (2002)

\section{Conceptual framework and approach}

The Safe Motherhood Conceptual Framework developed by McCarthy and Maine in 1992 (see appendix 1) provided the basis for designing the project interventions and overall approach. In addition use of the three delay model focused the activities in reducing maternal, perinatal and neonatal deaths: (i) delay in deciding to seek appropriate care; (ii) delay in reaching an appropriate health care level; and 
(iii) delay in receiving adequate emergency care once at a facility (Thaddeus and Maine, 1994). The project also took into consideration the World Health Organization's (WHO 1995) four pillars of Safe Motherhood: antenatal care, clean and safe delivery, essential obstetric care and family planning. Family planning was not emphasized in this project as other partners in $\mathrm{RH}$ were supporting this component adequately at the time of the design.

The SMDP model (figure 1) was developed taking into consideration the three delay and the WHO models. The SMDP model also took into consideration the results of an initial situation analysis and stakeholders meeting which identified factors contributing to the high number of maternal deaths. This model encapsulates the processes required to increase utilization of quality services and thereby reduce maternal and neonatal deaths.

Figure 1. A pproaches to addressing safe motherhood

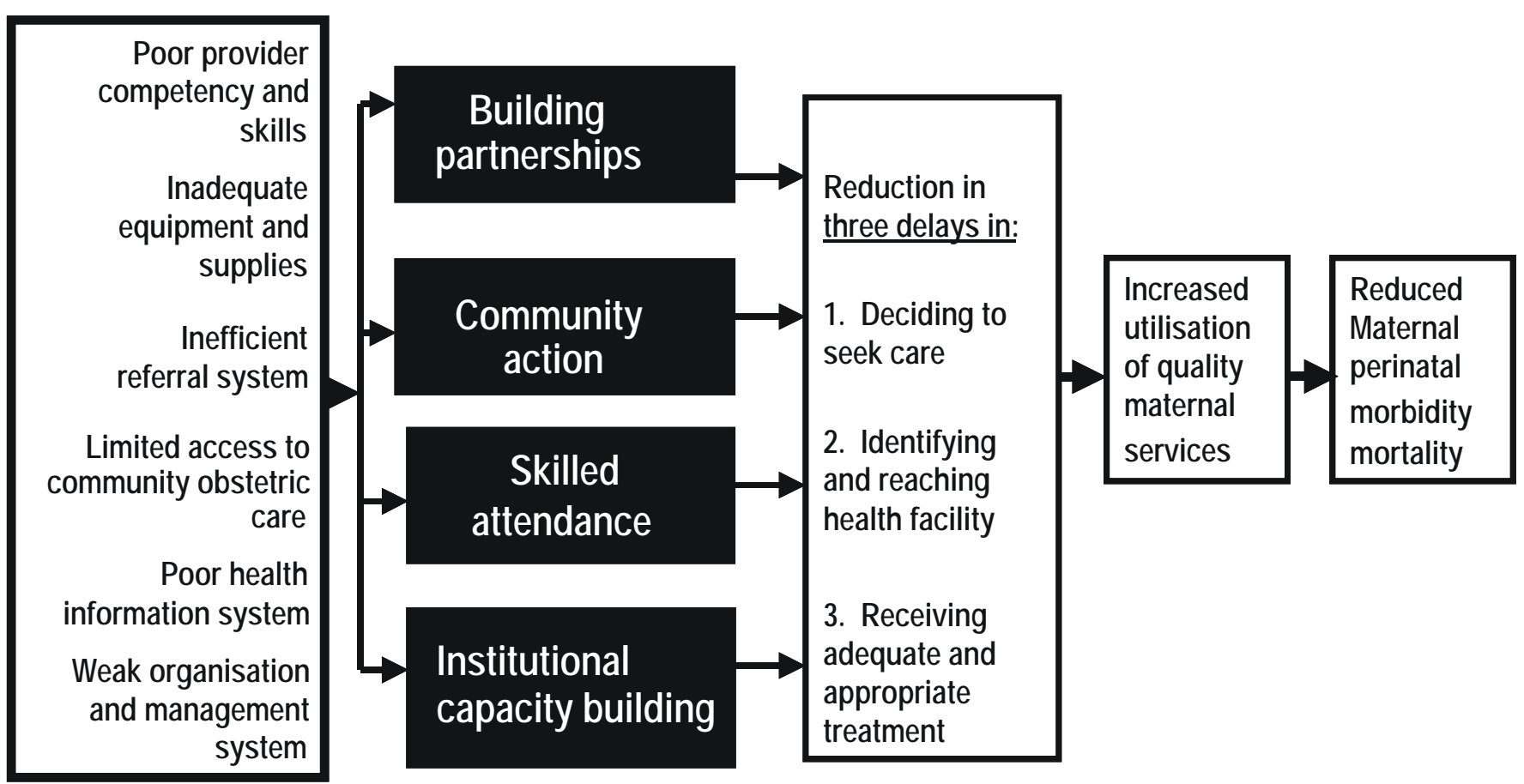




\section{Programme Plan}

\section{Participatory Approach in Project Planning}

To ensure that the project becomes sustainable and its activities replicable and scalable, targeted effort was made from project inception to involve all relevant people and institutions in problem identification, situation analysis, development of the logical framework planning matrices, implementation of activities, as well as monitoring and evaluation. The participants and institutions included the following: Population Council, staff from the Division of Reproductive Health and Ministry of Health headquarters, the Western Provincial Health Management Team, the Kakamega, Vihiga, Lugari and Bungoma District Health Management Teams and Boards, teaching staff of the University of Nairobi Departments of Obstetrics \& Gynaecology and Community Health, Mission/ NGOs/ private/ GOK facilities, relevant NGOs operating in the four districts e.g. Maendeleo Ya Wanawake Organisation, Department of Births and Deaths, Provincial Administration and District Development Officers.

\section{Situation Analysis and Core Problems}

A situation analysis held in March 2000 by stakeholders at district level identified the following factors as contributing to high maternal and perinatal morbidity and mortality: poor referral systems, limited competence and skills among service providers, poor health information system, frequent shortages of essential equipment and supplies, weak management systems at all levels and limited access to basic obstetric care at the community level. The project focused on these areas in an effort to improve pregnancy outcome.

\section{Project I nterventions and Building Blocks at District Level}

Taking into account the problems identified during the situation analysis and the broader goal, purpose and outputs of the Safe Motherhood Partnership Fund the stakeholders designed interventions appropriate to each district following the development of the logical frame and the analysis of the baseline survey. The strategies used in the implementation were: improving provider competency and skills, strengthening health management systems (institutional capacity building), improving health information system, improving a sustainable system for equipment and supplies, improving the referral system, and aspects of essential obstetric care at community level.

These interventions and processes served as building blocks towards the realisation of improvements in the quality of antenatal care, essential obstetric care, clean and safe delivery, post-partum care, post-abortion care and management issues at all levels. In addition, the interventions and processes also sought to strengthen referral practices and address factors responsible for delays by pregnant women in making decisions on when, where and how to seek care at the community level.

Initiatives were designed to take full advantage of inherent strengths in place and existing infrastructure within each of the districts. It was realized that for the health teams to achieve the set objectives, they needed to change their working culture. This involved strengthening leadership approaches among the PHMT, DHMTs and HMTs, as well as improving technical capacities of health providers. Institutional preparedness preceded community mobilization to avoid a situation where mobilized community members were to attend institutions that were ill prepared for their various needs and concerns. 
Quality assurance was emphasised throughout the implementation phase of the project, particularly on issues that were important in guaranteeing safe outcome for mothers and their babies.

Quasi-experimental design was used (see Appendix 2 for details) to measure the process and outcome indicators of the SMDP. Both probability and non-probability sampling procedures addressed different study units and subjects within the project. Table 2 shows the instruments used to collect the data for the baseline and endline surveys. The number of study units was reduced at the end line due to a fewer number of indicators measured. Results from the two surveys were used to assess the outcome and impact of the pilot project.

Table 2. Instruments used and sample sizes at baseline and endline surveys

\begin{tabular}{|l|r|r|}
\hline Instrument & Baseline & Endline \\
\hline Women at household & 4026 & 1427 \\
\hline Antenatal exit & 337 & 152 \\
\hline Postpartum exit & 279 & 97 \\
\hline Post abortion care exit & 13 & 6 \\
\hline Health care provider interview & 307 & 143 \\
\hline Health facility & 83 & 59 \\
\hline Record review for normal labour & 243 & 213 \\
\hline Record review for eclampsia & 29 & 10 \\
\hline Record review for obstructed labour & 78 & 29 \\
\hline Record review for caesarean section & 21 & 70 \\
\hline Management & 8 & 8 \\
\hline FGDs men and women & 0 & 4 \\
\hline FGDs with TBAs & & 0 \\
\hline
\end{tabular}

\section{Programme interventions to enhance access to maternal care}

\section{Essential Obstetric Care at Community Level}

During the SMDP situation analysis, a number of issues were identified as contributing to high maternal and perinatal morbidity and mortality especially at the community level. These were: complications associated with incomplete abortion, poor management of labour by TBAs, unclean and high proportion of unsafe home deliveries, retrogressive practices including use of herbal medicine during labour, and limited use of maternity facilities for delivery. 
Other constraints include inadequate information on reproductive health issues for women, inadequate collection of essential health information at the community level (e.g number of births and deaths, disease prevalence), loss of public confidence in the institutions and the staff, unnecessary delays in seeking care by mothers in labour, lack of transport and delayed referral of women with obstetric complications to health facilities. Some of these constraints contribute either directly or indirectly to delays in deciding to seek care at the household or in the community.

In order to undertake activities for the identified constraints, a number of interventions were piloted at community level to make essential obstetric care services more available at the community level e.g. improving the opening hours of rural health facilities; encouraging dispensaries to conduct deliveries; introduction of birth preparedness cards and birth preparedness scheme; educating women on danger signs in pregnancy and child birth; piloting a domiciliary birth model; and involving TBAs in referral practices providing mobile laboratory services and increasing the number of outreach MCH clinics. These interventions are outlined below.

Strengthening dispensaries to conduct deliveries

Historically dispensaries did not provide delivery services and were staffed by enrolled nurses who had no midwifery skills. This changed in 1989 when the enrolled nurse curriculum was updated and all nurses studied midwifery in their training.

Following the EOC updates and practical experience gained in the maternity units in busy hospitals, many of the Nurses attending EOC update

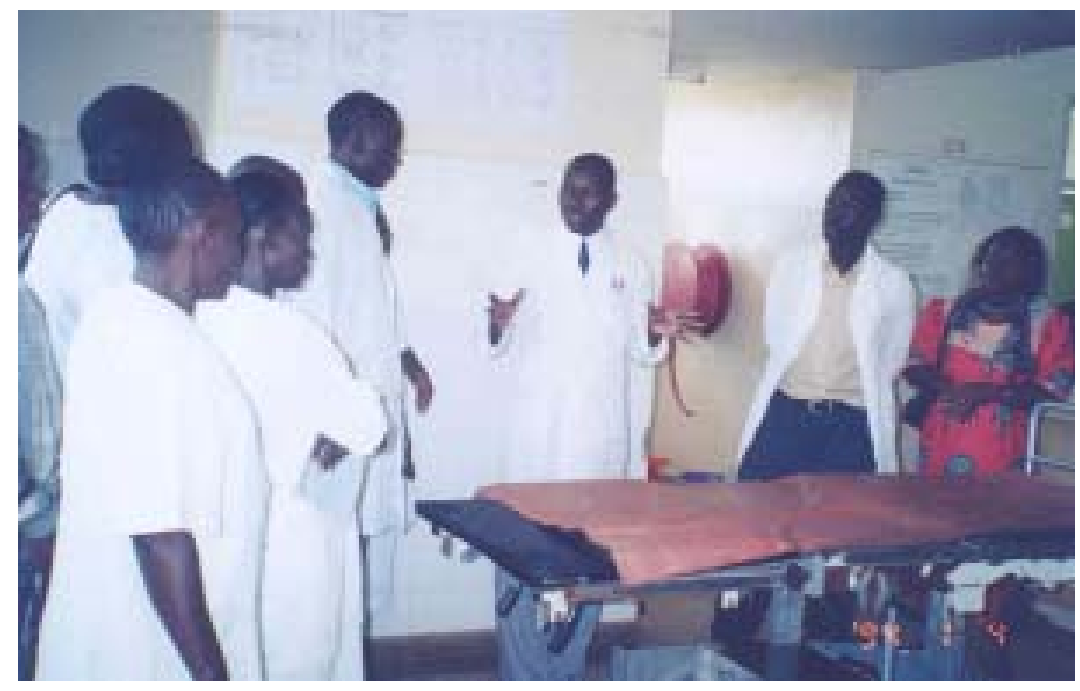
nurses/ midwives deployed to the rural facilities were encouraged to provide maternal services to women. Delivery kits and other equipment were provided to enable this to happen. In some districts, the Provincial Health Management Team re-deployed health care providers to ensure 24hour coverage of rural health facilities especially in situations where staff had been trained in EOC.

\section{Improving community awareness}

To address the issue of lack of knowledge and information on the danger signs related to pregnancy and childbirth within the community, appropriate IEC materials were either developed or existing ones adapted and distributed. This involved assessing existing materials at the Division of Reproductive Health, Division of Health Education, WHO and other RH partners. Posters and leaflets for mothers to take home, describing aspects of care during pregnancy, childbirth and the postpartum period were reprinted and distributed to the health facilities and community based groups. Community orientation materials for malaria in pregnancy and focused antenatal care devel oped by the DRH, DOMC and JHPIEGO were re-printed and distributed. 
Health care providers were encouraged to link with the rural health development committees to use every opportunity i.e. within churches and women's group meetings to pass healthy messages and recommendations to seek skilled attendance during and after pregnancy.

Husbands/ relatives or even TBAs were encouraged to escort women in labour to the health facility and to stay with the woman throughout her confinement to give her psychosocial support. This of course depends on the woman and family's preference. Evidence by WHO (2003) has shown that women who have a companion throughout labour in addition to skilled personnel are more likely to require less pain relief and have a more positive experience.

Birth Preparedness M odel

The birth preparedness model aims to stimulate active health care seeking behaviour among pregnant women. Given that a high proportion of deliveries still take place at home, most obstetric complications are therefore likely to occur at that level. In order to address this problem, a birth preparedness model was developed. It involved the development of a birth preparedness card (see figure 2) which has basic information on pregnancy care; birth preparatory arrangements (such as items that would be required during delivery and availability of funds); danger signs in pregnancy and childbirth; referral and where to seek help in an emergency; and is geared towards preparing the pregnant woman to engage in appropriate health care seeking practices. The model seeks to reduce mainly the first and second level delays.

Figure 2. Birth Preparedness M odel (These cards were distributed by women groups)

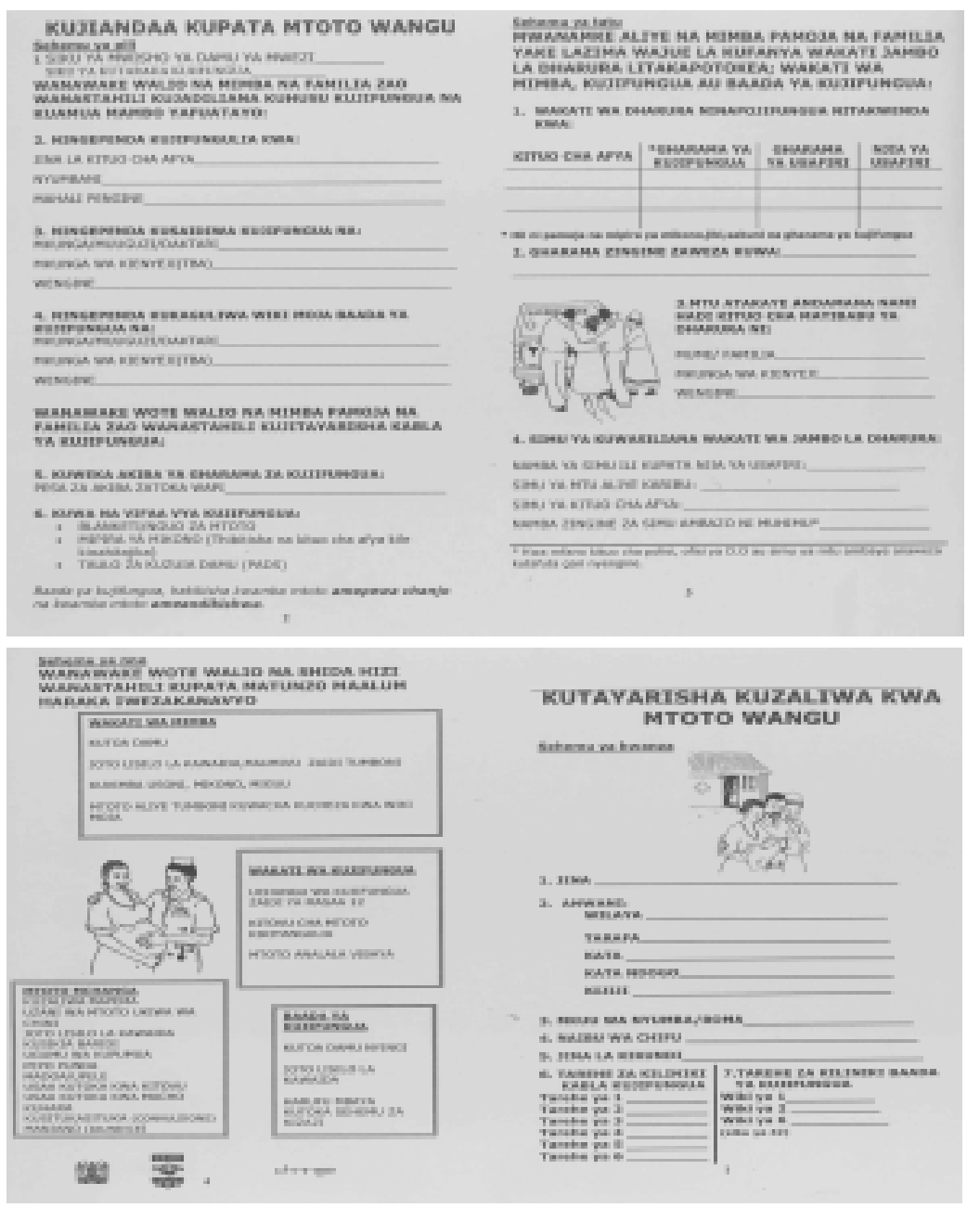


Prepayment Scheme

Many people in rural areas have meagre and irregular incomes. The livelihood of most households in Western Kenya is drawn from sale of farm produce or peddling household consumer goods. From this type of business, it is difficult to afford user fees for health care if paid as a lump sum. In response to the financial barriers preventing women from seeking health care; a pre-payment scheme was introduced to communities in catchment areas around four health centres to allow mothers to meet user fees by paying convenient instalments during pregnancy. The scheme seeks to promote early use of antenatal care and delivery with skilled providers. Once registered, a member of this scheme is entitled to a specific range of services when the need arises during the entire gestation period without having to pay at the particular time the service is given. Such benefits include:

- Discount if a pregnant woman requires referral to hospital from a health centre or dispensary;

- Standard laboratory tests required during pregnancy;

- Intermittent preventive treatment for malaria;

- Skilled attendance at birth, and appropriate referral to a comprehensive EOC facility.

To encourage enrolment, small instalments are distributed over the entire gestation period.

This model was implemented through Health Centre Management Teams, Health Centre Development Committees and community-based groups in both Lugari and Vihiga districts and members of Maendeleo Ya Wanawake Organization (MYWO) and the Department of Culture and Social Services.

Table 3 provides an estimate of the cost of one delivery in a rural health facility in Western Province if each item was to be bought separately. When women pay into the pre-payment scheme, the facility is then able to buy supplies and drugs in bulk thus reducing costs. Women who enrol early enough pay KShs 300 in instalments. Those who are unable to pay the full amount before delivery, pay the remaining balance after wards and still access the benefits of the scheme.

Table 3 A verage cost of inputs and services for a delivery in a rural health facility M arch 2003

\begin{tabular}{|l|c|}
\hline \multicolumn{1}{|c|}{ Item } & Cost (Kshs) \\
\hline Bed admission & 50 \\
\hline Suture (1 piece) & 75 \\
\hline Jik & 65 \\
\hline Cotton wool & 40 \\
\hline Cord clamp & 30 \\
\hline Gauze & 20 \\
\hline Ergometrine & 15 \\
\hline Washing soap & 15 \\
\hline 1 needle and syringe & 10 \\
\hline Hibitane & 5 \\
\hline Bathing soap & 5 \\
\hline Total & $\mathbf{3 3 0} \mathbf{( \$ 4 . 2 )}$ \\
\hline
\end{tabular}


D omiciliary Care M odel

Information from the baseline survey indicated that of $73 \%$ of deliveries that took place at home, only one percent did so with a skilled midwife. The domiciliary care model was therefore developed to increase the proportion of births receiving skilled attendance at home. Healthcare providers were equipped with the delivery kits and supplies required to assist women in labour within their neighbourhoods. Employed nurses also assisted when they are off duty, on leave, during weekends, public holidays and at night. Unemployed or retired nurses also assist at community level. The model's emphasis is focused on empowering the midwife with skills to assist women to give birth at home, to manage minor complications and know when to refer to an emergency centre from the home level.

Through this strategy, many women who would otherwise be unable to reach health facilities end up having equal access to professional care leading to safe deliveries. Willing midwives were given delivery kits for use within their respective communities.

M obile Laboratory

Majority of rural health facilities have no laboratory services. Vihiga District developed a system whereby laboratory personnel from the district headquarters travel to rural health facilities with equipment and reagents to provide laboratory services. This includes all tests recommended during pregnancy (antenatal care profile), such as haemoglobin estimation, VDRL, blood grouping and urinalysis. In addition, other tests such as Widal and blood slides for malaria parasites are offered at minimal costs for other patients too.

$M$ obile $M$ aternal and $C$ hild $H$ ealth Clinics

In order to provide services to areas with limited access to fixed maternal and child health care, rural health facilities were encouraged to run mobile outreach clinics. Historically these were quite common and popular, but due to lack of funds were often discontinued.

\section{I mproving the Referral System}

Improving access for women with obstetric complications can only be effective where there is a functional referral system, equipment and medical supplies including emergency drugs. The following interventions were put in place to make the system successful.

Telephones: Connection of landlines and public telephone booths were installed in appropriate heal th facilities. Cell phones were also made available. An agreement with police stations, DO's office, etc was made to allow health works to call a suitably located "ambulance" or vehicle to evacuate emergency cases to the next level of care.

V ehicles: Health facilities set aside part of their facility improvement fund to meet emergency transport costs. A functional ambulance was identified at the District level and served facilities in areas that were connected to the district hospital by telephone. SMDP funds repaired and/ or maintained these vehicles. Communities were encouraged and assisted to set up revolving funds from which families could borrow money to pay for transport to a referral facility during obstetric emergencies and refund later. This included meeting fuel costs for any ambulance in the neighbourhood where financial resources are not readily available. 
$M$ anagement: At the referral hospital level, management systems were reorganised to ensure improved handling of emergencies. A logbook for all referrals and referral letters were introduced giving referring facilities adequate information with regard to the patients' condition. Health Management Boards and Health Centre Development Committees were expected to ensure that vehicles were in good condition at all times and easily accessed during emergencies.

Training/updates and supervision: At health facility level, health workers received essential obstetric skills updates in order to manage labour optimally, recognise and refer or anticipate problems early. Midwives based at health facilities were encouraged to be actively involved in supervising existing TBAs and ensuring they were aware of when complications and emergencies were likely to occur to ensure timely referral.

Community level: Rural health facilities, communities and families worked together in devising ways to improve the linkages and networks for ensuring a rapid response regarding referral of emergency cases. Public Health Officers actively encouraged antenatal attendance, birth preparedness and skilled care at birth in an effort to reduce the first delay (in making a decision to seek care).

\section{Capacity Building at I nstitutional Level}

Strengthening of specific systems in health management took place at all levels within the four districts. At baseline, weak management of health services was a major factor underlying poor quality maternity care. Specifically, there was minimal maintenance of essential obstetric equipment and inadequate or erratic procurement system for consumable supplies and drugs. Management of health information was almost nonexistent and transport and referral was generally an ad hoc affair. Weak organisation skills among senior members of DHMTs, PHMTs and Hospital managers resulted in poor deployment of staff, out of date job descriptions, no duty rosters and minimal supervision and planning.

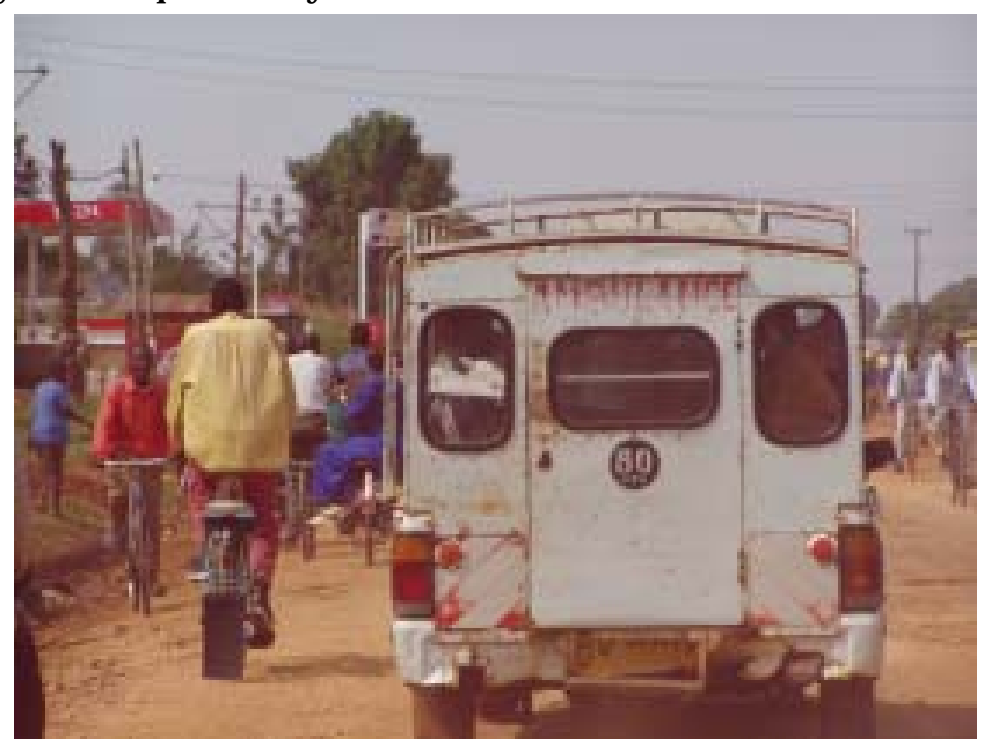

A $n$ ambulance used for transporting referral cases at $M$ abusi $H$ ealth $C$ enter, Luqari District

Management interventions involved a series of teambuilding and management workshops for hospital staff, DHMBs and DHMTs to improve their organisation and communication skills. Reviewing the flow of patients at the facilities; collection and utilisation of funds, planning and management of human resources and development of a sustainable procurement system of supplies and drugs were among other topics discussed. In addition, job descriptions were updated and circulated to relevant staff. Organograms organisation charts were also developed to demonstrate the management structures. 
As a strategy for strengthening the capacity of health managers in the SMDP districts, a visit to exemplary sites in Nyeri and Thika districts of Central Province took place in September 2001. The objective was to provide an opportunity for members of the DHMTs, HMTs, DHMBs and HMBs to visit other districts outside their province with a view to sharing experience and learning from each other. It was expected that the participants would gain knowledge and skills on strengthening health systems at all levels, share experience on different approaches to strengthening EOC at community level, and learn strategies for tackling service delivery constraints.

\section{I mproving the Health Management I nformation System}

All four Districts identified HMIS as an area to be addressed. This was confirmed by the baseline survey where, incomplete records were found or were non-existent. The areas addressed were at management and facility level and information collection at community level.

\section{Provincial Health Information}

Since the PHMT is the convenor of the Project Steering Committee meetings, it was deliberately engaged to ensure that timely reports by districts were prepared and submitted. It accomplished this through regular supervision of DHMTs and HMTs. The PHMT, in turn, prepared the provincial annual health report and submitted the same to the Ministry of Health headquarters with copies to the DHMTs and HMTs. Availability of the necessary stationery and forms was ensured through the FIF and routine government financial allocations. The EOC updates and other training sessions were also coordinated by the PHMT.

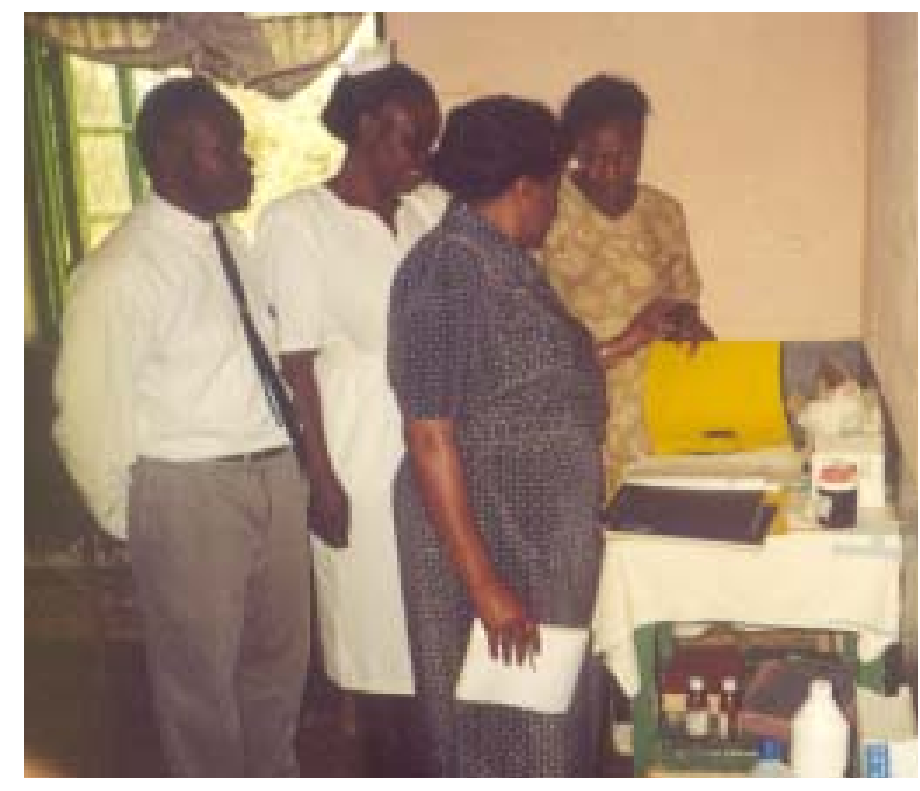

I guhu $\mathrm{H}$ ealth Centre staff, Kakamega D istrict and a representative from Division of Reproductive $\mathrm{H}$ ealth

H eal th Information System at facility level

The SMDP identified gaps in the collection and collating of health information pertaining to maternal and neonatal health. Patient registers; records, forms and charts were reviewed, revised and / or made available using the existing Health Information System. The SMDP provided sufficient copies of forms to each facility initially. Following this, the facility management committee were able to negotiate funds from cost sharing to ensure essential stationery was always available.

The registers that were available in most of the health facilities included: delivery registers, general admissions register, female ward register, operating theatre register and post - abortion care register. These registers were standardised following discussion between $\mathrm{MOH} / \mathrm{UoN} / \mathrm{PC}$. Maintenance of accurate maternity/ delivery records (and all other health facility records) at health centres and hospitals enabled health staff to plan and use the information. Each health facility staff received updates to maintain presentations on the notice boards or display boards in the appropriate service rooms or examples of the type of data and information displayed included monthly service utilization statistics such as: Antenatal clinic attendance; Child Immunisation; Postnatal/ partum clinic attendance: births by skilled attendants (both 
facility and community); Facility Improvement Fund (FIF) monthly collections; Family Planning clients (new, revisits and methods); and Deaths.

Community health information

Community based information was often collected by PHTs and Community Owned Resource Persons (CORPs) and submitted to the health facility within the catchment area. This information was then summarised and posted on the chalkboard for discussion with the respective rural health facility development committees and community members. Each facility submitted monthly reports to the DHMT, which reviewed and collated them into comprehensive district reports and sent them to relevant authorities and institutions. The DHMTs were encouraged and trained where necessary, to use computers to analyse, store and retrieve information.

\section{I mproving A Sustainable System for Equipment, Drugs and Supplies}

A vailability of functional and serviceable equipment was assessed at each facility and excess equipment was re-distributed to facilities in need while non-functional equipment was repaired. Based on identified gaps, a complement of obstetric equipment for each District was procured. A start up package of basic consumables was given to facilities through support of the SMDP..

A key intervention during the SMDP was improving the system for procuring drugs and supplies. Health Facility Management Committees (HFMC) were encouraged to purchase in bulk and to set fixed fees for service. Health workers received training in the use and maintenance of all equipment and they were provided with instructions and guidelines for proper cleaning, storage and servicing of the equipment. Comprehensive inventories were maintained and regular inspections carried out to monitor losses or damage in a timely manner. This facilitated budgeting for new and replacement of lost and/ or damaged items.

The routine supply of essential drugs and basic supplies in kits by the Government continued. Providers were trained in rational use of drugs including those used in obstetric care and provided with the national standard treatment guidelines (clinical guidelines). The World Health Organisation (WHO) has a well-defined essential drug list, as well as the

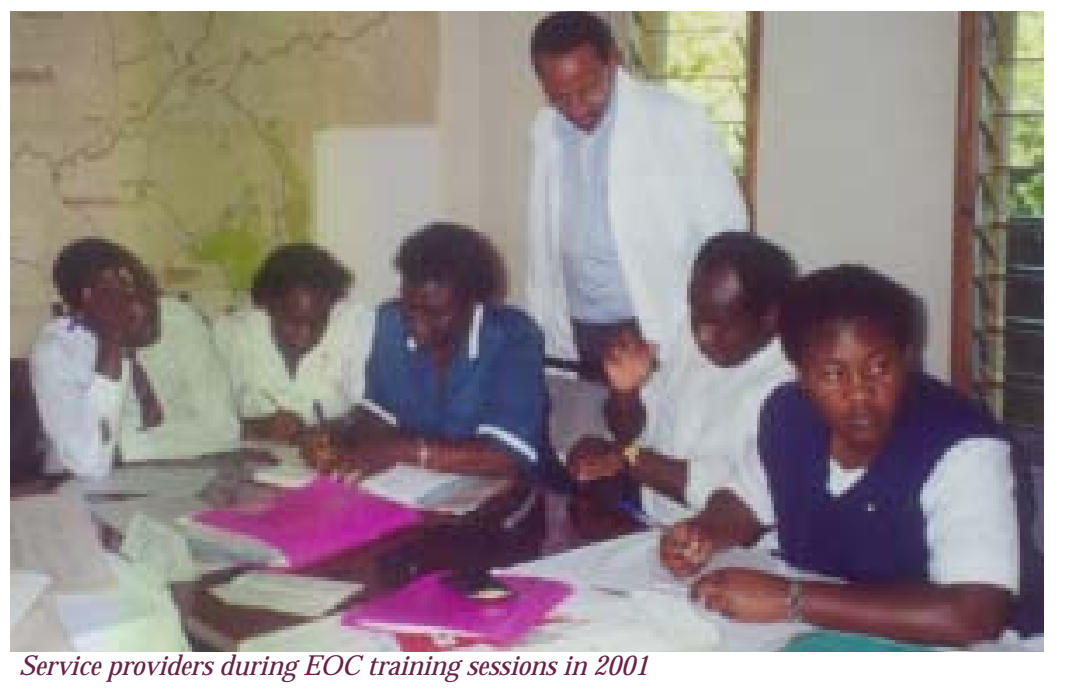
equipment list, for mother-baby package at each level (WHO 1994). These lists were adapted and provided to the District Health Management Teams.

Health Facility Management Committees have the mandate and autonomy to manage the cost sharing activities at the facility. They decide on the fee levels, the mechanisms to levy the fees as well as exempt those who cannot afford to pay. They also decide on priority expenditure areas and, with training and guidance from the DHMT and PHMT, manage the banking and expenditure of facility improvement funds. In particular, these committees procure supplementary drugs and basic supplies. Following consultations with the national level, the majority of public health facilities 
have been issued with guidelines on how to standardise user fees. In addition the project updated these committees on how to be more effective.

\section{Competency and Skills of Health Care Providers}

The competency and skills of health care providers at the various levels of institutions was improved through structured competency based training, regular facilitative supervision and technical updates for health care providers. This included On-the-Job Training (OJT) for health care providers (preceptors) in all aspects of essential obstetric care and incorporated the continuum of care from antenatal through to the post partum period and obstetric and neonatal complications. In addition modules on data collection, interpersonal skills, emergency preparedness and infection control were also included. The preceptors, upon return to their stations, continued OJT of their colleagues.

The EOC update was an intensive 5-day residential course based in one of the districts. Practical sessions took place in both the public and mission hospitals. For Kakamega and Vihiga participants the hospitals were PGH Kakamega and St Elisabeth's Hospital Mukumu. The theoretical sessions took place at the Kenafya PHC Centre. For Bungoma and Lugari participants the practical sessions took place in Webuye sub-district hospital, Bungoma District Hospital, Misikhu Mission Hospital and Lugulu Friends Mission Hospital. Theoretical sessions took place in Park Villa Hotel, Webuye.

The Dept ObGyn (University of Nairobi), the DRH and Population Council developed training materials on evidence-based practices in essential obstetric care, which were used in the technical updates. The Essential Obstetric Care M anual for $\mathrm{Health}$ Care Providers in Kenya was developed and disseminated to facilities in the four districts to further strengthen competency and skills of health care providers. The manual has a detailed section on management of normal labour and delivery including application of the partograph as well as the management of obstetric complications. In 2001, in Kenya, there were no formal publications or manuals on the management of women from antenatal care to the post partum period. The Ministry of Health has therefore adopted this manual for updating all health care providers in Essential Obstetric Care.

The DHMTs, the facility in-charges and nursing officers in-charge of maternity units as well as members from the DRH/UoN, provided facilitative supervision. Review of partographs used during normal labour in facilities in the four districts was part of the monitoring activities. This assessed completeness and accuracy of entering information on the important events during labour and appropriateness of the action that followed depending on the partograph findings. Health workers were encouraged to prepare and work according to daily work

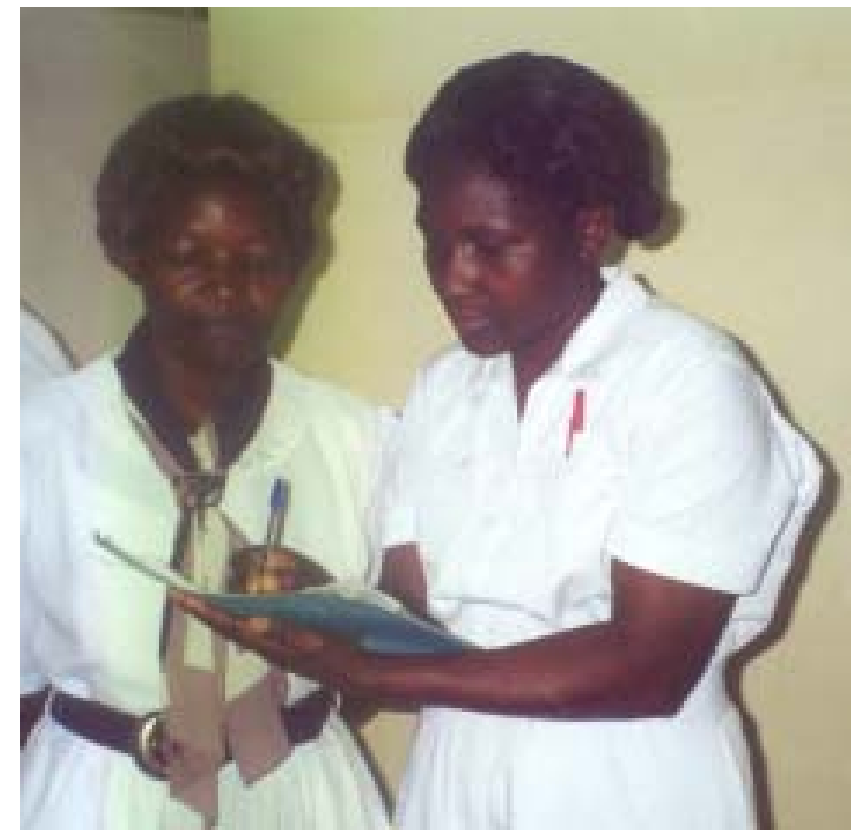

$\mathrm{N}$ ursing officers in-charge of maternity provided facilitative supervision (Sr A mina Baraka and M ical M uganda schedules and allocated tasks. 
A vailability of service provider manuals and guidelines was assessed and where there were shortages, the manual guidlines were distributed to providers in health facilities. Job aids developed by the $\mathrm{MOH}$ and other $\mathrm{RH}$ partners with information on essential obstetric care were adapted or reprinted for distribution to health care providers. These included the malaria in pregnancy and antenatal care guidelines developed by the DRH, DOMC and JHPIEGO; posters developed by $\mathrm{MOH}$; and WHO and a postpartum care job aide developed by Population Council.

At facility or unit level, providers met regularly (weekly) to review performance and plan for the week ahead. Regular clinical meetings were organised to provide staff with the opportunity to review, discuss and learn from case studies of patients. Monthly mortality meetings were arranged and documented. All maternal and perinatal deaths were reviewed in detail from admission to death to identify areas where corrective action was to be taken in future to prevent recurrence.

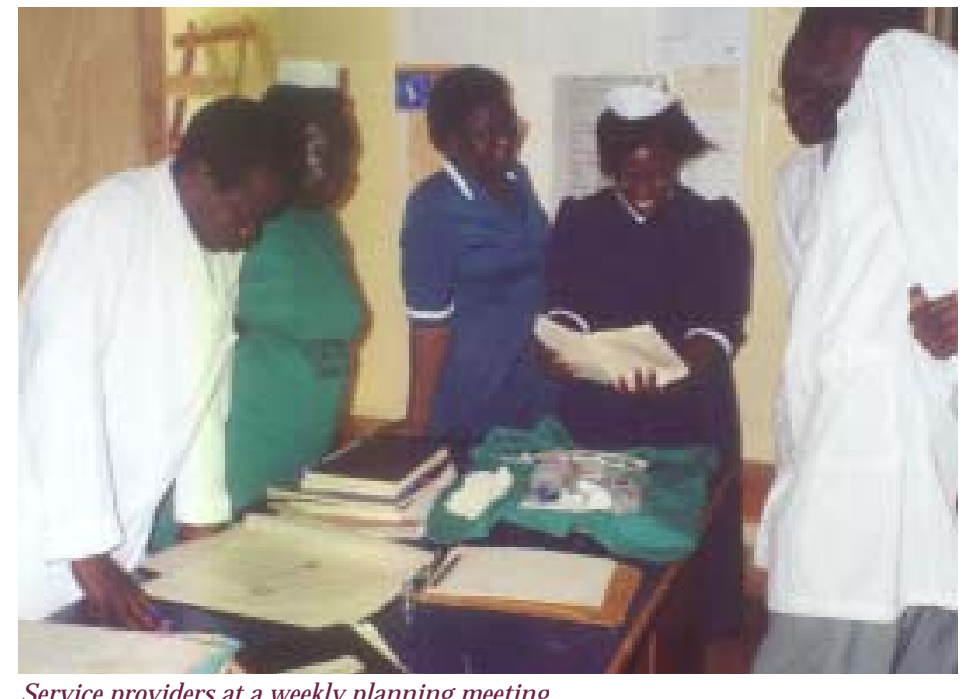

Providers at all levels were encouraged to adopt and sustain appropriate clientprovider relationships. A simple "safe motherhood newsletter" was produced and distributed to all health workers in the four districts to provide update on $\mathrm{RH}$ and topical issues in health. The PHMT coordinated this exercise with support from the Population Council. The newsletter was produced on a quarterly basis.

\section{Project coordination and management}

The DRH was responsible for the policy aspects of the project. Population Council in collaboration with the UoN provided Technical Assistance for the SMDP. However, the PMO chaired the Project Steering Committee and coordinated all SMDP activities. Members included the Medical Superintendent at Kakamega PGH, an Obstetrician Gynaecologist from the Provincial Hospital, the four Medical Officers of Health (MOHs) and District Public Health Nurses (DPHNs), as well as representatives from Mission hospitals. The Project Steering Committee provided guidance and coordination of all activities within the project area and served as a link between the districts and DRH at national level. The roles and functions of each partner are briefly outlined below.

\section{The Division of R eproductive H ealth}

The Division of Reproductive Health (DRH) facilitated the process of implementing the reproductive health programme including safe motherhood. DRH also undertook monitoring and evaluation of the programme. Representatives from other $\mathrm{MOH}$ departments were involved, including the Division of Nursing and Health Sector Reform Secretariat. 
The Provincial $\mathrm{H}$ ealth $\mathrm{M}$ anagement Team

The Provincial Health Management Team under the chairmanship of the PMO provided overall coordination of the programme at regional level with representatives from mission, provincial reproductive health teams, district health teams, NGO and private hospitals.

\section{The Clinical Support Team}

This team was made up of academic staff from the Dept of ObGyn, University of Nairobi, obstetrician/gynaecologists (including post-graduate registrars), paediatricians, medical officers of health, senior nurses and nurse trainers from DRH. The team was responsible for developing training materials and updating health care providers at all levels in EOC. This team has now been redefined as the Reproductive Health Training and Supervision Team at Provincial level.

The District $H$ ealth M anagement Team (D H M T)

The team coordinated and supervised all health and health-related activities in the district. The DHMTs worked closely with the clinical support team to train/ update health providers and health facility management committees. In addition, DHMTs participated in community mobilization activities.

The D istrict $\mathrm{H}$ ealth $M$ anagement Board (D H M B)

The boards ensured optimal management of facility improvement funds, that supplementary drugs and other supplies were procured, and that transport, fuel and telephones were paid for amongst others issues. In addition, the boards mobilised additional resources to support safe motherhood/ reproductive health initiatives.

The H ealth Facility M anagement Committee (HFM C)

Health Facility Management Committees participated in community mobilization and sensitisation activities. They were used as the entry point to the community at large for developing demand-driven services from health facilities.

Population Council

The Population Council backstopped the whole project and provided Technical Assistance to the $\mathrm{MoH}$ at Central, Provincial and District level. The Council also developed data collection tools and facilitated collection and analysis of data for both baseline and endline surveys. In addition, Population Council coordinated the development of training materials and training of health workers in both EOC and management and planning, and also assisted in developing pro-poor models to improve access and utilisation of various reproductive health activities including safe motherhood activities.

U niversity of $\mathrm{N}$ airobi: D epartments of $\mathrm{O}$ bstetrics and Gynaecology and Community $\mathrm{H}$ ealth The University of Nairobi worked closely in collaboration with Population Council to provide Technical Assistance to the $\mathrm{MOH}$ and specifically in training both health care providers and health managers and the development of technical manuals. They provided technical support across all areas of the project.

\section{Monitoring}

Population Council (in conjunction with the UoN and the DRH) developed a monthly monitoring tool on management issues and utilisation of services. This tool was used for each health facility (public, mission and private heal th facilities) in the four districts. 
Examples of data collected, included number and type of deliveries, maternal and neonatal deaths, antenatal and postnatal attendance; obstetric emergencies; signal functions of obstetric care, staffing levels; obstetric equipment and supplies, and management issues. Data were entered using EPI Info and analysed using SPSS.

Regular monitoring visits to the districts, individual facilities and communities took place. Monitoring teams included members from the DRH, DoN, UoN and Population Council. Health care providers were also followed-up closely through supportive supervision from the trainers and DHMT members. The SMDP was monitored throughout by the $\mathrm{MOH}$ and DFID. Monitoring and supervision included both internal and external annual reviews where project outputs were measured against the purpose. 


\section{FINDI NGS}

The results of the project are presented below in four sections: coverage and availability of obstetric and neonatal services, referral, community and maternal health services (including health organisation and management). The impact of the interventions is evaluated by making comparisons between baseline and endline findings in the intervention districts. Although some results are compared between districts, only those differences that are statistically significant between baseline and endline measures at the level of 0.05 or higher are considered meaningful.

\section{I mproving comprehensive and basic essential obstetric care and essential newborn care}

\section{Capacity to handle obstetric emergencies}

The United Nations obstetric process indicators use facility based data and population based estimates of the number of expected births and complications over a given time. They are based on the assumption that $15 \%$ of all women giving birth will require emergency obstetric care. To prevent the majority of maternal deaths, essential obstetric care must be available, accessible and equitably distributed and utilised by women who require this care. A basic essential obstetric care facility should be able to administer antibiotics, oxytocic drugs and anticonvulsants by injection or intravenously; perform manual removal of placenta and manual vacuum aspiration of retained placenta material, and perform assisted vaginal delivery. A facility providing comprehensive essential obstetric care should have the capacity to perform caesarean sections and blood transfusion besides the other six signal functions.

\section{Basic Essential O bstetric Care}

Generally intravenous antibiotics, anticonvulsants and oxytocics were the most available and administered drugs with over $80 \%$ of all facilities at endline carrying out these procedures. Most facilities can provide these functions easily and also have the potential to increase the range of services. Even though there has been an increase in the number of facilities able to provide MVA services, there are still a number of facilities unable to provide MVA all the time possibly because staff members are yet to be trained or women may still not be aware of the services available.

Although capacity may exist to conduct assisted vaginal deliveries (vacuum extraction at birth using instrument such as ventouse), there is an overall reluctance to practice this mode of delivery due to the anticipated high level of "failure rate" even in the Provincial General Hospital and district hospitals. It is generally believed that if the procedure fails the patient requires immediate emergency caesarean section (within half an hour). Reluctance among health care providers is probably due either to lack of competence and confidence or lack of equipment. However, in reviewing data from one of the mission hospitals only one out of ten cases of assisted vaginal delivery required an emergency caesarean section.

Health workers in rural health facilities have been advised to use the partograph to manage women in labour and refer early if there are any signs of prolonged or obstructed labour to CEOC Centres with caesarean section facilities. 
Table 4 outlines the situation in the four districts during the endline survey in 2003. Bungoma District has the highest proportion of CEOC facilities to population. However, three of these hospitals are private or mission facilities hence charge relatively high fees for their service and facilities therefore are not available for the poor women (see maps in appendix 10 for distribution).

Table 4. Coverage of Essential O bstetric Care Services M arch 2003

\begin{tabular}{|c|c|c|c|c|c|}
\hline \multirow[b]{2}{*}{ UN Process Indicators } & \multicolumn{4}{|c|}{ Districts/ Population (1999 census) } & \multirow[b]{2}{*}{$\begin{array}{l}\text { Recommended } \\
\text { Minimum }\end{array}$} \\
\hline & $\begin{array}{c}\text { Kakamega } \\
657,456\end{array}$ & $\begin{array}{l}\text { Vihiga } \\
543,558\end{array}$ & $\begin{array}{l}\text { Bungoma } \\
955,763\end{array}$ & $\begin{array}{l}\text { Lugari } \\
235,433\end{array}$ & \\
\hline $\begin{array}{l}\text { Number of Comprehensive } \\
\text { EOC Centres ( } 8 \text { functions) }\end{array}$ & $\begin{array}{c}2.6 \text { per } \\
500,000\end{array}$ & $\begin{array}{l}2.2 \text { per } \\
500,000\end{array}$ & $\begin{array}{l}11.47 \text { per } \\
500,000\end{array}$ & 0 & $1 / 500,000$ \\
\hline $\begin{array}{l}\text { Number of BEOC Centres } \\
\text { With } 6 \text { Signal Functions }\end{array}$ & $\begin{array}{c}0 \text { per } \\
500,000\end{array}$ & $\begin{array}{l}2.2 \text { per } \\
500,000\end{array}$ & $\begin{array}{c}3.8 \text { per } \\
500,000\end{array}$ & 0 & $4 / 500,000$ \\
\hline $\begin{array}{l}\text { Number of EOC Centres } \\
5 \text { Signal Functions } †\end{array}$ & 3 & 6 & 1 & 1 & \\
\hline $\begin{array}{l}\text { Other facilities with limited } \\
\text { capacity (or potential) }\end{array}$ & $18+$ & 8 & $21+$ & 14 & $\begin{array}{l}\text { This includes mainly } \\
\text { public facilities }\end{array}$ \\
\hline
\end{tabular}

$\dagger \mathrm{N}$ one of these $\mathrm{H}$ ealth Centres performed A ssisted V aginal delivery. This procedure is usually performed in hospitals only (see text).

Comprehensive Essential 0 bstetric Care

There are 11 facilities across the districts that are able to provide comprehensive essential obstetric care. Lugari District does not have a comprehensive essential obstetric care centre. Women in Lugari District requiring caesarean section have to go to hospitals in Kitale, Eldoret or Bungoma for such care. In the past, a mission hospital in Vihiga was able to perform caesarean section, but since the year 2000 , very few have been done due to lack of skilled personnel and management problems within this hospital. However, Vihiga District Hospital (opened in January 2002 and after a number of teething problems), now has a functioning theatre and is able to provide caesarean section.

\section{Obstetric met need}

The obstetric met need, which is the proportion of expected emergency cases that are actually managed in an EOC centre is calculated for each district. An indication of the met need within the two districts, which had comprehensive essential obstetric care centres throughout the project period, is reflected in Table 5.

The over all case fatality rate for obstetric complications (facility-based data) decreased from $3.0 \%$ in 2000 to $2.4 \%$ in 2002 . Bungoma continues to get late referrals from neighbouring districts that were not part of the SMDP. 
Table 5. Process indicators and met need for obstetric care

\begin{tabular}{|c|c|c|c|c|c|}
\hline $\begin{array}{l}\text { Process } \\
\text { indicators }\end{array}$ & Kakamega & Vihiga & Bungoma & Lugari & \\
\hline \multicolumn{5}{|c|}{ Births attended by skilled attendants at home and within facilities } & \multirow{3}{*}{$\begin{array}{l}\text { At least } 15 \% \text { of all births in } \\
\text { population. Every woman has } \\
\text { a right to skilled attendance at } \\
\text { delivery }\end{array}$} \\
\hline Baseline & $32 \%$ & $25 \%$ & $26 \%$ & $25 \%$ & \\
\hline Endline & $33.2 \%$ & $34 \%$ & $27 \%$ & $25 \%$ & \\
\hline \multicolumn{5}{|c|}{ Obstetric Met Need } & \multirow[b]{2}{*}{$\begin{array}{l}100 \% \text { of women with } \\
\text { complications are treated in } \\
\text { EOC facilities }\end{array}$} \\
\hline $\begin{array}{l}\text { Baseline } \\
\text { Endline }\end{array}$ & $\begin{array}{l}26 \% \\
34 \%\end{array}$ & $\begin{array}{l}\dagger \\
19 \%\end{array}$ & $\begin{array}{c}7 \% \\
17 \%\end{array}$ & $\begin{array}{l}\mathrm{N} / \mathrm{a} \\
8 \%\end{array}$ & \\
\hline \multicolumn{5}{|c|}{ Population based caesarean section rate } & \multirow[b]{2}{*}{$\begin{array}{l}\text { As a proportion of all births } \\
\text { between } 5 \& 15 \%\end{array}$} \\
\hline $\begin{array}{l}\text { Baseline } \\
\text { Endline }\end{array}$ & $\begin{array}{l}2.9 \% \\
3.2 \%\end{array}$ & $\begin{array}{c}\dagger \\
0.7 \% \\
\end{array}$ & $\begin{array}{l}1.2 \% \\
1.5 \% \\
\end{array}$ & $\begin{array}{l}\text { No } \\
\text { CEOC }\end{array}$ & \\
\hline \multicolumn{5}{|c|}{$\mathrm{C} / \mathrm{S}$ rate institutional: } & \\
\hline $\begin{array}{l}\text { Baseline } \\
\text { Endline }\end{array}$ & $\begin{array}{c}9 \% \\
12 \%\end{array}$ & $\begin{array}{c}\dagger \\
6 \%\end{array}$ & $\begin{array}{l}6 \% \\
8 \% \\
\end{array}$ & $\begin{array}{l}\text { No } \\
\text { CEOC }\end{array}$ & \\
\hline \multicolumn{5}{|c|}{ Case Fatality Rate } & \multirow{2}{*}{$\begin{array}{l}\text { For women with obstetric } \\
\text { complications should be }<1 \%\end{array}$} \\
\hline $\begin{array}{l}\text { Baseline } \\
\text { Endline }\end{array}$ & $\begin{array}{c}2.48 \% \\
1.6 \%\end{array}$ & $\underset{12 \% \dagger}{\dagger}$ & $\begin{array}{c}5.19 \% \\
4 \%\end{array}$ & $\begin{array}{l}\text { No } \\
\text { CEOC }\end{array}$ & \\
\hline
\end{tabular}

* Significant at 0.05 level † Information not available/ incomplete data available

Table 6 outlines the proportion of rural health facilities able to or had the capacity to provide key services or functions in 2002. A majority of the health facilities across the districts provide antenatal care and delivery services, while fewer offer laboratory services and the more invasive obstetric procedures requiring additional skills such as MVA.

Table 6 Proportion of health facilities with capacity to provide key services or functions for basic essential obstetric care in 2002

\begin{tabular}{|l|c|c|c|c|c|c|c|c|c|}
\hline District & ANC & $\begin{array}{c}\text { Normal } \\
\text { birth }\end{array}$ & $\begin{array}{c}\text { Lab } \\
\text { Service }\end{array}$ & MVA & $\begin{array}{c}\text { Assisted } \\
\text { Vaginal } \\
\text { Delivery }\end{array}$ & $\begin{array}{c}\text { Manual } \\
\text { Removal } \\
\text { Placenta }\end{array}$ & $\begin{array}{c}\text { IV } \\
\text { Anti - } \\
\text { biotics }\end{array}$ & $\begin{array}{c}\text { IV/IM } \\
\text { Oxytocics }\end{array}$ & $\begin{array}{c}\text { Anti } \\
\text { convulsants } \\
\text { (Valium) }\end{array}$ \\
\hline Kakamega & $100 \%$ & $79 \%$ & $60 \%$ & $21 \%$ & $12 \%$ & $27 \%$ & $100 \%$ & $82 \%$ & $93 \%$ \\
\hline Vihiga & $77 \%$ & $100 \%$ & $68 \%$ & $41 \%$ & $30 \%$ & $22 \%$ & $75 \%$ & $86 \%$ & $92 \%$ \\
\hline Bungoma & $95 \%$ & $92 \%$ & $73 \%$ & $25 \%$ & $21 \%$ & $10 \%$ & $100 \%$ & $97 \%$ & $100 \%$ \\
\hline Lugari & $100 \%$ & $94 \%$ & $52 \%$ & $18 \%$ & $7 \%$ & $0 \%$ & $100 \%$ & $100 \%$ & $93 \%$ \\
\hline
\end{tabular}

Essential N ewborn Care (EN C)This comprises of basic preventive care during pregnancy, clean birthing practices, warmth, eye and cord care and early and exclusive breastfeeding on demand. It includes early detection of problems or danger signs and appropriate referral, care seeking and treatment of key problems such as asphyxia and sepsis. 
Care of both mother and baby are inextricably linked - interventions during the SMDP included care of the newborn and resuscitation techniques in the Essential Obstetric Care updates and distribution of key equipment such as neonatal resuscitation bags and masks, increased availability of oxygen, and a resuscitare for PGH Kakamega. Facilities providing comprehensive obstetric care are able to care for the newborn.

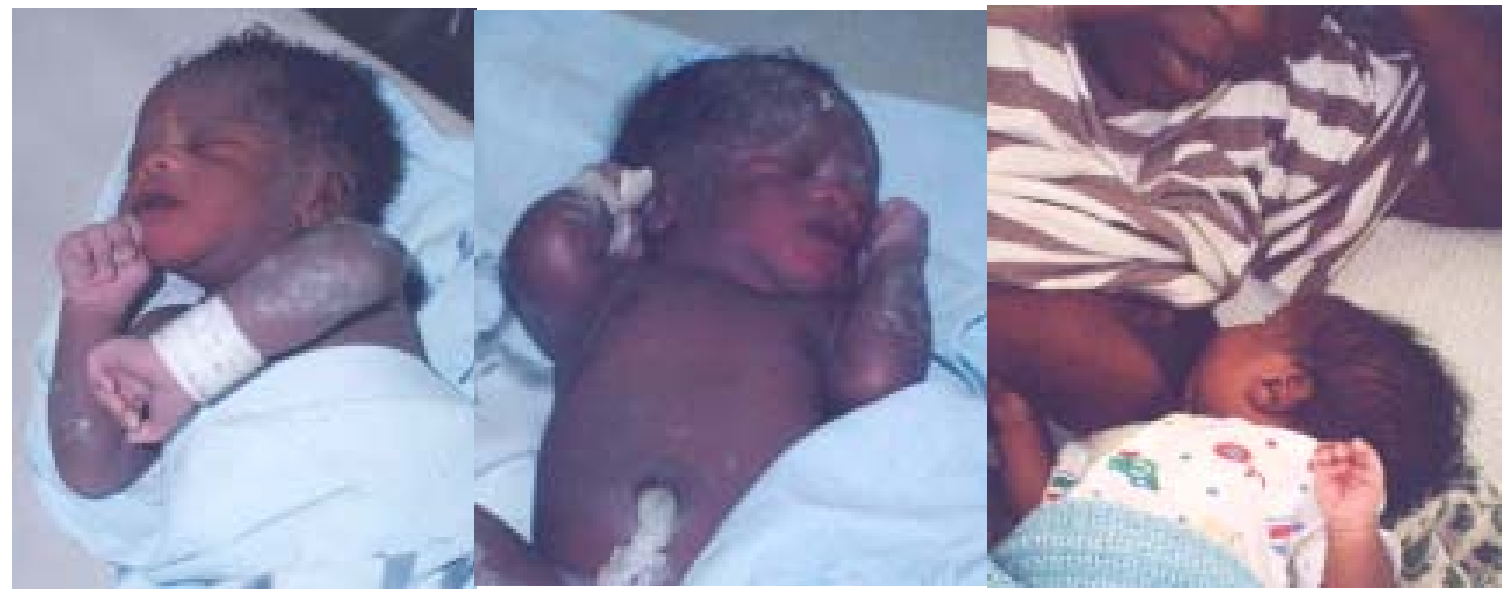

Clean birthing practices, cord care and early breastfeeding are among the components of ENC

M obile clinic/outreach services

Mobile or outreach clinics provide essential services for pregnant women within the community. The proportion of facilities that had mobile/ outreach clinics during the project period improved from $52 \%$ to $88 \%$ for baseline and endline respectively. This demonstrates an improvement in bringing services closer to where women and children live.

M obile laboratory services

Vihiga District developed a model whereby laboratory personnel from the district headquarters travel to rural facilities with necessary equipment and reagents and provide laboratory services to that community and/ or facility for that day. Between 2001 and 2002, 10 rural health facilities that did not have laboratories were covered under this pilot.

\section{Strengthening referral practices}

The network of referral system is crucial to enabling women with obstetric emergency access appropriate care as soon as possible. Therefore all types of transport and communication needs to be linked.

Across all districts, the bicycle taxi (or boda boda) was the most commonly used means of transport to reach health facilities (41\%). Other means of transport mentioned were car (27\%) and bus/ M atatu (15\%). At the time of emergency referral a number of options are available but they are not necessarily fast (wheel barrows, home made stretchers, tractors, oxcarts).

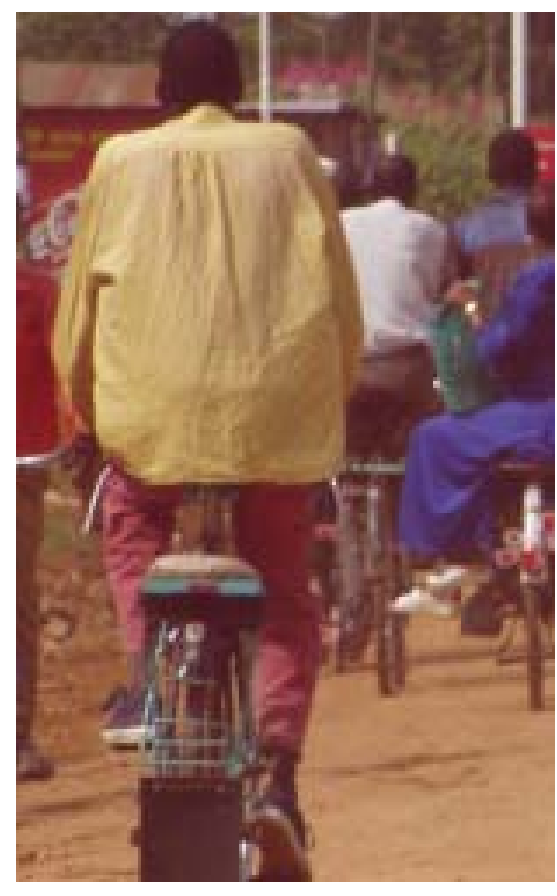


A vailability of functioning telephone and vehicles

By the end of the project period, all hospitals had telephones that worked (increased from $82 \%$ ) and $71 \%$ of rural health facilities either owned or had access to a functional telephone. Significantly more rural health facilities had access to a functioning telephone for emergency communication (from $34 \%$ to $42 \%$ ) and available ambulances at endline (increase from $23 \%$ to $31 \%$ ).

Transport arrangements to the referral site

There were no changes in the proportion of facilities that made transport arrangements to referral sites for obstetric emergencies. Vihiga District recorded a drop in the number of referrals made from $82 \%$ to $53 \%$. However, this is attributed to the opening of the new district hospital in the middle of intervention period as well as the improved capacity of health care providers and their institutions to deal with obstetric emergencies following EOC updates. There was also a rise from $64 \%$ at baseline to $75 \%$ at endline in the proportion of facilities that reported that a nurse or midwife accompanies an emergency obstetric or neonatal referral to the hospital.

There was no significant change in the proportion of women who required emergency referral at their last birth. There was also no change in the time that once the decision was made to refer a woman that transport was found and when she left the facility. Between $40 \%$ and $50 \%$ of the women were referred in less than half an hour. At baseline, in Kakamega and Bungoma districts, over $15 \%$ of the women had to wait for more than 2 hours before being transferred to the nearest health facility. At endline, no patient waited for more than one hour in a referring facility prior to leaving for the comprehensive essential obstetric care centre in all the four districts (see table 7).

Table 7. Time taken to get to the nearest health facility

\begin{tabular}{|l|c|c|c|c|}
\hline \multirow{2}{*}{$\begin{array}{l}\text { Time } \\
\text { (in minutes) }\end{array}$} & \multicolumn{2}{|c|}{ Baseline } & \multicolumn{2}{c|}{ Endline } \\
\cline { 2 - 5 } & No. & $\%$ & No. & $\%$ \\
\hline $1-30$ & 45 & 52 & 14 & 41 \\
\hline $31-45$ & 6 & 8 & 11 & 28 \\
\hline $46-60$ & 21 & 27 & 13 & 31 \\
\hline More than 60 & 11 & 14 & 0 & 0 \\
\hline Total & 83 & 100 & 40 & 100 \\
\hline
\end{tabular}

\section{Community Action}

\section{Access to and community involvement in maternal care}

Barriers to physical access

Women cited distance to the nearest facility as a barrier to accessing maternal care. Thirty four percent of women normally take at least one hour to reach the nearest health facility. At baseline $20 \%$ of women reportedly never attended ANC due to long distances to heal th facilities compared to $6 \%$ at endline. A small proportion said they never attended ANC due to lack of transport (4\%).

Women are dependent on the $\mathcal{T} \mathcal{B A s}$ because for a long time there was no facility. ( N divisi, Bungoma District.) 
Financial barriers

The main household expenditure over a period of 3 months preceding both baseline and endline surveys included food, health, education, general household expenses, clothes, farming activities, transport, donations and other expenses e.g. development activities. During the baseline survey, the average household expenditure in Kakamega district was Kshs. 12,018, Vihiga was Kshs. 12,219, Bungoma was Kshs. 8,435 and Lugari was Kshs. 10,301. The average health costs for the three-month period were

"It depends on whether

one has casual work - if

there is none then one has

to rely on the $\mathcal{T} \mathcal{B A s}$

Male - Vifiga district

between $10 \%$ and $16 \%$ of the total expenditure. There were no significant changes in spending patterns during the endline survey. When asked to comment on the amount of money spent on healthcare at household level, $59 \%$ of women at baseline and $63 \%$ at endline rated the expenditure on healthcare as 'too much'. However, $25 \%$ of women at baseline and $28 \%$ at endline thought the expenditure on healthcare was reasonable while $16 \%$ of women at baseline and $9 \%$ at endline said they were willing to pay more.

Lack of money to pay for services was therefore evidently an important inhibiting factor for women to access maternal care services. Moreover, there was an increase in the number of health care providers (from $44 \%$ to $70 \%$ ), ANC clients (from $47 \%$ to $63 \%$ ) and postpartum clients ( $24 \%$ to $34 \%$ ) who cited "lack of money" as an obstacle to seeking care.

Other non-financial obstacles for not seeking care included family and religious objections (6\%), no perceived need (22\%) and busy in the shamba (3\%). During the project period, user fees for ANC services remained relatively

"Charges for de livery at $\mathcal{T} \mathcal{B} A$ s

clinic range from $100 /$ - to $500 /$ - or

you pay in kind with a chicken. constant at an average of Kshs 50 . These charges included costs for ANC card, laboratory tests, and medication. Women paid an average of Kshs 580 for a normal birth and Kshs 10,350 for a caesarean section. Facilities reported that, on average, assistance for a normal birth costs Kshs 450 . There has been minimal change in the proportion of facilities that indicated that their patients were unable to pay for services ( $16 \%$ at baseline and $12 \%$ at endline).

An increased proportion of patients benefited from the waiver system (from $59 \%$ to $76 \%$ ) when they were unable to pay for services, and an overall reduction in the proportion of facilities demanding credit with collateral, detaining patients and conducting follow-ups to enforce payment.

Results of prepayment schemes

In one of the sites piloting the prepayment scheme (Matete Health Centre in Lugari District) between 20 and 30 deliveries were taking place each month at endline, compared to the average of 3 per month in 2000. Of the 200 mothers enrolled in the scheme at Matete by 2003 , health providers delivered $80 \%$ in the health centre and $20 \%$ were referred to the sub district hospital in Webuye. 


\section{Provider attitude}

There were no significant changes among ANC clients who indicated dissatisfaction with the services that they received. Eleven percent of women whose last birth was in a health facility

"Health providers need to be

provided with skills in fumanity". Vifiga District

reported that they had had some bad experiences but there was no significant reduction in the reasons given. However a third of these women said that negative provider attitude contributed to their bad experience.

Improving staff attitude

To improve heal th providers' attitude, emphasis was increased on interpersonal communication and counselling (IPCC) skills during the EOC updates run by the SMDP. Overall, the most significant gains concern the fact that clients feel able to discuss the progress of pregnancy with the health care providers (increase from $62 \%$ to

"There were supplies and the

facility is very organised. It has older health providers who have peoples needs at heart"

Vifiga District $77 \%$ ) as well as being given chance to ask questions (significant increase from $32 \%$ to $42 \%)$. Client privacy increased from $76 \%$ to $85 \%$.

An increase in the interaction between health providers and pregnant women led to improvements in the knowledge of women on danger signs in pregnancy and childbirth. This also created an opportunity for health providers to assist women especially during childbirth. Significant proportions of women were able to recognise the danger signs of high blood pressure (from 31\% to 47\%), anaemia (from 31\% to 40\%) and haemorrhage (37\% to $52 \%$ ).

Supplies and drugs

There has been a $50 \%$ decrease ( $35 \%$ baseline to $18 \%$ endline) in the percentage of facilities that require mothers in labour to bring gloves, syringes, cleaning liquids and other supplies and drugs. The proportion of facilities that had a sustainable stock of essential obstetric drugs improved over the project period. Data on specific drugs and supplies collected from facilities during the years 2002 and 2003 are demonstrated in A ppendix 5. The SMDP was not responsible for procuring drugs but improved the capacity of those responsible for ensuring a consistent essential drug supply. Unavailability of certain drugs is due to gaps in the essential drug kit system delivered by the Central Medical Stores in Nairobi.

Dispensary births

During the baseline survey (2000), only 4 out of the 9 dispensaries visited were conducting deliveries, compared to 8 out of 9 dispensaries visited during the endline survey (2003). These results are consistent with findings from the facility monitoring data, the number of dispensaries conducting deliveries $(n=73)$ rose from $14 \%$ in 2001 to $45 \%$ in 2003. Although more dispensaries do provide maternity services there was minimal increase in the number of rural health facilities offering maternity services at night and during weekends. 


\section{Home births}

The proportion of all births conducted at home by a skilled attendant increased significantly from $1 \%$ at baseline to $4 \%$ at endline in the four districts. The most notable increase was in Vihiga district where the proportion of skilled attendance at home increased from $1 \%$ to $9 \%$. Discussions with the DHMT in Vihiga revealed that the majority of nurses in the district who are employed in the district are expected to be equipped all the time with basic supplies for conducting a delivery such as gloves, cord ligatures, razor blade, soap etc. This may explain the significant rise in results in the district when compared to others.

\section{Educating women on danger signs in pregnancy}

There was a significant improvement in the knowledge of the women exiting antenatal clinic on danger signs during pregnancy and childbirth from baseline to endline. More women mentioned signs such as haemorrhage and high blood pressure, which are direct causes of maternal deaths. Despite the overall improvement in the knowledge of the women on danger signs, the proportion of mothers who mentioned obstructed/ prolonged labour appeared to have declined from the baseline to the endline period.

\section{Birth preparedness}

This model was implemented in Lugari District in September 2002 through community-based groups, members of the Maendeleo Ya Wanawake Organization (MYWO) and the Department of Culture and Social Services for administration and coordination. Following sensitisation meetings 48 women groups across the 28 sub locations agreed to pilot the model. Pregnant women were enrolled into the scheme by women group members and given a brief on the benefits of attending antenatal clinic and skilled attendance at delivery. Each pregnant woman received a birth preparedness card (see appendix), which gives information on how to make a birth plan and be prepared in the event of emergency. Besides birth preparedness cards, the Maendeleo Ya Wanawake Organisation and women groups were also issued with record keeping and reporting forms to record the utilisation of the BP cards by pregnant women. This information was sent to the DHMT. Although this scheme is still new, there were positive signals towards its success. For example, about 5,000 cards had been issued by end of May 2003. At the same time, the district recorded a $33 \%$ increase in the number of mothers attending antenatal clinic and deliveries at facilities has increased from $11 \%$ at baseline to $32 \%$ be endline.

\section{Involving TBAs in Referral Practices}

The emphasis in the project has been to build partnerships between health facility staff and Community Owned Resource Persons such as TBAs to refer and where necessary to accompany women in labour to health facilities. Health facility boards and committees devised locally suitable approaches to link the TBAs more effectively with the facility staff.

Women's preference for $\mathcal{T} \mathcal{B} A$ s is usually because of the physical and social access, positive at titude of the $\mathcal{T} \mathcal{B A}$, as well as flexibility in the mode of payment.

Overall there has been limited change in the number of TBAs escorting women to facilities and referring but individual health facilities have made some impact and have created sustainable working partnerships. 


\section{Maternal Health Services}

\section{Focused Antenatal Care}

WHO and the Ministry of Health now recommend that a pregnant woman should attend comprehensive antenatal care. This is focused care provided to pregnant women, which emphasises the woman's overall health, her preparation for childbirth and readiness for complications (emergency preparedness). It includes a minimum of 4 comprehensive personalised visits spread out during the entire pregnancy during which specific activities are carried out to guide the woman through to a positive pregnancy outcome. Focused ANC should provide the early detection and treatment of complications during pregnancy; health promotion and prevention of disease; birth preparation and complication readiness; and delivery with skilled attendant (see Table 9 for summary).

Over $90 \%$ of women said they attended antenatal clinic at least once in their most recent pregnancy. Initial attendance depended on financial capability and if women felt there were no problems during their pregnancy they were more likely to delay attending clinic. Most women interviewed first attended clinic in the third

"If the re is a problem, women will

start at tending clinic even as

early as the first month but if

they have no problem, they relax

and go late". Woman from Madzu,

Vifiga

trimester. In Kakamega district, $82 \%$ of the women attended for the first time in the third trimester while in Vihiga and Bungoma districts, the proportions were $61 \%$ and $59 \%$ respectively. In Lugari district slightly more than half $(52 \%)$ had attended for the first time within the second trimester.

However there was no significant change in the number of visits women made to ANC over the project period. The majority of women (over $80 \%$ ) attended ANC, three or more times throughout their pregnancy. This is consistent with findings across Sub Saharan A frica (WHO/ UNICEF 2003). In Western Province the number of women who visited ANC 4 times increased marginally from $55 \%$ to $58 \%$ between the two surveys (the national target is at least 50\%).

\section{Early detection of disease and treatment of complications}

One of the important aspects of antenatal care is screening of blood and urine in order to detect any predisposing conditions. There were significant increases in the number of women who had blood tests to check their haemoglobin, and blood groups. In addition significantly more women had their blood pressure checked. High blood pressure is an early warning sign of pre-eclampsia.

\section{Prevention of disease}

\section{Malaria}

Malaria continues to be a killer among the population in Western Kenya. Pregnant women are more susceptible to the disease especially those in their first pregnancy. According to the $\mathrm{N}$ ational Malaria Guidelines, every pregnant woman living in malaria zones should have two doses of intermittent preventive treatment of Sulphadoxine Pyrimethamine (SP) between 16 and 36 weeks. There was a significant increase in the proportion of women who received both the first and second doses of SP at antenatal clinic. This is a result of improved availability of SP (during 2002 over $95 \%$ of facilities in the four districts had stock of SP throughout the year) and the inclusion of focused antenatal care in the EOC updates for health care providers implemented by the SMDP. 
Chart 1. Percent of women who received a first dose of SP at ANC**

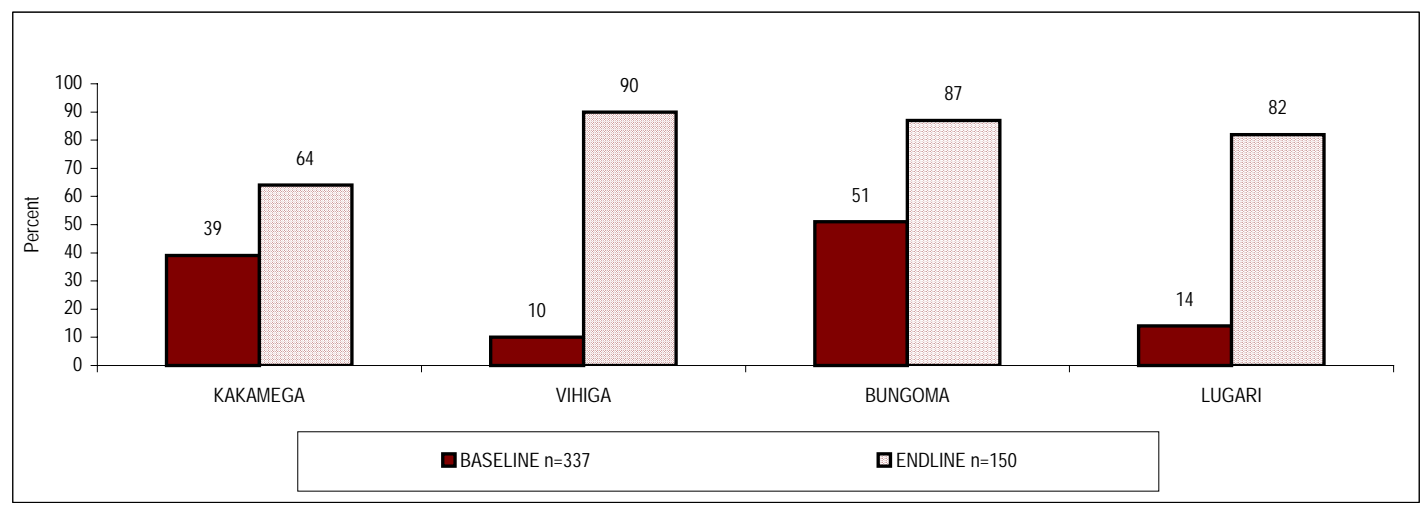

** Significant at 0.01 level

Despite the high incidence of malaria in Western Kenya, few women attending antenatal clinic said they slept under a mosquito net the previous night. Only $15 \%$ in Vihiga, $21 \%$ in Lugari and $27 \%$ women in Kakamega said they had slept under a mosquito net. However, $36 \%$ of women in Bungoma said they did - this may have been an impact of the Bungoma District Malaria Initiative funded by USAID from 1998 to 2002 , which had a focus on malaria in the community. A bout three quarters (74\%) of the women who reported sleeping under a mosquito net had bought it from a shop, $20 \%$ from a health facility and the remaining $6 \%$ had bought it from a chemist.

Iron and folic acid supplementation

Women who are anaemic during pregnancy should receive iron and folic acid supplements early to correct their haemoglobin levels. In all the districts, significantly more women received iron and folic acid supplements in antenatal clinic at endline than at baseline. Although there was an increase of women receiving iron and folic acid, the proportions were still below the expected coverage.

Coverage of folic acid in Lugari was only $24 \%$, even though the majority of facilities had the drug as shown in Table 8. The most likely explanation is that women may have been charged for these drugs and this was beyond their financial capability.

Table 8. Percent of facilities with stocks of SP, iron and folic acid, 2002

\begin{tabular}{|c|c|c|c|c|c|c|c|c|c|c|c|c|}
\hline \multirow[t]{2}{*}{$\begin{array}{l}\text { Time in } \\
\text { months }\end{array}$} & \multicolumn{3}{|c|}{$\begin{array}{c}\text { Kakamega } \\
\quad(n=48)\end{array}$} & \multicolumn{3}{|c|}{$\begin{array}{l}\text { Vihiga } \\
(n=22)\end{array}$} & \multicolumn{3}{|c|}{$\begin{array}{c}\text { Bungoma } \\
(n=40)\end{array}$} & \multicolumn{3}{|c|}{$\begin{array}{l}\text { Lugari } \\
(n=17)\end{array}$} \\
\hline & SP & Iron & Folic & SP & Iron & Folic & SP & Iron & Folic & SP & Iron & Folic \\
\hline All the time & 71 & 67 & 63 & 56 & 36 & 36 & 78 & 75 & 73 & 82 & 94 & 100 \\
\hline 6-11 months & 23 & 31 & 29 & 23 & 36 & 32 & 17 & 25 & 27 & 18 & 6 & 0 \\
\hline$<6$ months & 6 & 2 & 8 & 23 & 28 & 32 & 5 & 0 & 0 & 0 & 0 & 0 \\
\hline
\end{tabular}

At endline $17 \%$ of women visiting antenatal clinic had haemoglobin recorded as less than $10.5 \mathrm{~g} / \mathrm{dl}$ indicating anaemia. Of this group, $73 \%$ had received the first dose of SP but only 31\% received iron supplements.

Things have changed under $S \mathcal{M D P}$, pregnant women are well at tended at the health facilities - Makunga $\mathcal{H C}$ 


\section{Health promotion and counselling}

Significantly more women were able to discuss the progress of their pregnancy and had a chance to ask questions during their interaction with the provider in the ANC clinic. However, there were no improvements in the proportion of women who receive counselling on breast feeding, family planning, care of the mother and her new baby and there was no change in the proportion of women who received a health talk about STIs, HIV/ AIDS.

Proportion of pregnant women who discussed where to give birth with provider at endline Lugari (56\%) Vifiga (59\%)

Bungoma (44\%) Thakamega (23\%)

A dvice on where to give birth

Significantly more women were advised where to give birth with the majority advised to give birth in a health facility. Nurses in Lugari district who work in antenatal clinic were most likely to give advice on the place of birth at $52 \%$.

\section{Birth preparedness and complication readiness}

Women's knowledge of danger signs

In an attempt to find answers to issues that address the first delay, i.e. delay in deciding to seek care for obstetric problems, women were asked about their knowledge on danger signs in pregnancy and childbirth. While women still appear to lack information on some of the danger signs, there were significant improvements specifically in knowledge of haemorrhage and high blood pressure. In Lugari District birth preparedness cards were distributed to pregnant women through MYWO, which has shown an increase in the number of facility deliveries. However there was no significant change in the number of women who reported using one. Table 9 outlines the results of four key aspects of focused ANC.

Table 9. Improvements in Antenatal care in Western Province

\begin{tabular}{|c|c|c|}
\hline Antenatal & $\begin{array}{c}\text { Baseline } \\
n=337\end{array}$ & $\begin{array}{c}\text { Endline } \\
\mathrm{n}=150\end{array}$ \\
\hline \multicolumn{3}{|l|}{ Early detection of disease: } \\
\hline Early detection of Anaemia: Haemoglobin* & $26 \%$ & $34 \%$ \\
\hline Pre/eclampsia: Blood pressure measured* & $68 \%$ & $79 \%$ \\
\hline Syphilis: VDRL* & $18 \%$ & $26 \%$ \\
\hline \multicolumn{3}{|l|}{ Prevention: } \\
\hline Was asked to come back & $94 \%$ & $94 \%$ \\
\hline ANC attendees receive IPT 1 for malaria** & $29 \%$ & $75 \%$ \\
\hline ANC attendees receive IPT 2 for malaria** & $11 \%$ & $24 \%$ \\
\hline Blood Group ** & $11 \%$ & $26 \%$ \\
\hline Iron tablets given* & $31 \%$ & $42 \%$ \\
\hline Tetanus Toxoid & $90 \%$ & $89 \%$ \\
\hline \multicolumn{3}{|l|}{ Health promotion and counselling: } \\
\hline Discussed progress of pregnancy ${ }^{\star *}$ & $77 \%$ & $82 \%$ \\
\hline Met in privacy & $77 \%$ & $82 \%$ \\
\hline Chance to ask questions ${ }^{*}$ & $32 \%$ & $42 \%$ \\
\hline Median time spent with provider** & 8 minutes & 10 minutes \\
\hline \multicolumn{3}{|l|}{ Birth Preparation and Complication Readiness } \\
\hline \multicolumn{3}{|l|}{ Client's knowledge of risks/danger signs: } \\
\hline Haemorrhage $^{\star \star}$ & $37 \%$ & $52 \%$ \\
\hline High $\mathrm{BP}^{* *}$ & $31 \%$ & $48 \%$ \\
\hline Anaemia/pallor* & $31 \%$ & $40 \%$ \\
\hline No foetal movements* & $10 \%$ & $17 \%$ \\
\hline Abnormal lie* & $18 \%$ & $23 \%$ \\
\hline \multicolumn{3}{|l|}{ Place of birth identified: } \\
\hline Advised where to give birth* & $32 \%$ & $47 \%$ \\
\hline Advised to give birth in facility/skilled attendant & $31 \%$ & $45 \%$ \\
\hline
\end{tabular}

* Significant at 0.05 level ** Significant at 0.01 level 


\section{Quality of antenatal care}

There were no significant changes in client waiting time prior to being attended to. The majority of clients were attended to within half an hour and this was far more likely in Bungoma and Lugari than in the other two districts. Any increase in estimated waiting time can be attributed to the fact that providers were spending more time attending to the clients than they did at baseline. A significant increase was noted in the mean time spent with the health care provider.

There was an increase in the proportion of pregnant women who reported that they had been attended to in privacy, had discussed the progress of the pregnancy and given a chance to ask questions at the endline survey. An inquiry was made about the type of environment in which the clients were seen on the day of interview. At least $60 \%$ (65\% at baseline and $60 \%$ at endline) reported that they were initially seen in the presence of other clients. This includes activities such as weighing and blood pressure measurement. One of the key constraints in the majority of facilities is the lack of space and lack of sufficient staff for antenatal clinics.

However when physical examination took place, (ie palpation of abdomen etc) over two thirds of women said they had been attended to in privacy - from $64 \%$ in Kakamega, 76\% in Bungoma, 85\% in Lugari to 98\% in Vihiga. Just over a half of women in Bungoma and over three quarters of women in Kakamega felt they had been told about the progress of their pregnancy compared to over $93 \%$ in Vihiga and $91 \%$ in Lugari. In Vihiga and Lugari, over half of the women were given a chance to ask questions - compared to less than a third in Bungoma and Kakamega.

\section{Financial constraints}

Lack of money (63\%), either to pay for transport or the services (range from 50 to 200 Kenyan shillings) emerged as a major deterrent for women to attend antenatal clinic throughout the project period. Similar reasons were cited during focus group discussions. There were no significant changes in why women may not attend although reasons such as negative provider attitude (20\%) and preference for the TBA (15\%) persist.

Client satisfaction with antenatal care

Clients were asked about their satisfaction with the services they had received on the day of the interview both at the baseline and endline surveys. The satisfaction levels rated the same in both surveys at $84 \%$. A spects of care that made the clients satisfied included being examined, counselled and given advice by staff who were friendly and gentle, and even being attended to fast. The clients were

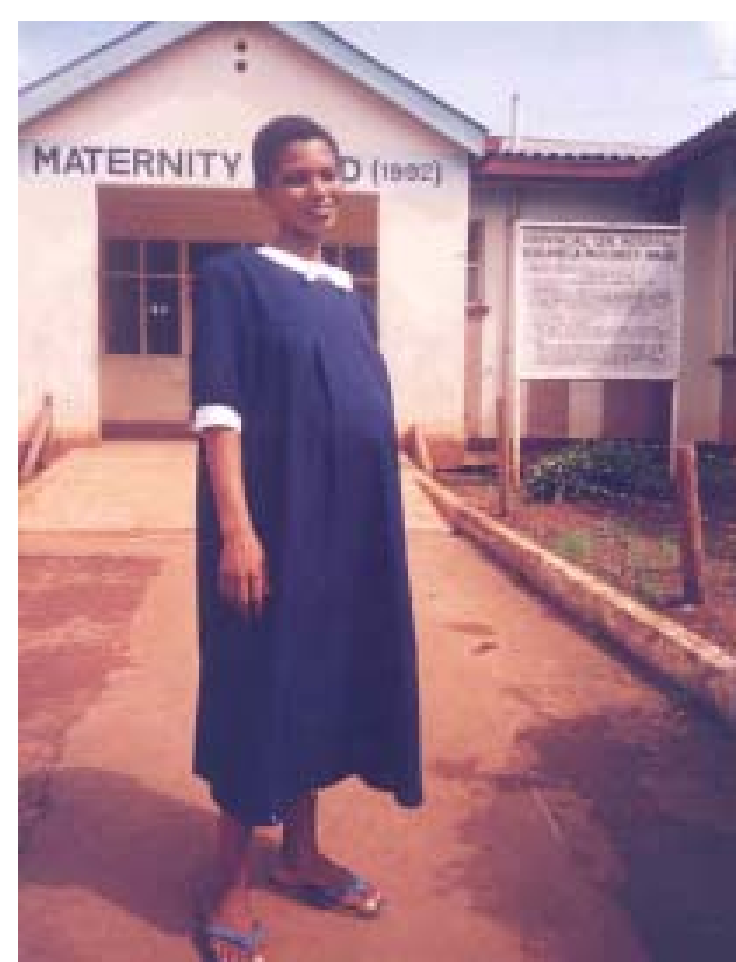

$M$ any women do not attend clinic unless they are in pain, if not in pain she will not go until she delivers (maleMihuu, Bungoma District) dissatisfied when their complications persisted, when they had to wait for long before being attended to, and when they did not receive the services they expected. 
A ntenatal cards

There was a marked improvement in the use of standard antenatal cards in health facilities rising from an overall $42 \%$ (baseline) to $97 \%$ (endline) as Chart 2 shows.

Chart 2. Percent of facilities using MOH standard ANC cards

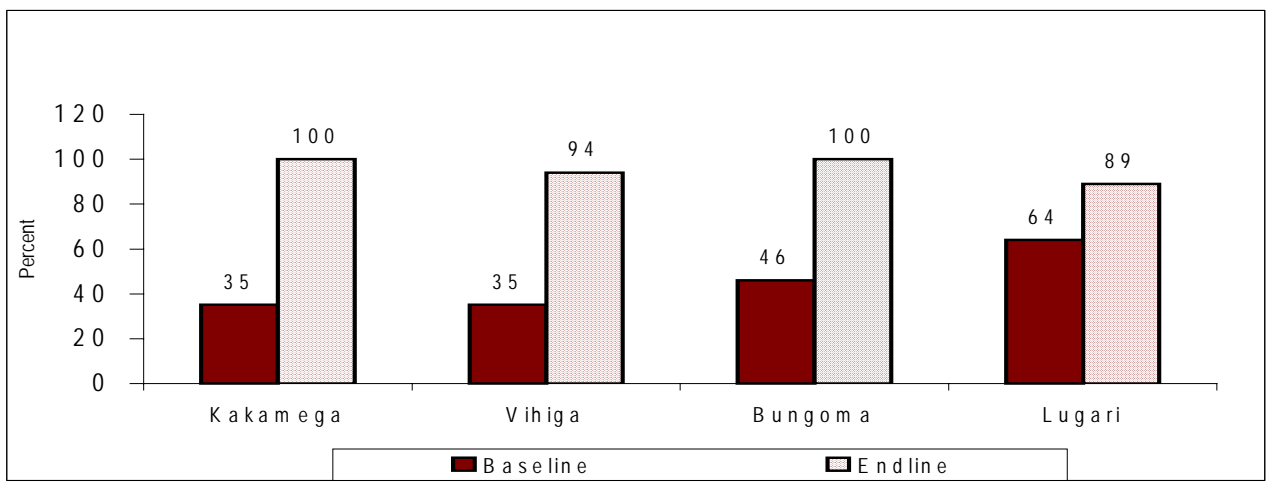

\section{Intrapartum care}

There is a known discrepancy between the proportion of women who attend antenatal clinic (92\%) in the four districts and those who seek birth assistance from skilled attendants and health facilities (30\%). The number of births that took place with a skilled health care provider in Western Province increased from $27 \%$ to $29 \%$ between the two surveys. Although a small increase, some provinces in the KDHS 2003 saw a fall in the proportion of women attended at birth by health care providers. Although there was an increase in number of facility births across the districts the proportion is still low when compared to

Men would like to be able to he ar what advice their wives are given.

"..because some come

back home and expect big things to be done to the me by cheating that the staff of the hospital had said" Matete, Lugari district the proportion of women delivered at home. Table 10 demonstrates the range of assistance received by women who last gave birth within their own homes.

In Vihiga there was a significant increase in number of women assisted by a skilled attendant at home from $1 \%$ at baseline to $9 \%$ at endline. In the same period, women giving birth with TBA assistance in Vihiga dropped from $36 \%$ to $27 \%$. In Kakamega, and Lugari there was minimal change in the proportion of women attended by TBAs.

Table 10. Attendants assisting women to give birth in their homes (\%)

\begin{tabular}{|l|c|c|}
\hline Gave birth at home & $\begin{array}{c}\text { Baseline } \\
(\mathbf{n = 2 6 6 9 )}\end{array}$ & $\begin{array}{c}\text { Endline } \\
(\mathbf{n}=\mathbf{9 4 2})\end{array}$ \\
\hline Alone & 22 & 24 \\
\hline With relative & 24 & 24 \\
\hline With TBA & 53 & 48 \\
\hline With skilled midwife* & 1 & 4 \\
\hline
\end{tabular}

* Significant at 0.05 level 
Client satisfaction with care at birth

While $70 \%$ of the women gave birth at home $(n=942)$ during the endline period, $80 \%$ of them said they were happy with their birthing experience. Forty percent were comfortable with the assistance given by the TBA and a further $24 \%$ felt they had family support. Fifteen percent 'felt safe' and others preferred the low cost (9\%) and privacy (8\%). Bad experiences for those who had given birth at home were mainly due to the occurrence of complications $(46 \%)$ and giving birth alone (16\%). Of the $30 \%$ of women who last gave

"At home it can be good or 6ad: It can be good because you can deliver by yourself. It can be bad when one gets complications. In hospital it can be good because they are skilled and also they have the required facilities."

(Female respondent Mate te Division) birth in a facility at endline ( $n=388), 64 \%$ had been treated with respect (up from $50 \%$ at baseline) and there was no change in the proportion of providers who explained everything. Bad experiences were attributed to poor provider attitude and disrespectful treatment (13\%), relative not being allowed in (12\%) and unclean environment (6\%).

\section{Competency and skills in providing skilled attendance}

In the identification of the cardinal signs of labour there was a significant increase in the proportion of health providers who used cervical dilatation and uterine contractions to establish that a woman was in labour (Chart 3).

The proportion of healthcare providers who reported that they used partographs to monitor labour increased significantly. In Kakamega the increase among healthcare providers was from $18 \%$ to $81 \%$, in Vihiga from $25 \%$ to $70 \%$, and in Lugari from $10 \%$ to $78 \%$. In Bungoma the increase was from $12 \%$ at baseline to $42 \%$ in the endline survey.

Data from health facilities collected during 2002 confirms the above data, which shows that the partograph was used in $88 \%$ of deliveries. Generally, over $90 \%$ of hospitals and health centres had partographs compared to $31 \%$ of dispensaries and $50 \%$ of the clinics by December 2002.

Following birth there was a significant increase in the number of heal th care providers who reported that they usually advise women on infection prevention and nutrition immediately after birth by endline.

Chart 3 Percent of nurses by signs used to establish labour during the last delivery they attended

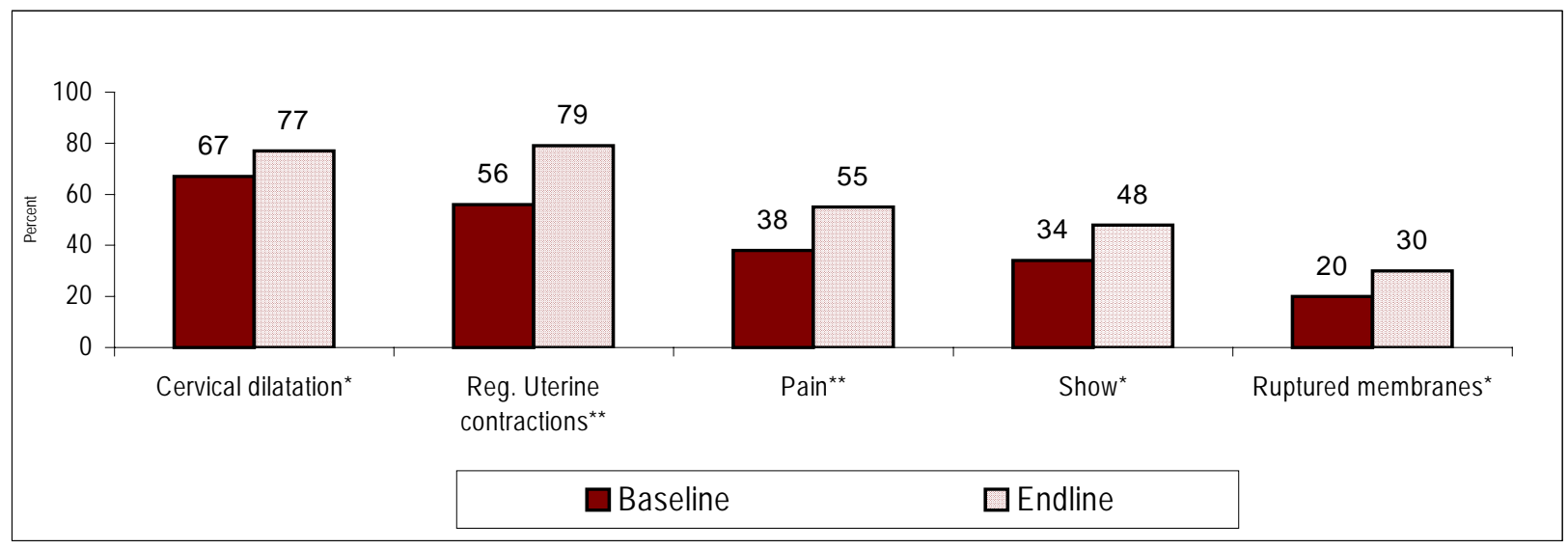


Table 11 describe significant improvements in quality of care provided through heal th care provider recall. The significant drop in the number of nurses who checked the urine of women in labour was due to the persistent lack of uristix across the province during the project period.

Table 11. Q uality of intrapartum care - health provider recall

\begin{tabular}{|l|c|c|}
\hline & Baseline & Endline \\
\hline Provider recall or knowledge and practice: & 307 & 142 \\
\hline Provider assisted at birth within past week ${ }^{* *}$ & $36 \%$ & $51 \%$ \\
\hline Use of partographs for managing labour ** & $17 \%$ & $72 \%$ \\
\hline Observations taken during labour & 230 & 119 \\
\hline Monitored uterine contractions** ${ }^{* *}$ & $44 \%$ & $58 \%$ \\
\hline Monitored blood pressure & $67 \%$ & $74 \%$ \\
\hline Monitored temperature* & $44 \%$ & $56 \%$ \\
\hline Checked urine for protein and glucose & $7.4 \%$ & $3 \%$ \\
\hline Advice given to mothers by nurses following delivery & 307 & 142 \\
\hline Nurses advise on infection prevention to mothers ${ }^{*}$ & $21 \%$ & $53 \%$ \\
\hline Nurses advise mothers on nutrition & $43 \%$ & $52 \%$ \\
\hline
\end{tabular}

* Significant at 0.05 level. ** Significant at 0.01 level

Normal labour usually lasts about twelve hours. There was a significant drop in the number of women who were in labour for more than twelve hours - depicting an improvement in the management of prolonged labour. In addition, the administration of oxytocics for proactive prevention of post partum haemorrhage and measurement of blood pressure showed significant improvements. Table 12 describes analysis of patient records for normal birth in facilities.

Table 12. Q uality of intrapartum care - normal birth records

\begin{tabular}{|c|c|c|}
\hline & $\begin{array}{l}\text { Baseline } \\
n=243\end{array}$ & $\begin{array}{l}\text { Endline } \\
\mathrm{n}=\mathbf{2 1 4}\end{array}$ \\
\hline Admission time to birth 5 to 8 hours ${ }^{\star *}$ & $17 \%$ & $31 \%$ \\
\hline Admission to birth above 12 hours $^{\star \star}$ & $25 \%$ & $8 \%$ \\
\hline Blood pressure measured $1-3$ times $^{\star *}$ & $51 \%$ & $84 \%$ \\
\hline Foetal heart rate observed $5+$ times $^{* *}$ & $21 \%$ & $54 \%$ \\
\hline Blood loss measurement following birth ${ }^{\star *}$ & $61 \%$ & $79 \%$ \\
\hline Status of membrane and placenta recorded ${ }^{\star *}$ & $73 \%$ & $86 \%$ \\
\hline Oxytocics administered following birth ** & $65 \%$ & $86 \%$ \\
\hline Blood pressure measured following birth** & $35 \%$ & $76 \%$ \\
\hline Baby's weight recorded following birth* & $86 \%$ & $93 \%$ \\
\hline
\end{tabular}

* Significant at 0.05 level. ** Significant at 0.01 level 


\section{Obstetric complications}

The direct causes of obstetric morbidity and mortality are haemorrhage, infection, ruptured uterus, ectopic pregnancy, complications of abortion, and edampsia. Indirect causes include other medical conditions, which are often exacerbated by pregnancy and childbirth such as malaria, anaemia, TB and HIV/ AIDS (see Table 13). Over the project period, health care providers have seen an increasing number of women seeking skilled care for obstetric emergencies.

Table 13. Health providers experience and management of obstetric problems

\begin{tabular}{|l|c|c|}
\hline & $\begin{array}{c}\text { Baseline } \\
\mathbf{N = 3 0 7}\end{array}$ & $\begin{array}{c}\text { Endline } \\
\mathbf{N = 1 4 2}\end{array}$ \\
\hline $\mathrm{APH}^{* *}$ & $18 \%$ & $54 \%$ \\
\hline $\mathrm{PPH}^{* *}$ & $51 \%$ & $74 \%$ \\
\hline Severe malaria ${ }^{* *}$ & $24 \%$ & $49 \%$ \\
\hline Severe anaemia ${ }^{*}$ & $45 \%$ & $66 \%$ \\
\hline Eclampsia $^{* *}$ & $18 \%$ & $43 \%$ \\
\hline Sepsis $^{*}$ & $11 \%$ & $20 \%$ \\
\hline
\end{tabular}

*Significant at 0.05 level **Significant at 0.01 level

A significantly higher proportion of providers had seen maternal deaths due to unsafe abortion, obstructed labour and eclampsia by endline.

Table 14. M ajor causes of death according to health providers' experience

\begin{tabular}{|l|c|c|}
\hline Cases of obstetric complications seen in past month: & $\begin{array}{c}\text { Baseline } \\
\mathbf{N = 3 0 7}\end{array}$ & $\begin{array}{c}\text { Endline } \\
\mathbf{N = 1 4 2}\end{array}$ \\
\hline Unsafe abortion $^{* *}$ & $31 \%$ & $42 \%$ \\
\hline Obstructed labour $^{* *}$ & $24 \%$ & $38 \%$ \\
\hline Eclampsia & $15 \%$ & $18 \%$ \\
\hline
\end{tabular}

*Significant at 0.05 level **Significant at 0.01 level

H ealth Care Providers' knowledge of complications in pregnancy and childbirth

The health care providers work in units or facilities covering a range of maternal services. However not all of them work in or have worked in a labour or maternity ward unit recently. In addition most patients seeking post abortion care are managed in the female ward, which is separate to the maternity units. Moreover, some of the health care providers updated in Essential Obstetric Care during the project period have now moved to other departments.

The findings are based on health providers' recall of the last patient they managed with the specific problem. Details of the specific signs and actions for the obstetric complications are stated in Appendix 3. The criteria used to develop the composite indicators may appear "strict" given that the improvements while significant are still low as shown in Table 15. However, the criteria include only specific signs and actions that are essential to saving life. 
Table 15. A ssessing health providers knowledge and practice in their management of obstetric complications

\begin{tabular}{|l|c|c|}
\hline Indicator & $\begin{array}{c}\text { Baseline } \\
\mathrm{n}=307\end{array}$ & $\begin{array}{c}\text { Endline } \\
\mathrm{n}=142\end{array}$ \\
\hline Composite knowledge indicator for PPH signs $^{* *}$ & $2 \%$ & $15 \%$ \\
\hline Composite indicator for PPH actions ** $^{*}$ & $2.5 \%$ & $12 \%$ \\
\hline Composite indicator for Abortion $^{\star *}$ & $1.5 \%$ & $9 \%$ \\
\hline Severe malaria treat with IV quinine and dextrose ** & $29 \%$ & $73 \%$ \\
\hline Severe anaemia $=\mathrm{Hb}, 5 \%^{* *}$ & $17 \%$ & $68 \%$ \\
\hline
\end{tabular}

*Significant at 0.05 leve **Significant at 0.01 level

The proportion of staff able to recall the appropriate management of a patient with post partum haemorrhage and incomplete abortion increased significantly. The proportion of nurses who said they would provide MVA more than doubled from $23 \%$ to $54 \%$ over the project period. There were no significant changes in health care providers' knowledge or recall for composite indicators for APH, retained placenta, eclampsia, puerperal sepsis or obstructed labour, although significant changes were noted in the individual signs and actions for the obstetric complications.

It appears that the knowledge of warning signs of obstetric emergencies during pregnancy, delivery and after delivery by health workers in Western Kenya has improved as can be seen in Chart 4. Significant increases for warning signs to prompt referral included bad obstetric history $(\mathrm{BOH})$, high blood pressure, sepsis and "no foetal heart rate".

Chart 4. Percent of providers by warning signs that would prompt a referral

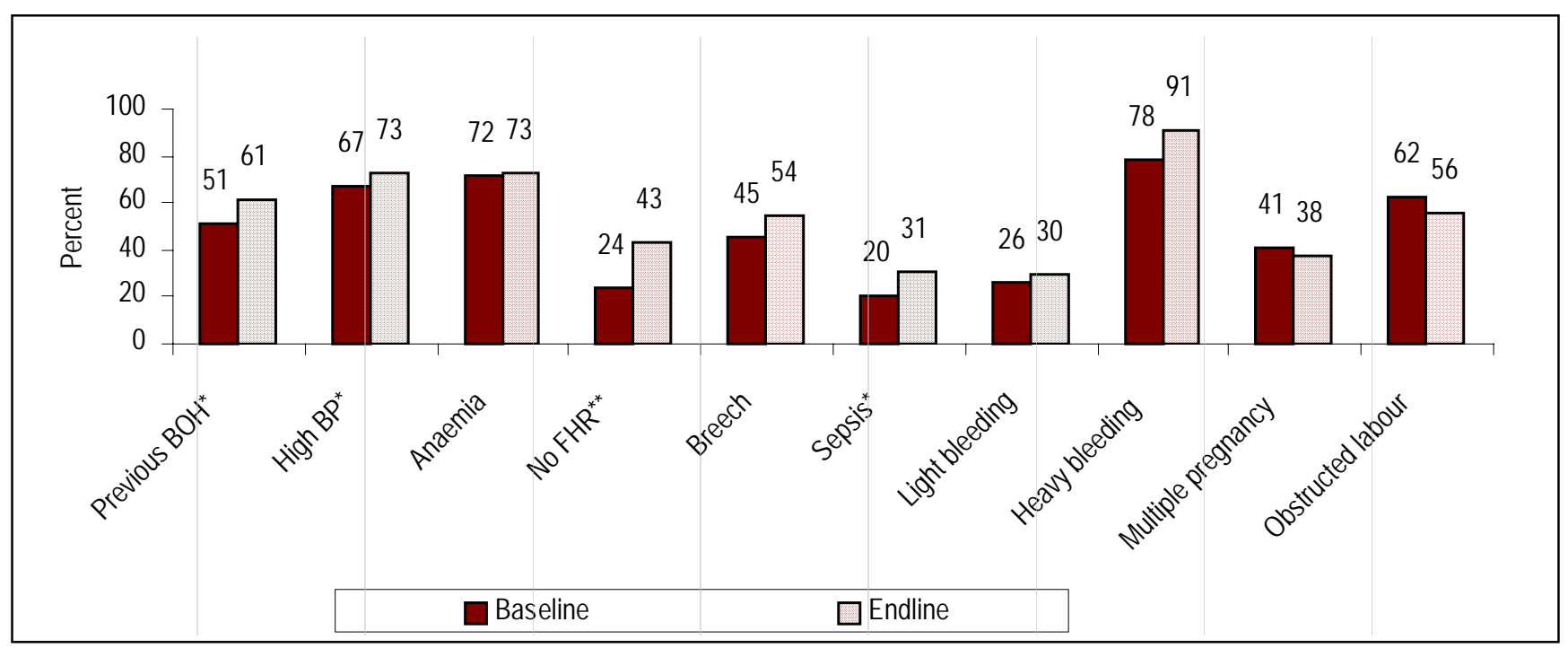

*Significant at 0.05 level ** Significant at 0.01 level

By the end of the project, healthcare providers were more likely to recognise signs and symptoms of severe anaemia with a significant increase of $53 \%$ in the proportion who said that low haemoglobin is indicative of anaemia. Hospital nurses were more likely to recognise marked pallor (92\%) than rural health facility nurses $(80 \%)$. In managing anaemia, just over half of the nurses said they would take blood for grouping and cross matching (51\% compared to $36 \%$ at baseline). There was a $15 \%$ increase in the proportion that mentioned 'drawing blood' to check for malaria parasites at endline. 
A higher proportion of nurses in hospitals (89\% in Bungoma and 100\% in Vihiga) said they would admit a patient with severe anaemia straight away compared to $7 \%$ nurses in rural health facilities in Kakamega and 32\% in Lugari. However, providers stationed in rural health facilities were much more likely to refer such a patient to hospital $(79 \%$ in Lugari and $100 \%$ in Kakamega), which is the correct way to manage severe anaemia as no rural health facility is able to provide blood transfusion services.

There was a significant increase in the proportion of nurses with correct knowledge of signs for malaria and action (specifically in the use of IV quinine) to be taken in cases of severe malaria. In countries such as South Africa and Zambia there has been an increase in the number of indirect maternal emergencies and deaths due to HIV/ AIDS. Currently this information is not available for accurate analysis in Western Province.

In addition to measuring health care providers recall of signs and management of obstetric emergencies, a random selection of patient records were collected from the public, mission and private facilities. Similar proportions of patient records (for normal delivery, obstructed labour, pre/ eclampsia and caesarean section) from hospitals, health centres and dispensaries were reviewed. This information assessed the quality of care given and recorded accurately. Table 16 outlines some of the significant improvements in management of obstructed labour and caesarean section. The number of records for patients with eclampsia was too few to assess for significance.

\section{Caesarean section record review}

The caesarean section record review at baseline and endline provided information on; availability of theatre notes, age and parity/ pregnancy distribution as well as the indications for caesarean section, utilisation of the partograph for monitoring the progress of labour, and maternal and neonatal outcome. The partograph was used in $63 \%$ of cases requiring caesarean section at endline compared to $16 \%$ at baseline. The most common indications for caesarean section were obstructed or prolonged labour and foetal distress. There was no change in the proportion of patient notes recording cervical dilatation of 2-6 cm, normal foetal heart rate and meconium stained liquor at the time of decision to perform a Caesarean Section. However, twenty-nine percent records had no indication at all on the descent of the presenting part at endline.

Overall, there was a significant reduction in the duration of time between when the decision was made to do a caesarean section and the time the actual operation was performed as shown in Table 16. Reasons for a delay of even two hours were mainly due to medical staff shortages - only one doctor covering a whole hospital as the only clinician as well as acting as the Medical Superintendent (e.g. Webuye Hospital).

Table 16. I mprovements in management of obstetric complications

\begin{tabular}{|l|c|c|}
\hline & Baseline & Endline \\
\hline Obstructed labour records: & $\mathrm{n}=78$ & $\mathrm{n}=29$ \\
\hline Descent static/contraction more than 3 hours ${ }^{* *}$ & $52 \%$ & $97 \%$ \\
\hline Uterine contractions checked half hourly & $51 \%$ & $71 \%$ \\
\hline Maternal pulse rate monitored & $43 \%$ & $54 \%$ \\
\hline Caesarean Section records: & $\mathrm{n}=83$ & $\mathrm{n}=70$ \\
\hline C/S performed in one hour or less from decision ${ }^{* *}$ & $0 \%$ & $13 \%$ \\
\hline C/S performed more than 5 hours from decision & $10 \%$ & $0 \%$ \\
\hline
\end{tabular}

* Significant at 0.05 level ** Significant at 0.01 level 
Complicated births - obstructed labour record review

Of the 29 records reviewed at endline for obstructed labour, $72 \%$ of the cases were managed using a partograph compared to $34 \%$ at baseline $(n=78)$. The main parameters used to evaluate obstructed labour are strong uterine contractions with no progress for 3 or more hours and a static presenting part (no descent). There was significant improvement in the proportion of health providers who had recorded both the uterine contractions and foetal descent and that uterine contractions were checked half hourly and in the proportion of records that monitored the maternal pulse rate. This points to an improvement in diagnosis and management of obstructed labour by providers over the three-year period.

Over $80 \%$ of women's records reviewed (both base and endline) indicated obstructed labour as the main reason for Caesarean Section. There was no change in the time taken after the decision to perform the operation to the actual delivery at endline for obstructed labour. With regard to the pregnancy outcomes at baseline, 63 (89\%) of the babies were live births. Nearly all, 8 out of the 9 stillbirths were fresh stillbirths and this is attributable to the foetal distress that usually accompanies prolonged labour. There was no maternal death for mothers diagnosed with obstructed labour at baseline. However, one maternal death was recorded at endline. Twenty-four $(73 \%)$ of the births at endline were live, even though 5 (17\%) of them had a poor score.

\section{Eclampsia}

Parameters used to review records of patients with eclampsia included blood pressure recordings, proteinuria, eclamptic fits, fluid input and output, and foetal heart rates. Twenty-nine records were reviewed at baseline compared to ten at endline. Fewer women were recorded to have fits, (baseline 15/ 29, endline 4 / 10). More women had their blood pressure measured hourly (Baseline 14/29, End line 6/ 10) and there was a significant increase in the proportion of foetal heart rates checked (Baseline 10/ 29, Endline 8/ 10). The reduced number of women tested for proteinuria from $80 \%$ to $30 \%$ is due to the concomitant lack of uristix available across districts during 2002-2003.

As regards the maternal and perinatal outcome, the survival rate was $100 \%$ at endline with all mothers and their babies discharged alive and well. At baseline, half of the babies were still born and there was one maternal death.

\section{Post-abortion care}

Records show that there was an increase in the use of the technique using manual vacuum aspiration (MVA) of retained products of conception. This compares to the more invasive procedure of dilation and curettage, which requires the patient to undergo anaesthesia and to be an inpatient. The proportion of women seeking post abortion care who were managed using MVA procedure increased from $16 \%(n=83)$ to $46 \%$ ( $n=59)$ by endline.

Only 13 and 6 post abortion clients were available to be interviewed in hospitals throughout the data collection period, (three weeks and one week during the baseline and endline surveys respectively). An inquiry about the problem that prompted them to go to hospital to seek for medical services established four main causes in order of priority as vaginal bleeding, abdominal pain, foul smelling discharge, and fever and chills. All the post-abortion clients used vehicles to reach the facility at endline. 
Once at hospital, such cases should be attended to immediately. In the baseline survey, 5 of the 13 clients received immediate attention for the manual vacuum aspiration (MVA) procedure, but in the endline survey all clients waited for two or more hours before undergoing MVA. All clients experienced varying degrees of pain, with the majority experiencing more pain than expected. A number of the clients did receive family planning information while at the hospital, but this does not appear to have been a routine activity. When asked to express their opinion on the duration they had waited, 7 of the clients at baseline complained that the waiting was too long and all clients interviewed at endline felt the waiting was too long. The majority of the clients felt that the waiting time from examination to evacuation was too long as they waited for a minimum of two hours.

The age range of the patient record reviews shows that the majority of women (71\%) were less than 30 years of age from the records reviewed for normal birth. Twenty four percent were less than 19 years of age, $28 \%$ were 20 to 24 years and $19 \% 25$ to 29 years as show in Table 17.

Table 17. A ge range of women from case patient records reviewed (by numbers)

\begin{tabular}{|l|c|c|c|c|}
\hline $\begin{array}{l}\text { Age range } \\
2003\end{array}$ & $\begin{array}{c}\text { Normal birth } \\
(\mathbf{n}=\mathbf{2 1 4})\end{array}$ & $\begin{array}{c}\text { Eclampsia } \\
(\mathbf{n}=\mathbf{1 0})\end{array}$ & $\begin{array}{c}\text { Prolonged labour } \\
(\mathbf{n}=\mathbf{2 9})\end{array}$ & $\begin{array}{c}\text { Caesarean } \\
\text { Section } \\
(\mathbf{n}=\mathbf{7 0})\end{array}$ \\
\hline Under 19 years & 52 & 4 & 14 & 22 \\
\hline $20-24$ years & 60 & 2 & 7 & 20 \\
\hline $25-29$ years & 41 & 1 & 2 & 8 \\
\hline $30-34$ years & 25 & 0 & 3 & 8 \\
\hline $35-39$ years & 15 & 2 & 3 & 1 \\
\hline More than 40 years & 5 & 0 & 0 & 3 \\
\hline No age recorded & 16 & 1 & 0 & \\
\hline
\end{tabular}

\section{Postpartum care}

There was a significant increase in the proportion of women who said they attended post-partum care during the endline $29 \%(n=1294)$ when compared to baseline survey $7 \%(n=3594)$. If a woman delivers with a skilled attendant she is significantly more likely to attend postpartum care.

Postpartum clients were asked about the services they and their babies had received from health providers since their time of giving birth. During the postpartum visits, mothers are supposed to receive all the services shown in Table 18 with the exception of Pap smear, irrespective of the facility type.

Measurement of blood pressure, performing abdominal examination and enquiring about any abnormal bleeding, were the only services that showed a significant increase between the two surveys. Services for the baby i.e., examination, weighing and immunisation were given most attention as at least $65 \%$ of the mothers reported that their babies had received these services. 
Table 18. Type of postpartum service received by mother since giving birth

\begin{tabular}{|l|c|c|}
\hline $\begin{array}{l}\text { Type of service rendered for the } \\
\text { mother }\end{array}$ & $\begin{array}{c}\text { Baseline } \\
\mathbf{n = 2 7 9}\end{array}$ & $\begin{array}{c}\text { Endline } \\
\mathbf{N}=\mathbf{9 7}\end{array}$ \\
\hline Measured blood pressure $^{\star *}$ & $36 \%$ & $53 \%$ \\
\hline Performed abdominal examination $^{* *}$ & $33 \%$ & $52 \%$ \\
\hline Asked about any abnormal bleeding $^{* *}$ & $24 \%$ & $39 \%$ \\
\hline
\end{tabular}

**Significant at 0.01 level

Although there is a noted improved trend where more mothers are receiving care after giving birth, there was no significant change in the proportion of health care providers providing essential care to postpartum women. Specifically there was no change in the providers giving advice on breast-feeding, care of the baby and family planning. From the focus group discussions, it was clear that the discussants understanding of the value of postpartum/ post natal services was for the baby and often the health providers did not encourage women to use these services.

Clients were asked to state how long they had waited from the time they arrived at the health facility to the time they were seen by a service provider on the day of interview. The average waiting time decreased from 45 minutes to 40 minutes. The continued length of waiting time may be explained by the fact that if both the mother and baby are examined thoroughly, the other clients will have to wait longer.

Me $n$ were not

aware that women

should attend

postpartum "women

do not go to clinic it

is for the $6 a b y$

\section{Maternal and child mortality}

Measuring mortality over a short period of time is challenging, therefore as a proxy, women were asked if they had heard of a woman dying of obstetric complications that year. The proportion of women who had heard of a woman dying because of pregnancy related problems reduced over the project period. At baseline $54 \%(n=2157)$ of women had heard of a woman dying compared to $33 \%(n=467)$ at endline. However more recalled that the maternal deaths appeared to have occurred during pregnancy at endline (an increase from $10 \%$ to $23 \%$ ), but fewer women died during childbirth (reduced from $50 \%$ at baseline to $45 \%$ endline and after childbirth reduced from $40 \%$ to $32 \%$ ). This increase of deaths during pregnancy may indicate more deaths due to abortion complications although indirect causes cannot be ruled out.

Thirty percent of women ( $n=1147$ ) at baseline said they had lost at least one child at baseline compared to $28 \%(n=384)$ at endline. The age of children who had died was not asked at baseline but among women who had lost a child one year or less ( $n=112)$ at endline, $20 \%$ said their baby had died at birth, 33\% died within the first week, and a total of $36 \%$ died within the first month of birth. 


\section{Health organisational and management issues}

\section{Hours of operation}

Any facility offering maternity services should operate every day for 24 hours. All hospitals in the project area operated for 24 hours, seven days a week. There were no significant increases in the proportion of Health Centres (82\% endline from $60 \%$ baseline) and dispensaries (22\% endline from 19\% baseline), which were operating 24 hours, seven days a week. The proportion of rural health facilities whose outpatient departments were only open during the day Monday to Friday reduced from $17 \%$ at baseline to $10 \%$ at endline.

Significantly more (85\%) facilities had on-call services for complicated deliveries at night and weekends during the endline survey than during the baseline survey (65\%). While such increases were evident in Kakamega, Vihiga and Bungoma districts, there was no change in Lugari district where only $33 \%$ of the facilities could cater for complicated deliveries at night and weekends. During both surveys, all hospitals (except Kima Mission Hospital in Vihiga district) had on-call services for caesarean section at night and weekends. There was a marked improvement in the number of health facilities that now have organograms (from 39\% to 54\%) to show the lines of supervision and management.

A vailability of supplies, drugs and equipment

Overall, after two years of interventions the proportion of facilities that required women in labour to come along with supplies and drugs reduced significantly. Chart 5 illustrates the drop across the four districts.

Chart 5. Proportion of facilities requesting women in labour to bring drugs and supplies

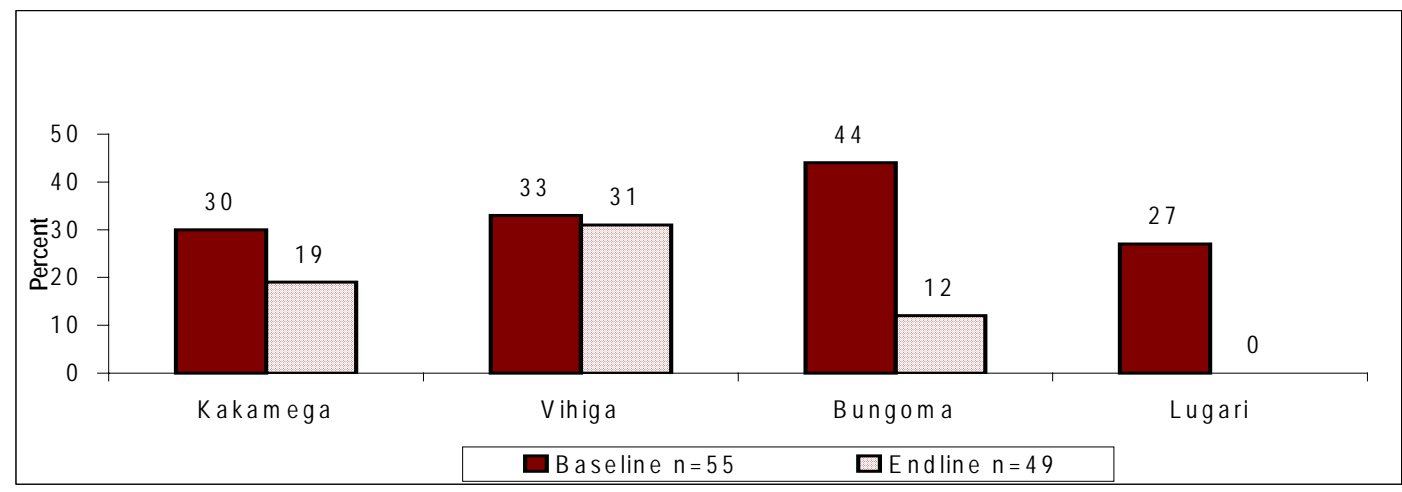

The most significant reductions took place in Bungoma and Lugari districts. The high performance in Lugari and Bungoma districts in supplies may be attributed to active participation of rural health management committees in nearly all facilities which ensure there are no stock outs by buying drugs and supplies locally while waiting for orders from central level.

At baseline there were fundamental gaps in functioning equipment. However, the SMDP distributed basic essential equipment to health facilities through DHMTs. In addition, existing non-functioning equipment was repaired. Following the distribution of "start up equipment", facilities have been able to procure further items through discussion with their health facility committees and use of facility improvement funds. Moreover other funds are available to the Ministry of Health through the 
decentralisation process of Health Sector Reform. Nearly all facilities providing delivery services now have delivery kits. Only 14 out of 45 facilities in Kakamega District and 2 out of 14 facilities in Lugari District did not have delivery kits during endline survey. One of the most pressing gaps that continues to exist is the lack of both adult and neonatal resuscitation kits.

Continuing professional development in obstetrics/midwifery

Continuing medical education sessions are now the norm in most hospitals. One way of ensuring retention of knowledge is to encourage individuals to prepare a presentation on a given subject for their colleagues or a wider audience. Some of the health care providers have also given presentations at conferences (KOGS 2002, ECSA OGS 2003, N NAK annual conference 2003 etc). Significantly fewer nurses (42\%) at endline said they had never received any formal training in obstetrics and midwifery compared to $55 \%$ at baseline. Although a greater drop was expected, it is possible that on-job-training (OJT) updates in EOC are seen as informal and therefore "do not count" towards formal training. An alternative explanation includes the recent re-deployment and a number of the 260 providers updated between 2001 and 2002 have retired or have been moved to other departments and replaced with new providers who have not been formally updated in essential obstetric care.

More providers (77\%) had received practical skills at the time of endline survey as compared to the baseline survey (61\%). From the baseline report, family planning, care of the patient during delivery, and antenatal care were the topics for practical skills updates (on job training). In contrast, the majority of those who received updates at the time of the endline survey related to the conduct of a normal delivery, use of partograph, and handling of obstetric emergencies. There was no change in supportive supervision given to health care providers in the facilities over the project period.

A vailability of guidelines or procedure manuals on EOC

The proportion of providers having access to guidelines or procedure manuals on essential obstetric care increased significantly: from $55 \%$ at baseline survey, to $80 \%$ at endline. The two main reasons for not having the guidelines (multiple response) were that they were either 'misplaced' (84\%) and/ or 'not received from supervisor' (43\%).

The most readily available manual at the time of the endline survey was the "Essential Obstetric Care Manual for Health Care Providers in Kenya 2002" (see figure 3), which was not available at all at the time of the baseline survey. Less than $10 \%$ of health providers in all four districts had access to the postpartum care manual. Guidelines on risks in pregnancy, unavailable in Vihiga and Lugari districts during the baseline survey, were available at the time of the endline survey.

Figure 3. Health care procedure manual for health providers at facility level

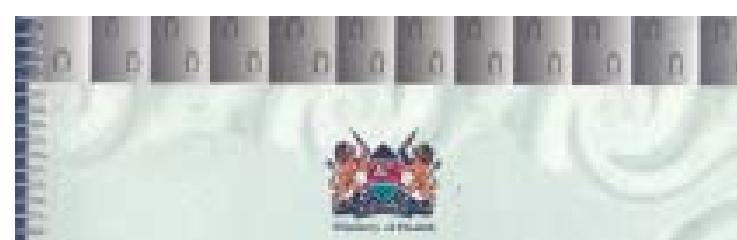

ESSENTIAL OBSTETRIC CARE MANUAL:

For Health Service Providers in Kenya

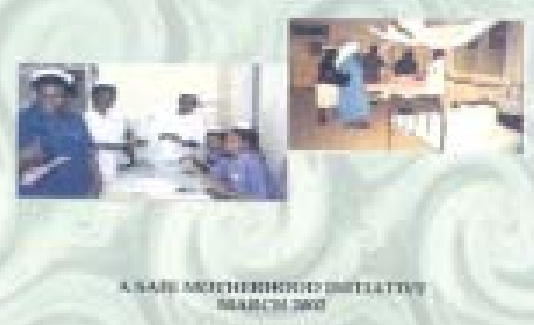




\section{Meetings to discuss patient care}

There was no change in the number of health providers (over $80 \%$ ) who reported that they met to discuss patient care. At least half of the meetings were held on a monthly basis. There was a decline in the proportion of health providers who reported that they discussed difficult cases during the endline survey (70\%) compared to the baseline survey (85\%), especially in Kakamega, Vihiga and Bungoma districts. Even though maternal deaths were being reported, maternal mortality meetings were not getting the attention they deserved.

Even for perinatal mortality meetings, majority (at least 74\%) of the health facilities had never held these meetings. The lowest reporting rate was in Lugari district where only $25 \%$ of them held perinatal meetings for every death by the time of the endline survey.

Problems in health facilities as perceived by providers

Health providers considered that the three most important management problems faced by health institutions were lack of equipment and supplies, staff shortage and poor means of transport as shown in Table 19.

Table 19. M M ajor problems facing health facilities as perceived by providers (multiple response)

\begin{tabular}{|l|c|c|c|c|}
\hline \multirow{2}{*}{ Problem } & \multicolumn{2}{|c|}{ Baseline } & \multicolumn{2}{c|}{ Endline } \\
\cline { 2 - 5 } & $(\mathbf{n = 3 0 7 )}$ & $\%$ & $(\mathbf{n = 1 4 2 )}$ & $\%$ \\
\hline Lack of equipment/supplies* $^{*}$ & & 72 & & 61 \\
\hline Staff shortage** & & 47 & & 68 \\
\hline Lack of transport $^{*}$ & & 30 & & 32 \\
\hline
\end{tabular}

*significant at 0.05 level **significant at 0.01 level

The perceived lack of equipment and supplies lessened significantly. On the other hand, the situation on shortage of staff appears worse: -in the past three years there has been no recruitment of new personnel in the health sector except for doctors. Another reason is increased workload, due to additional facilities seeing more clients and providing services for 24 hours as well as an increase in types of services now provided (e.g. FANC, PMTCT/ VCT services). The impact of the above problems varied from one district to another. Lack of transport continues to be a major problem in Lugari district while in Vihiga drug shortage is the most important problem. In Kakamega and Bungoma districts, lack of essential equipment was the second major problem. 


\section{DISCUSSION}

The discussion that follows addresses components of interventions identified by various stakeholders at district level. The main constraints at baseline were: poor provider competency and skills; inadequate equipment and supplies; inefficient referral system; limited access to community obstetric care; poor health information system; and weak organisational and management system. The SMDP model was developed to address these issues, through four broader elements, which are: skilled attendance, institutional capacity building, strengthened partnerships and community action. If these elements are addressed concurrently this will in turn reduce the three delays and increase utilisation of quality services. An increase in utilisation of services or meeting the obstetric met need will then lead to a reduction in maternal and perinatal morbidity and mortality.

\section{KEY FINDINGS}

\section{Ante natal Care}

- Increase in use of standard $\mathcal{A N C}$ cards

- Significant increases in IPT first and second doses in Antenatal clinic

- Increase in proportion of women receiving blood tests

- More women seen in privacy and given the opportunity to askquestions

- Women spend more time with provider

- Increase in women's knowledge on danger signs

\section{Intrapartum Care}

- Increase in proportion of partographs used for managing labour

- Increase in knowledge of danger signs among health care providers

- Increase in frequency in health providers assisting at 6irth

- Increase in measurement of vital signs during labour

- Improvement in management of obstetric complications

- Reduction in number of women in labour for more than 12 hours

Postpartum Care

- Increase in number of women attending PPC

- If women deliver with a skilled attendant they are significantly more likely to attend post partum care.

Complications

- Obstetric met need increased

- Reduction in Case Fatality Rate

- Increase in facilities providing $\mathcal{M V A}$ services for post abortion care

\section{Referral}

- Increase in access to telephone for referral

- Increase in access to functioning ambulance

- Emergency obstetric cases referred in one fiour or less

Management

- Increase in number of facilities open 24 hours

- Increase in number of health facilities using guidelines and protocols

- Less women required to bring supplies at time of delivery

- Health facility manage ment improved (organograms)

Community obstetrics

- Increase in number of women delivering at home with skilled at tendant

- Increase in number of dispensaries providing delivery care

- Prepayment model and birth preparedness models can increase skilled attendance 


\section{Skilled Attendance}

One of the key efforts and focus for the SMDP has been on increasing the knowledge and skills of health care providers across the four districts in order to increase the number of women giving birth with skilled attendance. This has resulted in improved knowledge and quality of care and the increasing trend in number of $\mathrm{C} / \mathrm{S}$ and a reduction of case fatality rate. In addition a supportive environment, which enables the health care providers to work more effectively now exists through the distribution of equipment and supplies as well as supportive supervision.

Overall, more staff received continuing education during the project period although more continuous updates are required given that $58 \%$ of staff said they had not received any continuing education at endline. Regular monitoring and supportive supervision are critical elements of management in ensuring that not only set targets are met but also in guaranteeing overall quality of health care at all levels. Staff attitude has improved but remains an issue among women and their families, as many feel helpless to do anything about it. (See box)

"In this world there are two people you do not differ with: you should not differ with the doctor or the magistrate - they have the power to harm you" (Vifiga District)
In the provision of focused antenatal care there remain some challenges. The time required to provide a comprehensive consultation, which includes the prevention and early detection of disease, health promotion and birth preparedness is insufficient given the current staff shortages and deployment. However if antenatal care can be improved then it is likely that there will be an increase in use of skilled attendance and postpartum care.

\section{Institutional Capacity Building}

For proper management of obstetric and neonatal complications, a functional referral system needs to be in place. Access to a functional ambulance is essential for facilities to effectively manage obstetric complications and refer appropriately. The number of facilities that had access to transport or were able to call for transport using telephones increased significantly. Moreover while it may be ideal for facilities with major maternity units to have their own facility vehicles it would be more appropriate for an overall review of all health transport needs/ vehicles at district level to take place and develop a transport pool that can be accessed swiftly when required.

There was an increase in the number of facilities operating at night and during weekends. Most facilities had procedure manuals and for those who did not have access to them, this was mainly an internal issue and not unavailability per se.

Management of health information at facility level improved over the project period. Some districts e.g. Lugari and facilities in other districts took the initiative to develop and print individual patient folders, registers and other stationery. Hospitals and other health facilities were able to improve their patient records and storage as well as compiling their monthly reports following training updates.

The challenge remains for the facility management to ensure regular availability of the partographs and other essential stationery. Due to the improved management systems in procurement and financial control, drugs and supplies were available most of the time. Purchasing of supplies and equipment has now been decentralised to district level. 
There was no improvement with regard to holding of maternal and peri-natal mortality meetings, despite there being regular meetings that discussed patient care. These mortality meetings are important as they are meant to reduce future occurrences and should therefore be held on a regular basis.

The majority of women were of the opinion that they spent too much on health care. Waivers and exemptions, put in place by the $\mathrm{MoH}$ at the time the 'cost-sharing' was introduced do exist but many women are deterred from seeking skilled care and have no financial capability to pay for the health services. In spite of the MoH 'cost-sharing' guidelines the system remains ineffective in its implementation. Some public heal th facilities have limited their provision of waivers and exemptions citing declining resources from the central government as a reason for not granting them.

Even in situations where formal fees are low or non-existent, there may exist other costs (including transport, drugs and supplies) that deter women from seeking care. For instance, some women mentioned transport costs as a reason for not attending clinic. This was reinforced during the FGDs with the mothers where they stated that due to the poor economic situation, it was better to spend the money on food rather than spend it as transport and payment for ANC services. Long distances were a handicap in accessing quality maternal care given that $34 \%$ of the women normally took at least one hour to reach the nearest health facility.

\section{Partnerships}

Within the SMDP building partnerships was a key strategy to empower all levels of health care and to strengthen linkages between and within institutions. The tripartite approach involving the Ministry of Health, University of Nairobi and Population Council has resulted in an efficient and effective implementation partnership, which is replicable and scalable.

Involving many stakeholders from the districts has resulted in a high level of ownership and subsequently increased likelihood of sustainability. Since the training of health care providers in Essential Obstetric Care, linkages created between the public and mission hospitals have continued. Trainers selected from these institutions remain part of the continuing medical education programme at district level in the form of the Reproductive Health Training and Supervision Teams.

Utilization of facilities has improved where there was good partnership between health facilities and the community. Where health care providers have a positive attitude towards traditional birth attendants, the likelihood of TBAs bringing women to the health facilities increases when problems occur. Some facilities have provided small incentives to TBAs to escort women in labour to the facility and provide psychosocial support during labour. In one rural health facility, the staff helped the TBAs develop performances, which include songs and dancing explaining when women should seek care and how to care for themselves during pregnancy. 


\section{Community Action}

Lack of a clear policy on the role of dispensaries has been translated into denial of BEOC services for women seeking care in dispensaries. In the past this meant that any woman who turned up at a dispensary for delivery was often referred to a health centre. However as result of the SMDP there has been an increase in availability of services in the peripheral facilities. Domiciliary care has increased significantly indicating a trend to assist women to deliver in the location they feel most comfortable in.

\section{Maternal Morbidity and Mortality Reduction}

Evidence from the SMDP has shown that the case fatality rate while not yet less than $1 \%$ has started to reduce in the four districts. There has been an increase in number of complicated cases seen and managed and an increase in the number of caesarean sections done for obstetric emergencies. Health care providers are now more likely to see obstetric complications (an indication that more women are reaching facilities in time) and also have improved knowledge and skills to deal with the problems.

Every maternal death is a tragedy. Increased efforts using maternal death review at facility and community level can contribute to learning why these deaths happened and procedures put in place to prevent the same thing happening again.

\section{Lessons Learned from the SMDP}

The SMDP adopted a participatory approach in problem identification, analysis and proposing possible solutions by bringing together all stakeholders at all levels. This approach to project implementation was effective in raising morale and increasing levels of commitment and motivation amongst health managers, health providers and members of facility management boards and committees and community representatives. Arising from experiences of the SMDP, some of the lessons learnt are as follows: -

- The Tripartite Approach involving Ministry of Health, University of Nairobi and Population Council has resulted in an efficient and effective implementation partnership, which is replicable and scalable at a national level.

- Use of participatory approach in projects from planning to evaluation enhances ownership and sustainability, and especially when new project activities build on existing management infrastructure.

- Districts are able to organise, on their own, inter-disciplinary support teams to undertake continuing medical education activities such as training in essential obstetric care and as well organize intensive support supervision and follow up.

- Effective management of various resources including human resource deployment, institutional preparedness as well as strengthening basic systems such as health management and information system does improve coverage and quality of health care in facilities.

- While the growth of the private sector has important lessons on how public facilities should be run, staffed and resourced, far too little attention has been paid to effective means of securing better health outcomes from the private sector, or to obtain greater complementarity between private and public sector. 
- Public/ Private/ Mission health facility collaboration involving personnel exchange, sharing of supplies and facilities can ensure 24-hour coverage.

- Emphasis on partograph use reduces third delay and assists staff in rural facilities in deciding to refer in time.

- Postgraduate ObGyn registrars seconded to provincial hospitals can address gaps in specialised care and supervise Continuing Medical Education.

- Inclusion of laboratory technicians, public health officers and health information officers in EOC training improves support to maternal services.

- Considerable barriers to accessing BEOC and CEOC do exist for the poor. Financial barriers to accessing health care remain a major constraint. The current waiver and exemption system does not adequately ensure access for the poor.

- In facilities where there is active participation by community members on the facility committees, referral and utilisation of services improved.

- Effective linkages with community based caregivers (CHWs and TBAs) does increase the number of women with complications being referred in time.

- Individual birth plans distributed by women's groups provides social support as well as raising awareness for seeking care for obstetric complications.

- Information from monitoring and evaluation activities should be used for annual district plans. Only if information is seen as useful will health service staff collect data properly. 


\section{Challenges for SCAli ng up SAfe Motherhood AND Neonatal Health Programmi ng}

Despite the achievements mentioned within this report, there remain some challenges. These must be taken into consideration prior to any scale up of activities. The following areas require increased focus with the Ministry of Heal th taking a more pro-active role in the coordination of all aspects of $\mathrm{MNH}$ services in order to reduce maternal and neonatal morbidity and mortality.

N eonatal Care: Improving maternal care has some impact on improving newborn lives. Health care providers were updated in resuscitation and care of the newborn as part of the EOC updates and resuscitation equipment supplied, however there remain weaknesses in terms of coverage and specifically essential care of the newborn in the community.

PM TCT: This was not a focus during the demonstration phase, however some of our partners (FHI, NARESA) were piloting interventions within Kakamega District and elsewhere in Kenya. Increased support to integrate PMTCT within maternal and neonatal services is necessary at all levels.

Y oung mothers: There was no particular focus on adolescent mothers. However data shows that there was increased attention on adolescent health needs. There is now an adolescent RH policy, which should be an integral part in any scale up plan.

Male involvement: Results from focus group discussions indicate that men are increasingly aware of the problems their women face during pregnancy and childbirth. Safe motherhood and newborn life will benefit if men are included.

Postpartum Care: Although some progress has been made in this area, women do not always receive early post partum care. Nurses appear reluctant to provide this care especially in busy units. Women and newborn babies continue to die within the first week. Increased emphasis must be focused during this crucial period.

Retaining trained staff in maternal services: Although SMDP updated 260 health care providers in EOC; many have since been transferred to other units or have retired. A critical mass of providers skilled in midwifery/ obstetrics must be maintained within the districts and hospitals to ensure quality maternal and neonatal care. Multiple trainings, which are not, integrated with other essential health service packages pull health care providers away from their stations for too long - a strong CME programme would help resolve this.

Policy for TBAs required: In some districts, TBAs are still an important provider of care in the community in some districts. However, an important finding was that where domiciliary care was active the TBA s' role was found to have reduced such as in Vihiga District. A policy regarding the role of the TBA needs to be reviewed nationally.

M aintaining Q uality: Quality of care is a composite indicator that relies on many inputs and participation of many institutions and departments. The biggest challenge is to generate interest especially at the community level to encourage demand-led services. Evidence has shown that where communities are actively involved in the delivery of health services, utilisation increases. 
Participation: The participatory nature of the project design (requiring all stakeholders to be involved in problem identification, planning and management) took longer than anticipated. However, the fact that the project was built on existing government, NGO and private sector structures made it more acceptable and realistic. This approach is therefore replicable and sustainable within the constraints of the public heal th system.

Community Advocacy: This is a key area that cannot be ignored. Although the SMDP adapted and distributed a range of IEC materials, not enough reached the women and their families who needed it. Materials written in the vernacular will improve access to essential information to assist decisions regarding care-seeking behaviour to improve.

Emergency $O$ bstetric Care: There is still a large shortfall with regard to obstetric met need, caesarean section rate and case fatality rate. Future work in this area needs to take into account the relative contribution of indirect causes (specifically HIV/ AIDS, TB and Malaria) of maternal morbidity and mortality.

Health information system: The information culture within the public health system is low. Health facilities do not use information at source for planning. HIS nationally needs a strategic review.

$H$ ealth sector reform: In any programme more direct linkages must be made with other essential packages. For example, malaria, integrated management of childhood illnesses, Expanded Programme of Immunisation and HIV/ AIDS.

\section{Way Forward and Programme Sustainability}

Stakeholders from Kakamega, Vihiga, Bungoma and Lugari districts developed strategies to continue activities grouped under nine themes viz., consolidating achievements made and improving on skilled attendance, strengthening partnerships at all levels, maintaining equipment and ensuring a regular supply of supplies and drugs, regular supervision of staff, rolling out to other districts within the Province, redefining the role of the TBAs, community involvement and sensitisation, institutional capacity building, initiating other reproductive health programmes and involving men in the same. Details of these are outlined in a separate district dissemination report3.

Although the RH policy documents in Kenya emphasise the need for equitable coverage of maternal and child health services across all districts in the country, the absence of specific resource allocation criteria in the health sector has continued to undermine this policy intention. This has created gaps in geographical coverage as well as inadequate programme coverage. For example, some districts have very limited donor support while others are overwhelmed with external collaborators. Often external support focuses on individual components of safe motherhood rather than adopting a holistic approach to improving women's health. A holistic approach gives women an opportunity to benefit from the continuam of care from conception, during pregnancy to delivery and the postpartum period including family planning.

The Division of Reproductive Health has therefore, developed a Kenya model for SMNH with members of the Safe Motherhood Working Group (who includes Population Council, KOGS and Dept of ObGyn University of Nairobi) (see appendix 10). This model serves as the basis for any further maternal and neonatal programming in Kenya.

${ }_{3}^{3}$ District Dissemination Report for SM DP August 2003 Population Council 


\section{CONCLUSI ON AND RECOMMENDATIONS}

\section{Conclusions}

It is evident from the results that the project has largely achieved its purpose, which was to increase utilization of quality maternal services in the selected districts. Specifically, the project has made substantial progress in the area of maternal health as well as in the broader health system issues through building partnerships, supporting and strengthening community action, use of skilled attendance at birth and having in place a strengthened and supportive health management system at all levels. Emerging lessons from the project point to the fact that realising improvements requires a systems approach and that the four strategic interventions identified above need to work in a synergistic manner to increase utilisation of maternal services in order to improve maternal health in Kenya especially for poor women.

The decision to build in the issue of project sustainability during the planning and design stages of the programme has resulted in high ownership at district level. Judging from the overwhelming support the project has received from the local community it is evident that the interventions being implemented do address a felt need within the implementing districts.

A ware that the three delays were responsible for the majority of maternal and perinatal morbidity and mortality in the four districts, the project developed a variety of strategies to tackle the underlying obstacles at the institutional level, during referral of patients with obstetric emergencies and at the community level. This was done through provision of direct support to the districts e.g. giving a range of inputs in training, supplies and systems development; identification of models of best practice through operational research and finally, generating useful lessons for wider dissemination and for feeding into policies and national strategies.

In addition the collaboration between Population Council, Ministry of Health and University of Nairobi has resulted in an efficient and effective implementation partnership, which is replicable and scal able. Although there wasn't adequate time to scale up some of the pro-poor strategies such as pre-payment schemes, mobile laboratories, birth preparedness scheme etc to all parts of the demonstration districts, in the long term they will contribute towards achieving improved quality maternal services given the enthusiasm and momentum shown by the districts in implementing these innovations.

\section{Recommendations}

- Ensure effective replication and scal e up of safe motherhood initiatives in other provinces in Kenya in line with the Division of Reproductive Health Safe Motherhood and Neonatal Model.

- Strengthen the technical capacity of the Division of Reproductive Health as well as the Provincial Reproductive Health Supervision and Training Teams.

- Incorporate the integrated reproductive health curricula into the basic training courses in all health-training institutions and disseminate evidence based best practice widely, including updates for all trainers/ lecturers. 
- Safe Motherhood and Neonatal Health is considered one of the essential packages within health sector reform and linkages with the other packages must be strengthened at national level in order to guide linkages at provincial and district level.

- Develop a National RH policy and National Advocacy Strategy for Maternal and Neonatal Health: improve policy darity and wide communication on making pregnancy safer issues (e.g. a national transitional strategy for TBAs is developed and domiciliary care strengthened).

- Ensure pro-poor systems are in place to provide equitable maternity services country wide 


\section{REFERENCES}

1.) Inter-Agency Group for Safe Motherhood, 1997. The Safe M otherhood Action Agenda: Priorities for the N ext Decade. A Report on the Safe M otherhood Technical Consultation, 18-23 October, Colombo, Sri Lanka.

2.) Graham W and Murray S: 1997. A Question of Survival? Review of Safe Motherhood. Options Consultancy Service Limited UK.

3.) Kenya Service Promotion Assessment 1999. MACROINCPD.

4.) Ministry of Health, 1994. Health Policy Framework Paper. Government Printer, Nairobi, Kenya.

5.) Ministry of Health, 1996. National Reproductive Health Strategy, 1997-2010. Government Printer, Nairobi, Kenya.

6.) Ministry of Health and UNICEF, 1998. Safe Motherhood in Kenya - Lessons from an Assessment of Maternity Care. Government Printer, Nairobi, Kenya.

7.) Ministry of Health, 1998. Implementation Plan for National Reproductive Health Strategy 1999-2003. Government Printer, Nai robi, Kenya.

8.) Ministry of Health, 1999. National Health Sector Strategic Plan, 1999-2004. Government Printer, Nairobi, Kenya.

9.) Ministry of Health, 1999. Strategies for Health Care Financing. Government Printer, Nairobi, Kenya.

10.) National Council for Population and Development, 1999. Kenya Demographic and Health Survey, 1998. Calverton, Maryland.

11.) Ministry of Health and Population Council and UoN, 2002. Essential Obstetric Care for Health Service Providers in Kenya: Second edition.

12.) Ministry of Health and professional associations (KOGS, NNAK, KCOA). December 2002. Standards for Maternal Care in Kenya, Population Council. Nairobi, Kenya.

13.) Ministry of Health and Population Council, January 2002. A Demonstration Project on A pproaches to Providing Quality Maternal Care in Kenya: Findings from a Baseline Survey in four Districts in Western Province, Kenya.

14.) Ministry of Health, (Undated), 2000-2001. Financial Performance of the Cost Sharing Programme: Annual Report.

15.) Owino, Wasunna, and Julius Korir, 1997. Public Health Sector Efficiency in Kenya: Estimation and Policy Implications. A Discussion Paper No. DP/ 007/ 97 Nairobi, Kenya: Institute of Policy Analysis and Research (IPAR).

16.) Republic of Kenya, 2001. 1999 Population and Housing Census, Volume I. Central Bureau of Statistics, Ministry of Finance and Planning. Government Printer, Nairobi, Kenya.

17.) Thaddeus and Maine, 1994 Too Far to Walk: Maternal Mortality in Context Social Science and M edicine 38 (8): 1091-110.

18.) Data source: 1999 Kenya Population and Central Bureau of Statistics Ministry of Planning and National Development (data 2002)

19.) WHO: Global Action for Skilled Attendants for Pregnant Women: - Making pregnancy safer, 2003. Dept. RHR, WHO, Geneva.

20.) WHO/ UNICEF, 2003. Antenatal Care in Developing Countries Promises, A chievements and Missed Opportunities: An analysis of trends, levels and differentials, 1990-2001. 


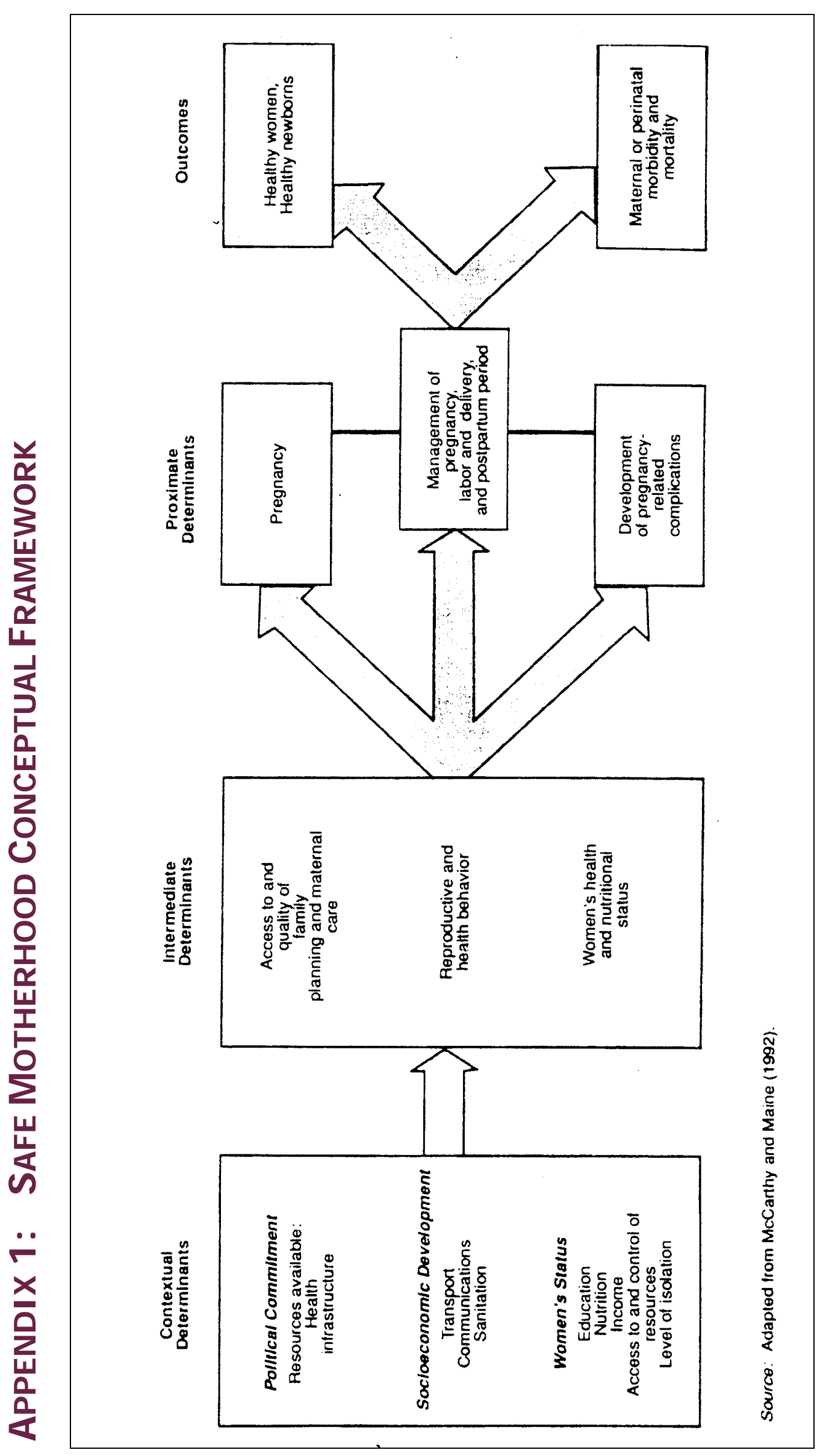




\section{APPENDIX 2: DeSI GN AND Methodology}

\section{Study Design}

A participatory approach was followed in problem identification and analysis in all the four districts of Kakamega, Vihiga, Bungoma and Lugari. The process entailed bringing together all stakeholders involved in various aspects of Safe Motherhood activities at national level and in the pilot districts. As a start, a baseline survey was conducted in the four pilot districts to provide information on the current status of safe motherhood in these districts. The results from the baseline survey and the recommendations from the internal review were consolidated to form the basis for the interventions adopted, which aimed at improving the quality of care for improved pregnancy outcome. Through a collaborative effort involving the Division of Reproductive Health, the University of Nairobi and Population Council, questionnaires and guidelines for focus groups were developed to address all issues raised by the stakeholders. The then existing strengths, opportunities and constraints were identified and indicators for monitoring project performance established through the use of the logical framework analysis. After two years of implementation, an endline survey was conducted. Results from the baseline and endline surveys were used to assess the effectiveness of the interventions hence providing a basis for possibilities of replicating similar interventions elsewhere.

\section{Sampling and Data Collection}

Both probability and non-probability sampling procedures were used in this study. The selection of study sites was purposeful. Enumeration A reas (EAs) were deliberately selected to provide information about the population in the pilot sites. A combination of sampling techniques were used: (i) systematic sampling was used to identify case files for record review and clients for various obstetric services; (ii) multi-stage cluster sampling for selection of women respondents at household level; and (iii) stratified sampling was used to select administrative divisions within each district.

\section{Women at household level}

Using the census enumeration areas for 1999 (Republic of Kenya 2001) for the four districts, divisions, locations, sub-locations and enumeration areas (EAs) were listed. Using the total population per division within each district, purposive sampling of divisions was conducted to include proportionate number of divisions with high populations and an equal number with low. For each division sampled, locations were randomly selected. For those locations identified, all the sub-locations within it were included for sampling. Within each sub-location, EAs were picked at random, and all households within an EA formed the wider sampling frame for the household survey.

For each household a list of members from the oldest to the youngest, who usually live in the household, was compiled. Concentrating on females, women in the reproductive age group were identified. Further, all those who had either given birth in the past three years preceding the survey, or were currently pregnant were identified and their consent sought to be interviewed. From the four districts, 276 enumeration areas were selected for the baseline survey. A total of 4,026 women were interviewed in the four districts. For those not found at home during the first visit, two additional revisits were made. 
During the endline survey, a narrow range of indicators, were agreed upon with the Ministry of Health at national, provincial and district level. A total of 1,427 were therefore interviewed. This time, the focus was on mothers to children born since January 2001 and females who were currently pregnant.

\section{Traditional Birth Attendants}

In each location, a proportionate number of TBAs were randomly selected for the baseline survey using information from the local leaders. Interventions did not target specifically on TBAs. At endline their operations were covered through focus group discussions only.

\section{Health institutions}

A list of all health institutions providing any type of maternal care was compiled in each district. While all hospitals (including NGO/ private hospitals), health centres and nursing homes were visited; two dispensaries were selected in each district. Eightythree health institutions (56\%) were covered during the baseline survey. The number, which included all hospitals, heal th centres and two of the most active dispensaries (no nursing homes due to poor availability of data and lack of clients) in each of the four districts, was 59 (40\%) during the endline.

\section{Health providers}

Every member of staff in a hospital or nursing home working in maternity units or the outpatient $\mathrm{MCH}$ / FP and available at the time of interview, was identified by the incharge of each hospital or nursing home selected. All staff in health centres working in $\mathrm{MCH} / \mathrm{FP}$ including maternity, and available at the time of the survey, were interviewed. At dispensary level, all providers handling MCH/ FP clients/ patients on the day the facility was visited were interviewed.

\section{Exit clients}

Clients who had come for health services at the sampled institutions (all hospitals and health centres and selected dispensaries) were asked for interview. Due to the minimal number of women who attended nursing homes for antenatal care, delivery and postnatal at baseline, these facilities were not visited in the endline. The client exit interviews targeted clients who had come for antenatal care, postpartum care, and post abortion care. All post-abortion clients in all facilities visited were interviewed during the two surveys. However, there was a poor response rate and only a few of postabortion clients were interviewed during the baseline and endline surveys.

\section{Record review}

In all hospitals and nursing homes, records in the maternity and labour wards on various modes of delivery during the year 1999 (for baseline) and 2002 (for the endline) were subjected to a review. Records on normal delivery, prolonged or obstructed labour and caesarean section were randomly selected for review (every $10^{\text {th }}$ ) in order to obtain a sample throughout the year. However due to the low number of women expected to suffer from hypertensive disease in pregnancy, all available records on eclampsia were reviewed for the previous year.

\section{M anagement issues}

All district and hospital management boards and committees were selected for interview in the four districts but only three Heal th Centre Committees were selected per district. Twenty-one boards and committees were interviewed during the baseline survey. 
There were no questionnaires on management issues during the endline survey since such issues were either covered during the monitoring process or through the qual itative component.

\section{Focus group discussions}

To supplement data collected quantitatively, views were gathered on health in general and on safe motherhood in particular. Focus group discussions (FGDs) involving young women, adolescent girls and young men were conducted in each of the four districts. Within the sampled locations used for the household interview, villages were sampled to select three focus groups (one each of young women, adolescent girls and young men) in each district.

The FGDs were meant to seek for perceptions and practices of young men and women on issues concerning antenatal, intrapartum and postpartum care. During the baseline survey, additional information collected included: maternal health with a focus on perception of pregnancy, support during pregnancy, available services in terms of accessibility and cost; childbirth/ delivery, referral, postpartum care, adolescent pregnancy, pregnancy loss (miscarriage); and sources of information. Through such discussions, adolescent girls expressed their perceptions and knowledge on various RH issues including pregnancy and sexually transmitted infections.

In focus group discussions at the endline survey, the purpose was to elicit views and perspectives of the community based on their experiences with the Safe Motherhood Initiatives that had been in operation over the past two years. Specifically, the discussions sought views on ANC attendance and its importance, choice of site for delivery and relative costs, referral and use of postnatal services. Overall, the discussions were to establish whether there were changes in health service delivery, especially with regard to safe motherhood. Both men and women groups addressed the same themes and were asked to suggest the way forward. Besides the above categories of interviewees focus group discussions were also held with TBAs at endline.

\section{Data Analysis}

Quantitative data were coded and edited for completeness and accuracy. Data entry and cleaning was done in Nairobi after which necessary tables were produced for analysis. While the EPIDATA package was used for data entry (including routine monitoring data), analysis was done by SPSS. Using simple frequency distributions and cross tabulations of the quantitative data, the analysis was largely descriptive in nature. Comparison of the data for endline and baseline was done to capture the effect of interventions. Data from monitoring activities was also analysed to show the trend. Qualitative data from the transcripts were typed and then coded before being analysed. Where necessary, the qualitative data were used to explain and expound on some of the quantitative aspects. 


\section{APPENDIX 3: SUMMARY OF PROVI DERS RECALL ON SI GNS AND ACTI ON REQUI RED FOR OBSTETRIC EMERGENCIES}

\begin{tabular}{|c|c|c|c|c|}
\hline \multirow[t]{2}{*}{ Sign and action } & \multicolumn{2}{|c|}{ Baseline $(n=262)$} & \multicolumn{2}{|c|}{ Endline $(n=139)$} \\
\hline & Single $\%$ & Composite\% & Single\% & Composite\% \\
\hline \multicolumn{5}{|l|}{ Signs of $A P H$} \\
\hline Amount of external bleeding & 80 & \multirow{3}{*}{3} & 89 & \multirow{3}{*}{13} \\
\hline Signs of shock & 42 & & 64 & \\
\hline Abdominal tenderness & 15 & & 22 & \\
\hline \multicolumn{5}{|l|}{ Action for $A P H$} \\
\hline Refer to doc or hospital & 83 & \multirow{4}{*}{3} & 90 & \multirow{4}{*}{13} \\
\hline Check vital signs & 34 & & 45 & \\
\hline Blood for $\mathrm{Hb}$ group and $\mathrm{X}$ match & 28 & & 40 & \\
\hline Set up IV fluid & 30 & & 58 & \\
\hline \multicolumn{5}{|l|}{ Signs of $P P H$} \\
\hline Signs of shock & 64 & \multirow{4}{*}{2} & 78 & \multirow{4}{*}{$15^{\star}$} \\
\hline Amount of external bleeding & 68 & & 71 & \\
\hline Uncontracted uterus & 31 & & 49 & \\
\hline Retained products/placenta & 25 & & 44 & \\
\hline \multicolumn{5}{|l|}{ Action for PPH } \\
\hline Massage fundus & 25 & \multirow{4}{*}{2} & 41 & \multirow{4}{*}{$12^{*}$} \\
\hline Give ergometrine & 54 & & 66 & \\
\hline Empty bladder & 18 & & 34 & \\
\hline Start IV & 54 & & 66 & \\
\hline \multicolumn{5}{|l|}{ Action for retained placenta } \\
\hline Empty bladder & 36 & \multirow{3}{*}{0.4} & 50 & \multirow{3}{*}{4} \\
\hline Apply controlled cord traction & 28 & & 46 & \\
\hline Give oxytocin & 10 & & 15 & \\
\hline \multicolumn{5}{|l|}{ Signs of obstructed labour } \\
\hline No descent of presenting part & 76 & \multirow{4}{*}{6} & 87 & \multirow{4}{*}{12} \\
\hline No cervical dilatation & 61 & & 65 & \\
\hline Maternal distress & 50 & & 57 & \\
\hline Bandls Ring & 26 & & 37 & \\
\hline \multicolumn{5}{|l|}{ Action for obstructed labour } \\
\hline Refer/call doctor & 91 & \multirow{3}{*}{3} & 98 & \multirow{3}{*}{12} \\
\hline Start $10 \%$ dextrose & 28 & & 43 & \\
\hline Continuous bladder drainage & 6 & & 14 & \\
\hline
\end{tabular}




\begin{tabular}{|c|c|c|c|c|}
\hline \multirow[t]{2}{*}{ Sign and action } & \multicolumn{2}{|c|}{ Baseline $(n=262)$} & \multicolumn{2}{|c|}{ Endline $(n=139)$} \\
\hline & Single\% & Composite\% & Single\% & Composite\% \\
\hline \multicolumn{5}{|l|}{ Signs of puerperal sepsis } \\
\hline High fever/ pulse & 80 & \multirow{4}{*}{5} & 91 & \multirow{4}{*}{6} \\
\hline Foul smelling lochia & 83 & & 87 & \\
\hline Tender abdomen & 44 & & 53 & \\
\hline Septic shock & 20 & & 18 & \\
\hline \multicolumn{5}{|l|}{ Action for puerperal sepsis } \\
\hline Give antibiotics IV & 79 & \multirow{3}{*}{3} & 89 & \multirow{3}{*}{9} \\
\hline Examine lochia & 26 & & 35 & \\
\hline Start IV fluids & 11 & & 23 & \\
\hline \multicolumn{5}{|l|}{ Signs of Eclampsia } \\
\hline Oedema & 75 & \multirow{4}{*}{1} & 81 & \multirow{4}{*}{9} \\
\hline High BP & 89 & & 98 & \\
\hline Fits & 70 & & 78 & \\
\hline Proteinuria & 28 & & 18 & \\
\hline \multicolumn{5}{|l|}{ Action for eclampsia } \\
\hline Start vital signs & 44 & \multirow{4}{*}{0.4} & 38 & \multirow{4}{*}{9} \\
\hline Monitor fluid input and output & 16 & & 17 & \\
\hline Administer antihypertensive & 33 & & 53 & \\
\hline Administer anticonvulsant & 34 & & 51 & \\
\hline \multicolumn{5}{|l|}{ Signs of ruptured uterus } \\
\hline Blood stained liquor & 42 & \multirow{4}{*}{3} & 56 & \multirow{4}{*}{4} \\
\hline Tender lower uterine segment & 24 & & 32 & \\
\hline Signs of shock & 74 & & 83 & \\
\hline Easily felt foetal parts & 36 & & 43 & \\
\hline \multicolumn{5}{|l|}{ Action for ruptured uterus } \\
\hline Treat shock/start IV fluids & 39 & \multirow{3}{*}{11} & 58 & \multirow{3}{*}{12} \\
\hline Monitor vital signs & 17 & & 17 & \\
\hline Refer to hospital/doctor & 89 & & 94 & \\
\hline \multicolumn{5}{|l|}{ Action for incomplete abortion } \\
\hline Assess bleeding and vital signs & 37 & \multirow{4}{*}{1.5} & 50 & \multirow{4}{*}{9} \\
\hline Start IV and antibiotics & 41 & & 66 & \\
\hline MVA & 23 & & 54 & \\
\hline Refer & 63 & & 54 & \\
\hline
\end{tabular}




\begin{tabular}{|c|c|c|c|c|}
\hline \multirow[t]{2}{*}{ Sign and action } & \multicolumn{2}{|c|}{ Baseline $(n=262)$} & \multicolumn{2}{|c|}{ Endline $(n=139)$} \\
\hline & Single\% & Composite\% & Single $\%$ & Composite\% \\
\hline \multicolumn{5}{|l|}{ Action for prolapsed cord } \\
\hline Check pulsation & 42 & \multirow{3}{*}{13} & 59 & \multirow{3}{*}{25} \\
\hline Reduce pressure on cord & 49 & & 61 & \\
\hline Prepare for $\mathrm{C} / \mathrm{S}$ & 43 & & 42 & \\
\hline \multicolumn{5}{|l|}{ Signs of severe anaemia } \\
\hline Shortness of breath & 53 & \multirow{3}{*}{0.4} & 58 & \multirow{3}{*}{38} \\
\hline Marked pallor +++ & 79 & & 85 & \\
\hline Low $\mathrm{Hb}(<5 \mathrm{~g} \%)$ & 15 & & 68 & \\
\hline \multicolumn{5}{|l|}{ Action for severe anaemia } \\
\hline Blood grouping and $X$ match & 36 & \multirow{5}{*}{0.4} & 51 & \multirow{5}{*}{1.4} \\
\hline Transfuse & 8 & & & \\
\hline Vital signs & 15 & & 19 & \\
\hline Blood slide for MPS & 20 & & 35 & \\
\hline Refer & 57 & & 58 & \\
\hline \multicolumn{5}{|l|}{ Signs of malaria } \\
\hline High temperature & 80 & \multirow{4}{*}{2} & 91 & \multirow{4}{*}{4} \\
\hline Coma & 13 & & 22 & \\
\hline Pallor & 31 & & 48 & \\
\hline Jaundice & 19 & & 35 & \\
\hline \multicolumn{5}{|l|}{ Action for malaria } \\
\hline Admit & 54 & \multirow{3}{*}{7} & 78 & \multirow{3}{*}{19} \\
\hline Vital signs & 16 & & 28 & \\
\hline IV quinine and dextrose & 29 & & 73 & \\
\hline
\end{tabular}




\section{APPENDIX 4: COST OF THE SMDP In WESTERN KENYA}

The Ministry of Health and the Population Council initiated the Safe Motherhood Demonstration Project in 2000, with funding from DFID, with the purpose of reducing maternal and perinatal morbidity and mortality in Western Province. Both development and recurrent costs were incurred in this project.

Development costs incurred involved installation of telephone lines, a fax machine (in the PMO's office), purchase of mobile phones, procurement of medical equipment, and production of IEC materials, as well as training in EOC. The recurrent expenditure was for procurement of consumable supplies, payment of utilities such as telephone and fuel, seminars, workshops, on-the-job training and transport operating expenses.

Overall, about US\$1.4 million was used in implementing the project activities during the $2^{1} / 2$ year ( 3 years in Kakamega and Vihiga, and 2 years in Bungoma and Lugari) period. Highlights of the costs incurred by various components during the project period are given below.

\section{Overall Project Costs}

At the end of the project, the total cost incurred was $\$ 1,428,481$. Details of the cost breakdown are as depicted in Chart appendix 4.1 below.

\section{Chart $6 \quad$ Project costs by activity}

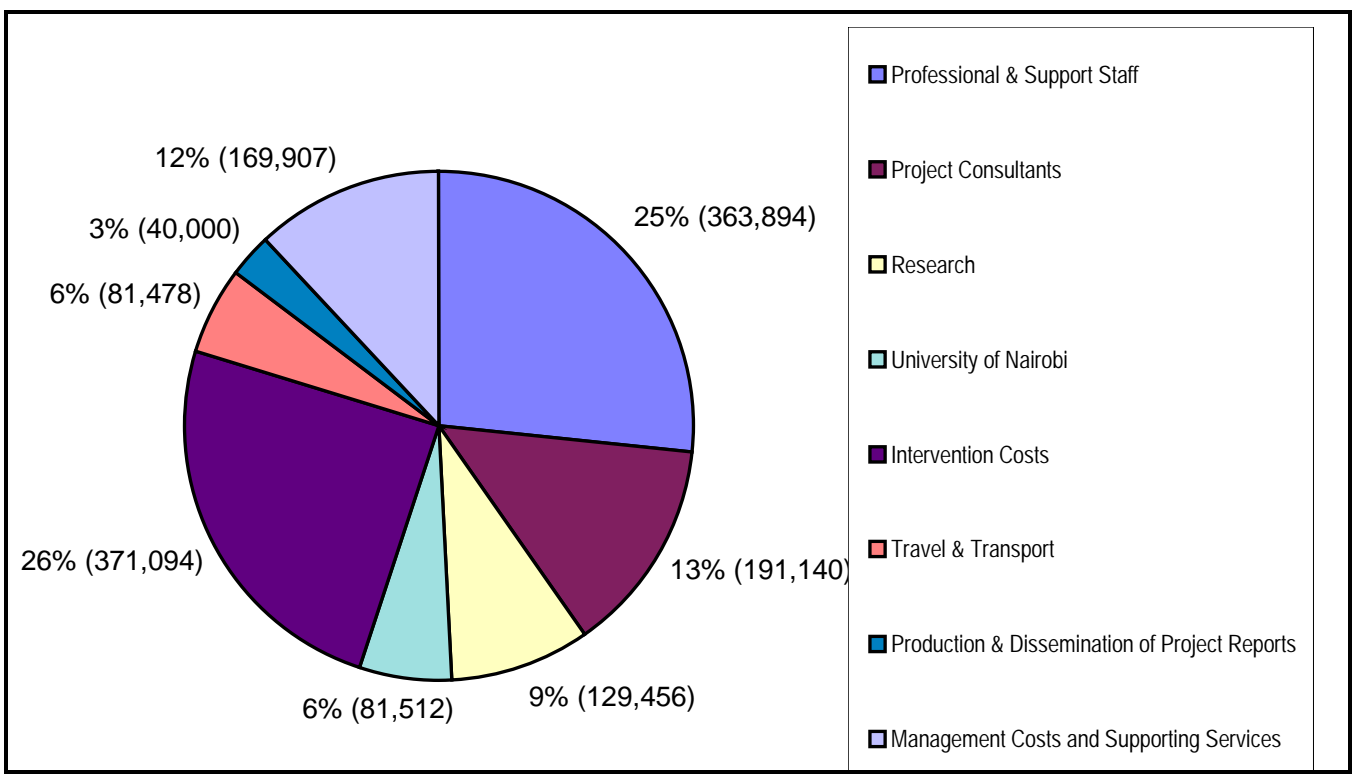

Further analysis of the costs for the project is described in a separate document. 


\section{APPENDI X 5: PeRCentage Of FACI LITIES WITH SELECTI ON OF KEY DRUGS AND SUPPLIES J AN 2002 TO J UNE 2003}

\begin{tabular}{|c|c|c|c|c|c|c|}
\hline \multicolumn{7}{|c|}{ Percent of facilities with drugs and medical supplies } \\
\hline $\begin{array}{l}\text { Type of drug, } \\
\text { medical supply }\end{array}$ & Type of facility & Jan 02 & Sep 02 & $\begin{array}{l}\text { Jun } \\
03\end{array}$ & $\begin{array}{l}\text { Jan-Jun } \\
02\end{array}$ & Jan-Jun 03 \\
\hline \multirow{3}{*}{$\begin{array}{l}\text { Sulfadoxine/ } \\
\text { Pyrimethamine }\end{array}$} & Hospitals & 92 & 100 & 100 & 86 & 98 \\
\hline & Health Centres & 86 & 91 & 96 & 84 & 99 \\
\hline & Dispensaries & 98 & 98 & 98 & 95 & 99 \\
\hline \multirow{3}{*}{ Quinine } & Hospitals & 83 & 83 & 89 & 70 & 87 \\
\hline & Health Centres & 48 & 70 & 75 & 47 & 69 \\
\hline & Dispensaries & 56 & 64 & 60 & 54 & 65 \\
\hline \multirow{3}{*}{ Ferrous Sulphate } & Hospitals & 67 & 83 & 89 & 83 & 90 \\
\hline & Health Centres & 82 & 84 & 98 & 73 & 92 \\
\hline & Dispensaries & 91 & 100 & 98 & 87 & 95 \\
\hline \multirow{3}{*}{ Folic Acid } & Hospitals & 83 & 92 & 100 & 80 & 93 \\
\hline & Health Centres & 73 & 84 & 100 & 66 & 100 \\
\hline & Dispensaries & 91 & 100 & 98 & 88 & 92 \\
\hline \multirow{3}{*}{ Ergometrine } & Hospitals & 100 & 100 & 100 & 96 & 97 \\
\hline & Health Centres & 93 & 100 & 100 & 90 & 100 \\
\hline & Dispensaries & 78 & 83 & 74 & 77 & 77 \\
\hline \multirow{3}{*}{ Gentamycin } & Hospitals & 83 & 67 & 89 & 77 & 77 \\
\hline & Health Centres & 32 & 47 & 59 & 34 & 58 \\
\hline & Dispensaries & 28 & 34 & 37 & 23 & 31 \\
\hline \multirow{3}{*}{ Flagyl } & Hospitals & 17 & 33 & 0 & 20 & 10 \\
\hline & Health Centres & 5 & 2 & 0 & 6 & 2 \\
\hline & Dispensaries & 1 & 2 & 0 & 3 & 2 \\
\hline \multirow{3}{*}{ Amoxil } & Hospitals & 8 & 8 & 0 & 7 & 0 \\
\hline & Health Centres & 11 & 2 & 0 & 6 & 0 \\
\hline & Dispensaries & 13 & 2 & 0 & 13 & 3 \\
\hline \multirow{3}{*}{ Ampicillin } & Hospitals & 58 & 50 & 33 & 52 & 27 \\
\hline & Health Centres & 7 & 7 & 9 & 5 & 8 \\
\hline & Dispensaries & 2 & 2 & 0 & 4 & 1 \\
\hline \multirow[t]{3}{*}{ Normal saline } & Hospitals & 92 & 97 & 100 & 94 & 95 \\
\hline & Health Centres & 68 & 70 & 72 & 68 & 79 \\
\hline & Dispensaries & 70 & 71 & 77 & 71 & 73 \\
\hline \multirow{3}{*}{ Dextrose } & Hospitals & 92 & 83 & 100 & 86 & 97 \\
\hline & Health Centres & 98 & 86 & 86 & 92 & 92 \\
\hline & Dispensaries & 84 & 94 & 83 & 81 & 83 \\
\hline
\end{tabular}




\begin{tabular}{|c|c|c|c|c|c|c|}
\hline \multicolumn{7}{|c|}{ Percent of facilities with drugs and medical supplies } \\
\hline $\begin{array}{l}\text { Type of drug, } \\
\text { medical supply }\end{array}$ & Type of facility & Jan 02 & Sep 02 & $\begin{array}{l}\text { Jun } \\
03\end{array}$ & $\begin{array}{l}\text { Jan-Jun } \\
02\end{array}$ & Jan-Jun 03 \\
\hline \multirow{3}{*}{ Penicillin } & Hospitals & 92 & 92 & 89 & 90 & 92 \\
\hline & Health Centres & 63 & 84 & 89 & 68 & 79 \\
\hline & Dispensaries & 83 & 89 & 79 & 85 & 85 \\
\hline \multirow{3}{*}{ Reagents for $\mathrm{Hb}$} & Hospitals & 92 & 83 & 100 & 96 & 97 \\
\hline & Health Centres & 52 & 65 & 66 & 58 & 64 \\
\hline & Dispensaries & 27 & 58 & 62 & 48 & 59 \\
\hline \multirow{3}{*}{ Reagents for VDRL } & Hospitals & 100 & 100 & 100 & 100 & 97 \\
\hline & Health Centres & 48 & 70 & 66 & 54 & 63 \\
\hline & Dispensaries & 18 & 45 & 59 & 35 & 57 \\
\hline \multirow{3}{*}{ Syringes/needles } & Hospitals & 100 & 100 & 100 & 100 & 99 \\
\hline & Health Centres & 93 & 98 & 93 & 95 & 95 \\
\hline & Dispensaries & 98 & 100 & 100 & 98 & 97 \\
\hline \multirow{3}{*}{ Gloves } & Hospitals & 100 & 100 & 100 & 100 & 97 \\
\hline & Health Centres & 98 & 100 & 98 & 98 & 98 \\
\hline & Dispensaries & 98 & 100 & 96 & 98 & 95 \\
\hline \multirow{3}{*}{ Cotton Gauze } & Hospitals & 100 & 100 & 89 & 100 & 99 \\
\hline & Health Centres & 82 & 98 & 77 & 87 & 85 \\
\hline & Dispensaries & 96 & 91 & 85 & 95 & 90 \\
\hline \multirow{3}{*}{ Cord tie } & Hospitals & 92 & 100 & 100 & 96 & 98 \\
\hline & Health Centres & 89 & 88 & 75 & 89 & 81 \\
\hline & Dispensaries & 67 & 45 & 72 & 70 & 60 \\
\hline \multirow{3}{*}{ IV Giving sets } & Hospitals & 100 & 100 & 100 & 100 & 99 \\
\hline & Health Centres & 100 & 98 & 84 & 97 & 94 \\
\hline & Dispensaries & 93 & 96 & 74 & 93 & 67 \\
\hline \multirow{3}{*}{ Urine dipsticks } & Hospitals & 50 & 75 & 100 & 59 & 83 \\
\hline & Health Centres & 39 & 67 & 41 & 38 & 52 \\
\hline & Dispensaries & 17 & 13 & 30 & 20 & 21 \\
\hline \multirow{3}{*}{ Chlorine solution } & Hospitals & 92 & 100 & 100 & 94 & 97 \\
\hline & Health Centres & 91 & 95 & 98 & 87 & 98 \\
\hline & Dispensaries & 93 & 96 & 96 & 94 & 97 \\
\hline
\end{tabular}




\section{ApPendi X 6: LIST Of Operati ONAL HeALth FACI liti es BY DISTRICT}

\begin{tabular}{|c|c|c|c|c|}
\hline Type of Facility & Kakamega & Vihiga & Bungoma & Lugari \\
\hline $\begin{array}{l}\text { Hospital } \\
\text { * Facility was visited during the } \\
\text { baseline survey } \\
+ \text { Facility was visited during the } \\
\text { endline survey }\end{array}$ & $\begin{array}{l}\text { Provincial General Hospital Kakamega *+ } \\
\text { St Elisabeth's Mission Hosp, Mukumu *+ }\end{array}$ & $\begin{array}{l}\text { Vihiga District Hospital+ } \\
\text { Kaimosi Hospital }_{+}^{*} \\
\text { Kima Hospital }_{+}\end{array}$ & $\begin{array}{l}\text { Bungoma District Hospital*+ } \\
\text { Lugulu Friends Mission }^{*} \\
\text { Hospi*+ }^{*} \\
\text { Kimilili sub district Hospital*+ }^{*} \\
\text { Lumboka Hospital }^{*} \\
\text { Misikhu Mission Hospital*+ } \\
\text { Webuye sub District Hospital*+ }\end{array}$ & $\begin{array}{l}\text { Lumakanda Hospital }^{*}+ \\
\text { (In name only - functions as } \\
\text { a health centre) }\end{array}$ \\
\hline $\begin{array}{l}\text { Nursing Homes } \\
\text { * Facility was visited during the } \\
\text { baseline survey } \\
+ \text { Facility was visited during the } \\
\text { endline survey }\end{array}$ & $\begin{array}{l}\text { Kakamega Central Nursing Home* } \\
\text { Kakamega Highway Nursing Home* } \\
\text { Bukura Community Nursing Home* } \\
\text { Emukaba Nursing Home* } \\
\text { Eshisiru Nursing Home* } \\
\text { Glory Nursing Home* } \\
\text { Lady Tharau Nursing Home* } \\
\text { Maraba Nursing Home* } \\
\text { Nala Nursing Home* } \\
\text { St. Paulines Nursing Home* }\end{array}$ & $\begin{array}{l}\text { Lundu Nursing Home* } \\
\text { Equator Nursing Home* }\end{array}$ & $\begin{array}{l}\text { Chetambe Hills Nursing Home* } \\
\text { Elgon View Nursing Home* } \\
\text { Mumias Road Nursing Home* } \\
\text { Webuye Nursing Home* }\end{array}$ & $\begin{array}{l}\text { Motraco Nursing Home* } \\
\text { Matunda Nursing Home* } \\
\text { Western Nursing Home* }\end{array}$ \\
\hline $\begin{array}{l}\text { Health Centres } \\
\text { * Facility was visited during the } \\
\text { baseline survey } \\
+ \text { Facility was visited during the } \\
\text { endline survey }\end{array}$ & $\begin{array}{l}\text { Bukura } \mathrm{H} / \mathrm{C}^{*}+ \\
\text { Bushiangala } \mathrm{H} / \mathrm{C}^{*}+ \\
\text { Bushiri } \mathrm{H} / \mathrm{C}^{*}+ \\
\text { Eregi } \mathrm{H} / \mathrm{C}^{*}+ \\
\text { Iguhu } \mathrm{H} / \mathrm{C}^{*} \\
\text { Ileho } \mathrm{H} / \mathrm{C}^{*} \\
\text { Kambiri } \mathrm{H} / \mathrm{C}^{*}+ \\
\text { Kilingili } \mathrm{H} / \mathrm{C}^{*}+ \\
\text { Malava } \mathrm{H} / \mathrm{C}^{*} \\
\text { Navakholo } \mathrm{H} / \mathrm{C}^{*}+ \\
\text { Shamakhubu } \mathrm{H} / \mathrm{C}^{*}+ \\
\text { Shibwe } \mathrm{H} / \mathrm{C}^{*}+ \\
\text { Shikusa } \mathrm{H} / \mathrm{C}^{*}+ \\
\text { Shiseso } \mathrm{H} / \mathrm{C}^{*}+ \\
\text { Singo } \mathrm{H} / \mathrm{C}\end{array}$ & $\begin{array}{l}\text { Banja } \mathrm{HC}^{*}+ \\
\text { Buyangu } \mathrm{HC}^{*} \\
\text { Ebusiratsi } \mathrm{HC}^{*}+ \\
\text { Ekwanda } \mathrm{HC}_{+} \\
\text {Emuhaya } \mathrm{HC}^{*}+ \\
\text { Enzaro } \mathrm{HC}^{*}+ \\
\text { Esiarambatsi } \mathrm{HC}^{*}+ \\
\text { Givundimbuli } \mathrm{HC}^{*} \\
\mathrm{Hamisi} \mathrm{HC}^{*} \text {, Ipali } \\
\mathrm{HC}^{*}+ \\
\text { Kegondi } \mathrm{HC}^{-} \\
\text {Lyanaginga } \mathrm{HC}^{*}+ \\
\text { Mbale } \mathrm{RHTC}^{*} \\
\text { Sabatia } \mathrm{HC}^{*}+ \\
\text { Serem } \mathrm{HC}^{*}+ \\
\text { Tigoi } \mathrm{HC}^{*} \text { Vihiga } \mathrm{HC}^{*}\end{array}$ & $\begin{array}{l}\text { Bokoli Health Centre }+ \\
\text { Bumula } \mathrm{HC}^{*}+ \\
\text { Chwele } \mathrm{HC}^{*}+ \\
\text { Kabuchai } \mathrm{HC}^{*}+ \\
\text { Khasoko } \mathrm{HC}^{*}+ \\
\text { Kibabii } \mathrm{HC}^{*} \\
\text { Kimalewa } \mathrm{HC}^{*}+ \\
\text { Malakisi } \mathrm{HC}^{*}+ \\
\text { Naitiri } \mathrm{HC}^{*}+ \\
\text { Ndalu } \mathrm{HC}^{*}+ \\
\text { Sirisia } \mathrm{HC}^{*} \\
\text { Webuye } \mathrm{HC}^{*} \\
\text { Tongaren } \mathrm{HC}+\end{array}$ & $\begin{array}{l}\text { Koromaiti } \mathrm{H} . \text { Centre+ } \\
\text { Likuyani } \mathrm{HC}^{*}+ \\
\text { Mabusi } \mathrm{HC}^{*} \\
\text { Matete } \mathrm{HC}^{*}+ \\
\text { Mautuma } \mathrm{HC}^{*}+\end{array}$ \\
\hline
\end{tabular}




\section{LIST OF OPERATI ONAL HEALTH FACI LITI ES BY DI STRICT}

\begin{tabular}{|c|c|c|c|c|}
\hline Type of Facility & Kakamega & Vihiga & Bungoma & Lugari \\
\hline Dispensaries & $\begin{array}{l}\text { Budonga Dispensary. } \\
\text { Bukhaya Dispensary } \\
\text { Chebwai Dispensary* } \\
\text { Emahola Dispensary } \\
\text { Ematete Dispensary } \\
\text { Ematsayi Dispensary } \\
\text { Enanga Disp. } \\
\text { Ingotse Disp. } \\
\text { Kakamega Forest Disp. } \\
\text { Kharanda Disp. } \\
\text { Kongoni Disp. } \\
\text { Namagara Disp. } \\
\text { Sango Disp. } \\
\text { Savane Disp.+ } \\
\text { Shihome Disp. } \\
\text { Shikokho Disp+. } \\
\text { Shikusa Disp. } \\
\text { Sirwa Disp. } \\
\text { Sivilie Disp. }\end{array}$ & $\begin{array}{l}\text { Buyani Disp. } \\
\text { Chamakanga Disp. } \\
\text { Chavogere Disp. } \\
\text { Esirulo Disp. } \\
\text { Fudumi Disp. } \\
\text { Kavirondo Disp. } \\
\text { Likindu Disp.* } \\
\text { Musitinyi Disp.+ } \\
\text { Nandaya Disp. } \\
\text { Shamakhokho Disp. } \\
\text { Shiru Disp.+ } \\
\text { Tiriki Mission Disp. } \\
\text { Vihiga Mission Disp. }\end{array}$ & $\begin{array}{l}\text { Bulondo Disp. } \\
\text { Chesamisi Disp. } \\
\text { Chesikaki Disp. } \\
\text { Chwele Disp. } \\
\text { Kamukuywa Disp. } \\
\text { Kamusinga Disp. } \\
\text { Kaptanai Disp. } \\
\text { Kimaeti Disp. } \\
\text { Kirima Disp. } \\
\text { Kimobo Disp. } \\
\text { Korosiandet Disp. } \\
\text { Lukhuna Disp. } \\
\text { Machwele Disp. } \\
\text { Makhonge Disp.* } \\
\text { Makutano Disp.+ } \\
\text { Mayekwe Disp. } \\
\text { Mechimeru Disp.* } \\
\text { Milo Disp.*+ } \\
\text { Mitua Disp. } \\
\text { Muhanda Disp. } \\
\text { Mukuyuni Disp. } \\
\text { Namwela Disp. } \\
\text { Ngwelo Disp. } \\
\text { Nzoia Sugar Co. Disp. } \\
\text { PP Mills Disp. } \\
\text { Sinoko Disp. } \\
\text { Sirakaru Disp. } \\
\text { Soyasambu Disp. } \\
\text { St. Damanio Disp. } \\
\text { St. Leos Disp. } \\
\text { St. Lukes Disp. } \\
\text { Tamlega Disp. } \\
\text { Tongaren Disp. }\end{array}$ & $\begin{array}{l}\text { Chekalini Disp.+ } \\
\text { Kongoni Disp.* }^{*} \\
\text { Koromaiti Disp.* }^{*} \\
\text { Lugari Forest Disp. } \\
\text { NYS Disp. } \\
\text { Nzoia Disp. } \\
\text { Sango Disp. }{ }^{*} \\
\text { Serenga Disp. } \\
\text { Turbo Forest Disp. } \\
\text { St. Mary's Mautuma+ }\end{array}$ \\
\hline
\end{tabular}

* Facility was visited during the base inesurvey

+Facility was visited during theendlinesurvey 


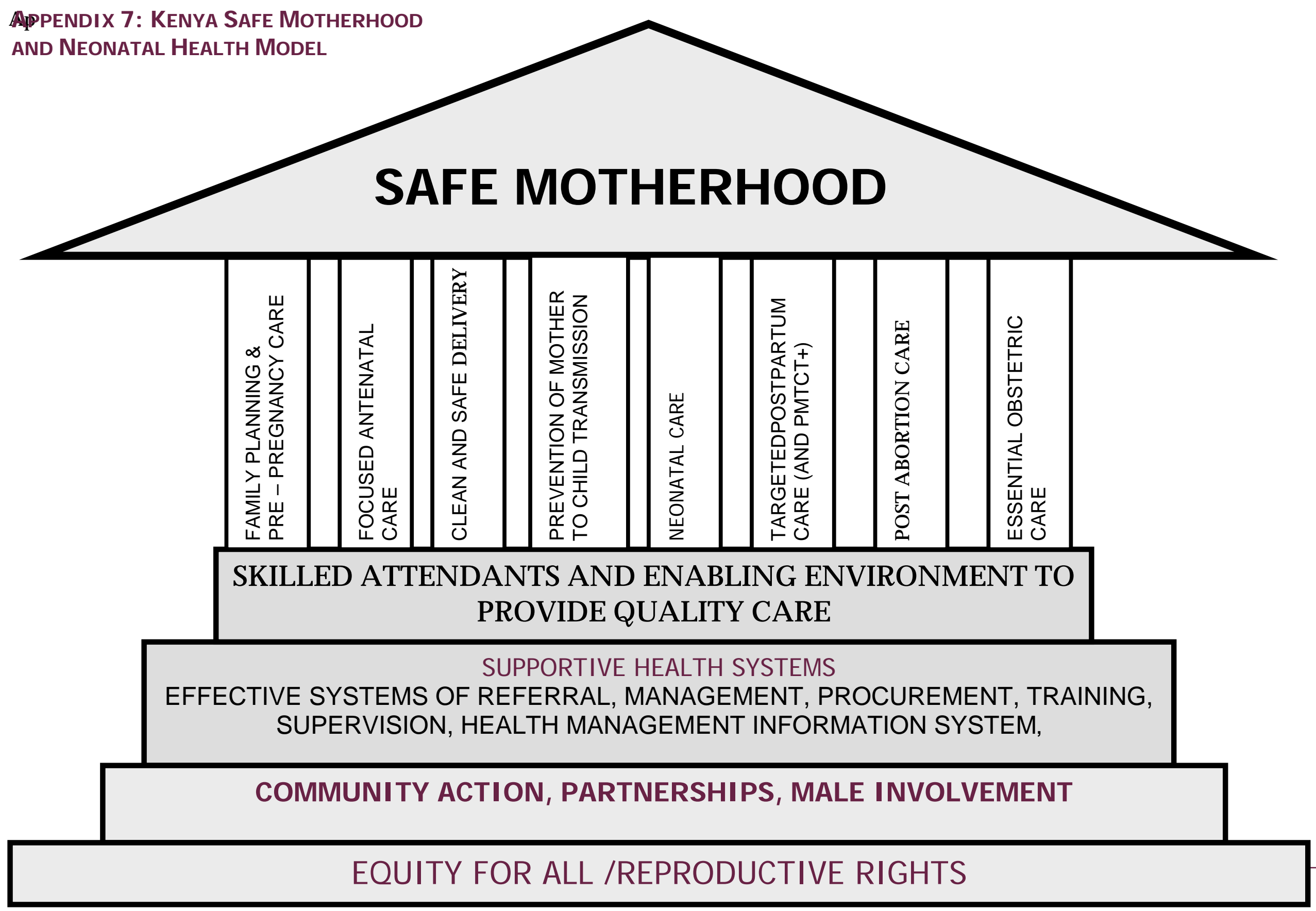




\begin{tabular}{|c|c|c|c|c|c|}
\hline \multirow[b]{4}{*}{ BASELINE SURVEY } & CATEGORY & Kakamega & Vihiga & Bungoma & Lugari \\
\hline & $\begin{array}{l}\text { MOH } \\
\text { Co-ordinators }\end{array}$ & $\begin{array}{l}\text { Judith Sitti } \\
\text { Pedro Lubale }\end{array}$ & $\begin{array}{l}\text { Jonathan Majan } \\
\text { Joyce Lung'aphar }\end{array}$ & Bilha Lugiri & Eunice Kiiru \\
\hline & Supervisors & Odylia Muhenje & $\begin{array}{l}\text { Emmy Kageha } \\
\text { Wycliffe Ngoda }\end{array}$ & Douglas Waswa & Helen Wanjala \\
\hline & $\begin{array}{l}\text { Research } \\
\text { Assistants }\end{array}$ & $\begin{array}{l}\text { Alfred Nyongesa } \\
\text { Annita Sisa } \\
\text { Irene Namai } \\
\text { Jael Olubero } \\
\text { Jane Kweyu } \\
\text { Michael Namayi } \\
\text { Millicent Oluteyo } \\
\text { Rosemary Mutakha }\end{array}$ & $\begin{array}{l}\text { Christiaan Adenya } \\
\text { Haron Ayugu } \\
\text { Jacqueline } \\
\text { Kesenwa } \\
\text { Joyce Oyangi }\end{array}$ & $\begin{array}{l}\text { Benson Khisa } \\
\text { Carolyne Nyongesa } \\
\text { Chrisostim Wataka } \\
\text { Churchill Seyle } \\
\text { Clementina Obonyo } \\
\text { David Wafula } \\
\text { Elizabeth Makali } \\
\text { Eric Walukano } \\
\text { James Simiyu } \\
\text { Vincent Makokha }\end{array}$ & $\begin{array}{l}\text { Angeline Wambanda } \\
\text { Catherine Juma } \\
\text { Cleophas Mukhutsi } \\
\text { Gilbert Gohole } \\
\text { Judith Mukhwami } \\
\text { Wesley Kidiavai }\end{array}$ \\
\hline \multirow[b]{3}{*}{ ENDLINE } & CATEGORY & Kakamega & Vihiga & Bungoma & Lugari \\
\hline & Supervisors & George Wanzala & Fred Lyani & Jonathan Majan & Amina Baraka \\
\hline & $\begin{array}{l}\text { Research } \\
\text { Assistants }\end{array}$ & $\begin{array}{l}\text { Michael Ochieng } \\
\text { Dorcas Mutsotso } \\
\text { Irene Namai } \\
\text { Millicent Oluteyo } \\
\text { Patrick Rapando } \\
\text { Jacquiline Kesenwa }\end{array}$ & $\begin{array}{l}\text { Wycliffe Ngonda } \\
\text { Joyce Oyangi } \\
\text { Jerida Angote } \\
\text { Kennedy Mwashi } \\
\text { Jackline Kivunaga } \\
\text { Mary Akoto }\end{array}$ & $\begin{array}{l}\text { Veronicah Echesa } \\
\text { Charity Makali } \\
\text { Quinto Mukamani } \\
\text { Martin Simiyu } \\
\text { Josephine Maleya } \\
\text { Judith Ngeresa } \\
\text { Sophie Ngugi } \\
\text { Charles Watitwa }\end{array}$ & $\begin{array}{l}\text { Wesley Kidiavai } \\
\text { Paul Welangai } \\
\text { John Namisiko } \\
\text { Catherine Juma } \\
\text { Gilbert Gohole }\end{array}$ \\
\hline
\end{tabular}

List of data processing and data analysis staff
Joel Kuria
Ben Obonyo
Sophie Ngugi
Florence Khakame
Sarah Mutua
Pauline Obong'o
Abigael Imbigu




\section{APPENDIX 9: LIST OF CONTRI BUTORS}

\section{Ministry of Health}

Division of Reproductive Health

Dr. Josephine Kibaru

Dr. Margaret Meme

Dr. Pamela Godia

Dr. Solomon Marsden

Mrs. Nancy Waweru

Mrs. Charity N dwiga

\section{Division of Nursing}

Mr. Chris Rakuom

\section{University of Nairobi}

Department of Obstetric and Gynaecology

Prof. Joseph G. Karanja

Dr. Patrick M. N davi

Dr. Guyo W. Jaldesa

\section{Department of Community Health}

Dr. Peterson Muriithi

Dr. Peter N joroge

Prof. Joyce Olenja

\section{Population Council}

Charlotte Warren

Wilson Liambila

\section{Administrative Assistance}

Joanne Lewa

Diana Mwangi 


\section{APPENDI X 10: DISTRICT MAPS SHOWI NG DI STRI BUTI ON OF EOC AND OTHER FACI LITI ES I N MARCH 2003}

\section{Kakamega District}

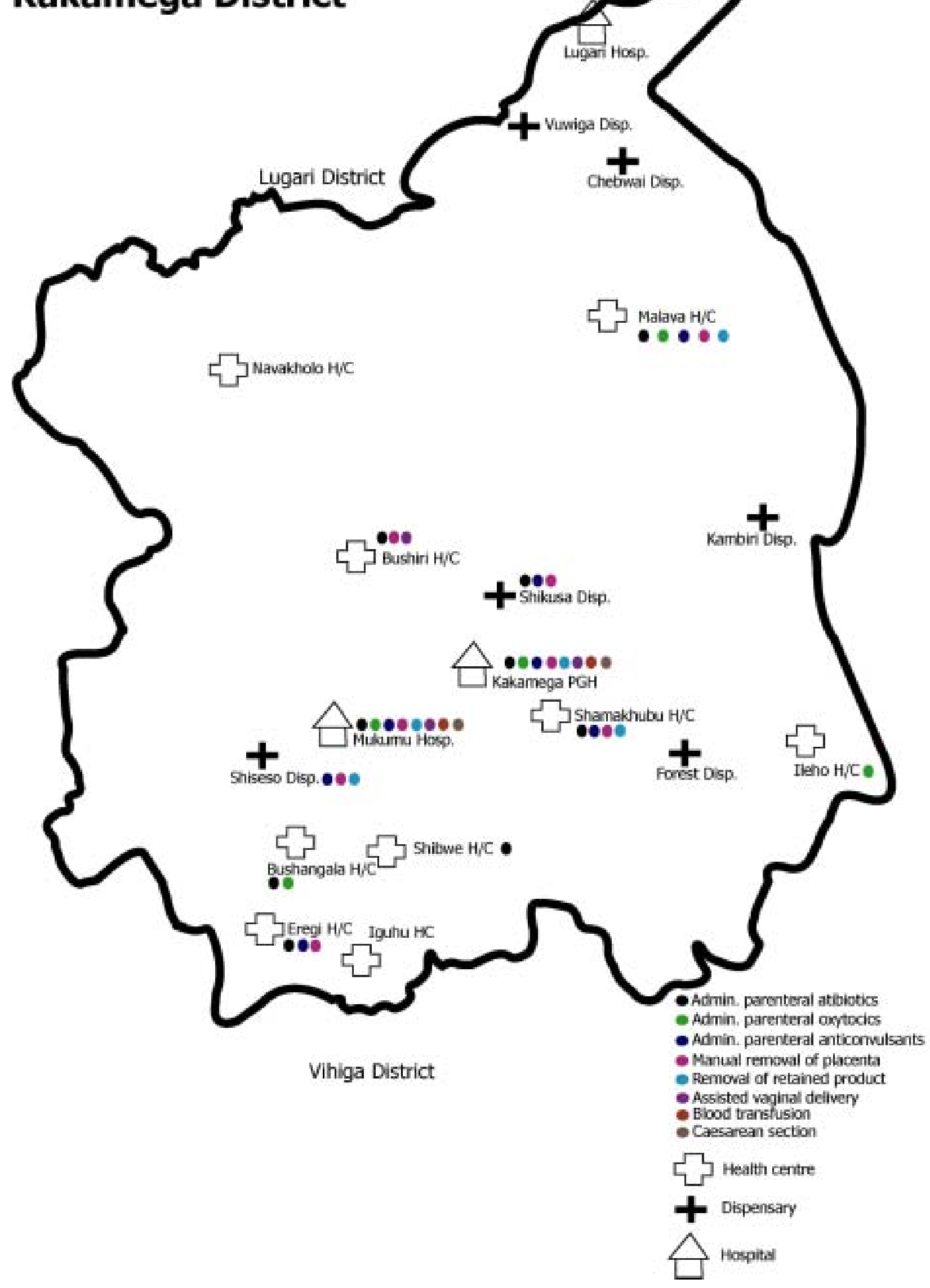




\section{Lugari District}

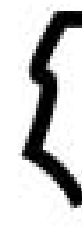
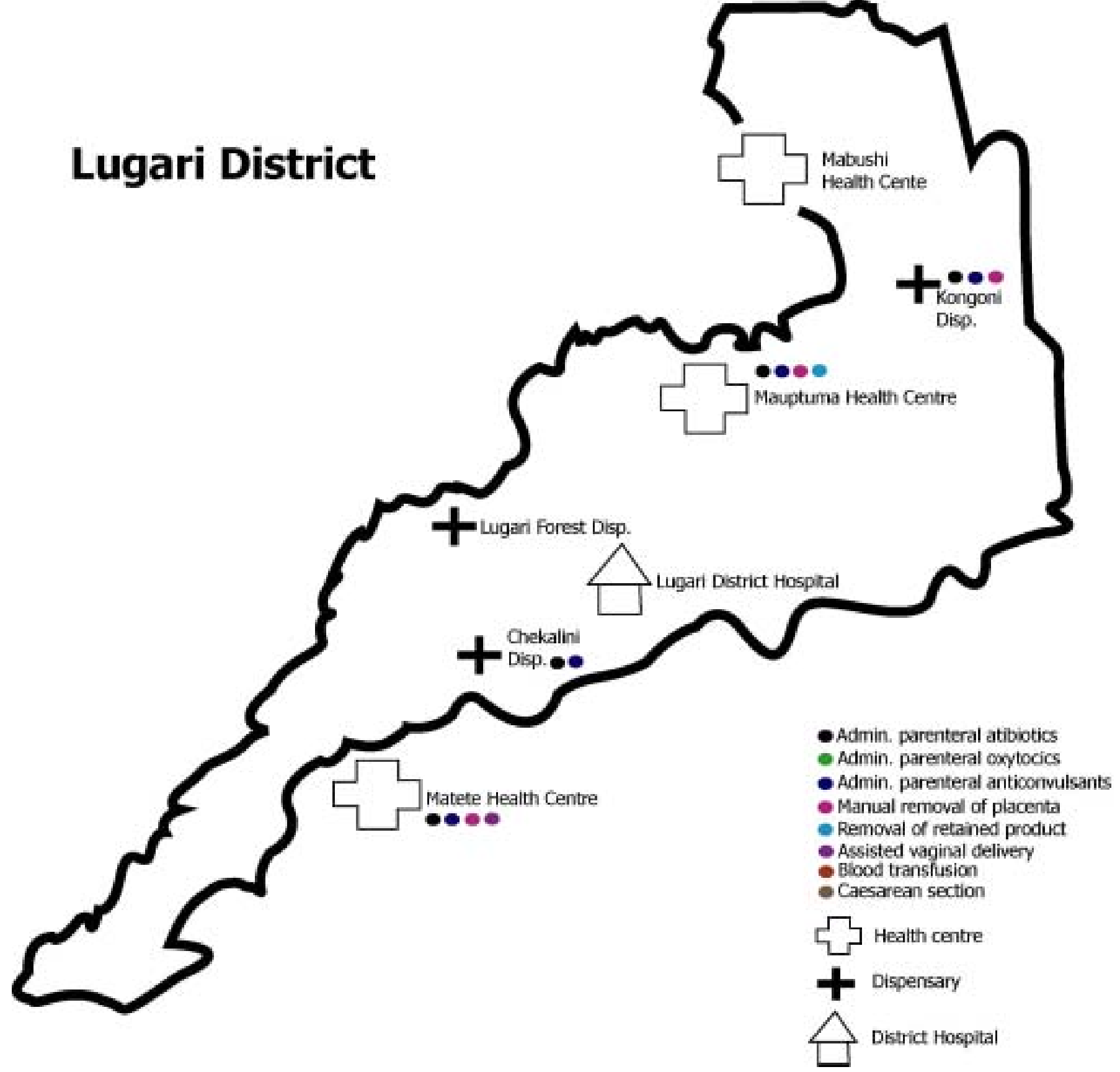


\section{Vihiga District}

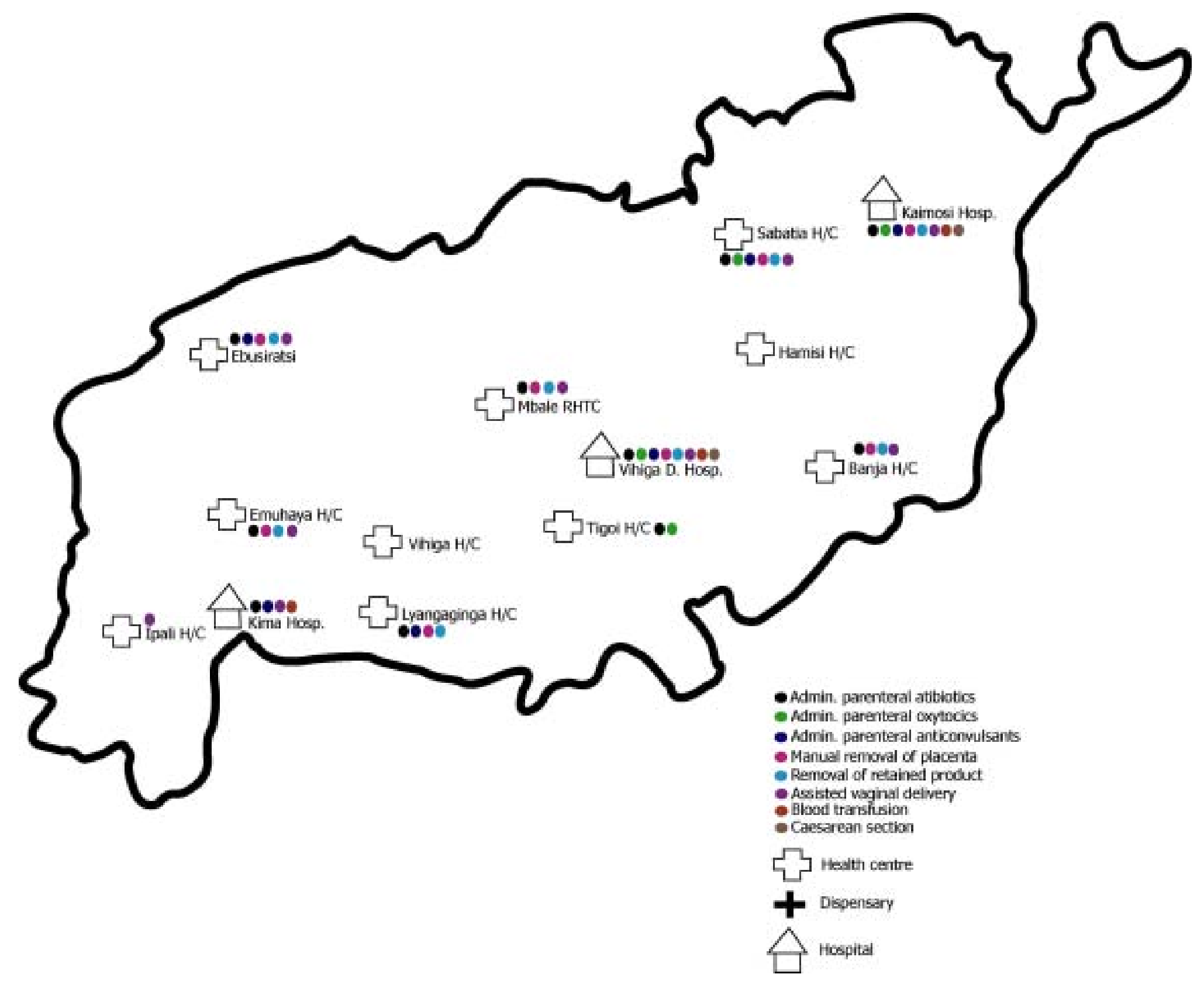




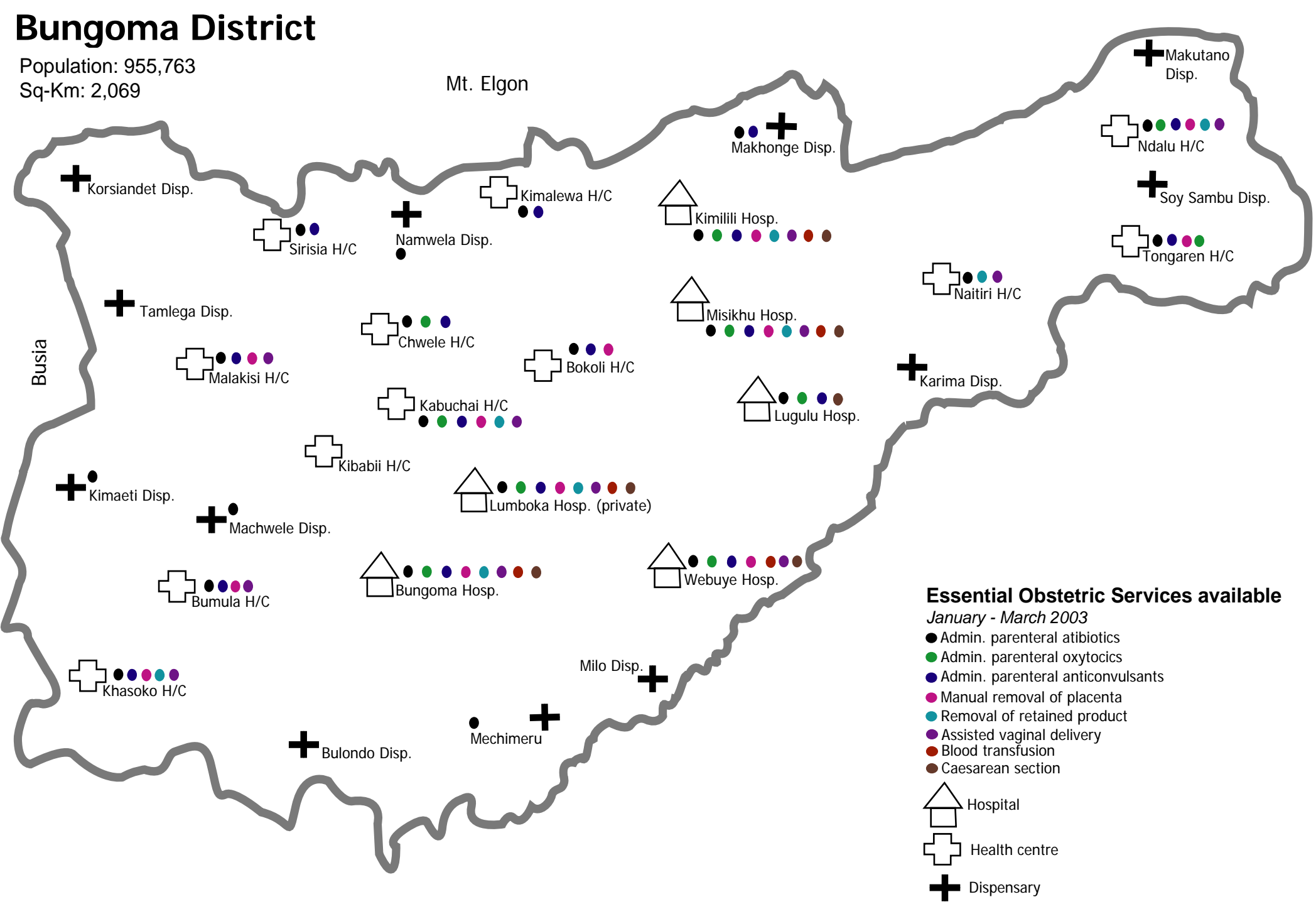

